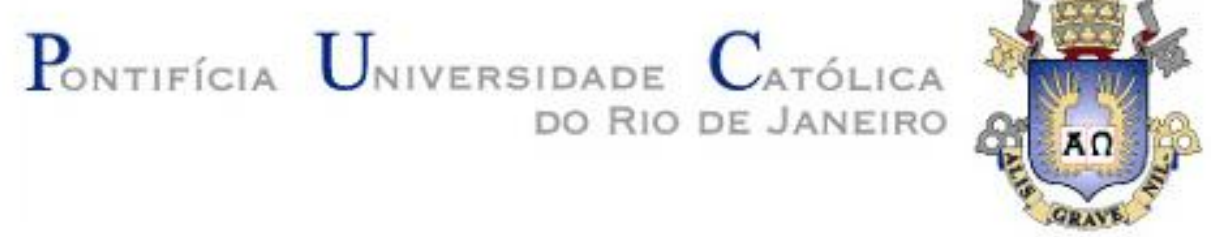

IGOR SWINERD MONTEIRO

\title{
Valuation of legal covenants in M\&A deals: Real Options and Contract Theory
}

TESE DE DOUTORADO

Thesis presented to the Programa de Pós-graduação em Administração de Empresas of PUC-Rio in partial fulfillment of the requirements for the degree of Doutor em Administração de Empresas.

Advisor: Prof. Luiz Eduardo Teixeira Brandão, Ph.D.

Rio de Janeiro

June 2019. 


\section{Pontifícia Universidade Católica $_{\text {ato }}$

IGOR SWINERD MONTEIRO

Valuation of legal covenants in M\&A deals:

Real Options and Contract Theory

Thesis presented to the Programa de Pós-graduação em Administração de Empresas of PUC-Rio in partial fulfillment of the requirements for the degree of Doutor - Administração de Empresas. Approved by the Examination Committee.

Prof. Luiz Eduardo Teixeira Brandão

Advisor

PUC-Rio

Prof. Leonardo Lima Gomes

PUC-Rio

Prof. Carlos de Lamare Bastian-Pinto

Pesquisador - Autônomo

Prof. Celso Funcia Lemme

UFRJ

Prof. Henrique Castro Martins

PUC-Rio

Rio de Janeiro, June 17th, 2019 
All rights reserved.

Igor Swinerd Monteiro

Bachelor in Business Administration at the PUC-Rio in 2012 and M.Sc. in Business Administration from PUC-Rio in 2015. Visiting researcher at University of Illinois Urbana-Champaign in 2016. Extensive experience in valuation for Venture Capital and Private Equity industry. Background in Credit Risk Analysis and Business Development.

Bibliographic data

Monteiro, Igor Swinerd

Valuation of legal covenants in M\&A deals : real options and contract theory / Igor Swinerd Monteiro ; advisor: Luiz Eduardo Teixeira Brandão. - 2019.

104 f. : il. color. ; $30 \mathrm{~cm}$

Tese (doutorado)-Pontifícia Universidade Católica do Rio de Janeiro, Departamento de Administração, 2019.

Inclui bibliografia

1. Administração - Teses. 2. M\&A. 3. Flexibilidades contratuais. 4. Opções reais. 5. Teoria dos contratos. I. Brandão, Luiz Eduardo Teixeira. II. Pontifícia Universidade Católica do Rio de Janeiro. Departamento de Administração. III. Título. 


\section{Acknowledgments}

To my advisor, Prof. Luiz Brandão, who has been following and guiding my academic development since I was an undergraduate. Witho ut his support, sense of partnership and empathy, my journey throughout the Ph.D. program certainly would not be viable. My deepest gratitude.

To PUC-Rio, which has been my second home over the past fourteen years, for all financial and intellectual support.

To the University of Illinois at Urbana-Champaign and Prof. Heitor Almeida, who received me as visiting scholar at Gies College of Business. Also, to my friends Eduardo Brunaldi, Filipe Correia and Tomás Urani, who made my stay at Illinois even more valuable.

To the researchers and colleagues of NUPEI for all the intellectual contributions over the past five years.

To my partners and friends, Eduardo Christoph and Felipe Guinle, for the unwavering partnership and confidence in my work.

To my parents, Ailton Gomes and Vitoria Swinerd, and to my brothers, Victor Hugo and Yuri Swinerd, for the tireless support and encouragement during the tougher times.

To Mariana Pereira, for the priceless love, the support and for accepting to be my partner and to join our lives together. My heartfelt and eternal thanks. 


\section{Abstract}

Monteiro, Igor Swinerd; Brandão, Luiz Eduardo Teixeira. Valuation of Legal Covenants in M\&A deals: Real Options and Contract Theory. Rio de Janeiro, 2019. 104 p. Tese de Doutorado - Departamento de Administração, Pontifícia Universidade Católica do Rio de Janeiro.

This thesis studies the impact of contractual mechanisms in M\&A valuation deals and proposes three models to evaluate them. Also, under the Contract Theory lens, we draw attention to the parties' behavior and its impact on clauses settings or transaction success.

First, we develop a model for earnouts and provide the foundation for understanding how they might best be structured and how their value might be estimated, especially considering their similarity to financial options. Furthermore, we also test different features for the earnout, such as binary options and a combination of binary and call options.

Second, we model the anti-dilution covenant, which provides additional protection for investors, especially in a venture capital context. Antidilution plays an important role as insurance for venture capitalists against "down round", which is a subsequent financing event at a lower valuation.

Lastly, we developed a valuation model for liquidation preference, which can be an alternative guarantee for investors in M\&A deals. Liquidation preference is typically defined as the right of the investor (usually holding preference shares), to receive its investment amount plus a certain agreed percentage of the proceeds in the event of a "liquidation" of the company, in preference over the other shareholders.

Our findings indicate that the typical legal covenants used in M\&A deals have a relevant impact on their fair value and may work as important tools to bridge the gap between the buyer and the seller, especially considering the information asymmetry on this context. On the other hand, depending on the clauses settings, the risk may be too skewed to the seller side, making the deal structure too expensive under his perspective. By testing the model's parameters sensitivity, we provided the inputs the seller needs to evaluate and pursue the optimal contractual terms.

\section{Keywords}

M\&A, contractual flexibilities, real options, contract theory. 


\section{Resumo}

Monteiro, Igor Swinerd; Brandão, Luiz Eduardo Teixeira. Avaliação de mecanismos contratuais em operações de fusões e aquisições: Opções Reais e Teoria dos Contratos. Rio de Janeiro, 2019. 104 p. Tese de Doutorado - Departamento de Administração, Pontifícia Universidade Católica do Rio de Janeiro.

Essa tese estuda o impacto de mecanismos contratuais no valor de operações de fusões e aquisições e propõe três modelos distintos de avaliação. Ademais, sob a ótica da Teoria dos Contratos, ressaltamos o impacto do comportamento dos agentes nas características das cláusulas utilizadas ou ainda no sucesso da transação.

Primeiro, desenvolvemos um modelo para earnouts fornecendo fundamentos para como essa cláusula em particular deve ser estruturada e como seu valor deve ser estimado, especialmente considerando sua similaridade com opções. Além disso, testamos diferentes formatos para o earnout, como opção binária e opção de compra.

Segundo, modelamos a cláusula de anti-diluição, a qual proporciona uma proteção adicional para investidores, em especial no contexto de Venture Capital. Anti-diluição tem papel fundamental como seguro para investidores contra rodadas de investimento futuras com valuation abaixo do que fora previamente pago pelo investidor.

Por fim, desenvolvemos um modelo de avaliação para preferência de liquidação, a qual também pode ser uma alternativa de garantia para investidores em operações de fusões e aquisições. Preferência de liquidação é tipicamente definida como o direito do investidor em receber seu investimento adicionado de um determinado montante em caso de algum evento de liquidação, em preferência os demais acionistas.

Os resultados indicam que os mecanismos contratuais largamente utilizados em operações de fusões e aquisições tem impacto relevante no valor justo da transação. Adicionalmente, os resultados sugerem que os mecanismos contratuais são importantes ferramentas para mitigar o risco para investidores, viabilizando determinadas operações que se tornariam inviáveis, especialmente ao considerarmos a assimetria de informação entre comprador e vendedor.

\section{Palavras-chave}

M\&A, flexibilidades contratuais, Opções Reais e Teoria dos Contratos. 


\section{Table of contents}

1 Introduction 9

2 Context and Literature Review 15

2.1. Context 15

2.1.1. Mergers \& Acquisitions: concepts and trends 15

2.1.2. M\&A contracts 21

2.1.3. Legal Covenants $\quad 24$

2.1.4. Earnout 26

2.1.5. Anti-dilution 32

2.1.6. Liquidation Preference 35

2.2. Literature Review 38

2.2.1. Mergers and Acquisitions 38

2.2.2. Valuation methods in M\&A 42

2.2.3. General background on Real Options Theory 48

2.2.4. Modeling uncertainties: The Geometric Brownian Motion 54

2.2.5. Real Options applied to M\&A 58

$\begin{array}{ll}\text { 2.2.6. Contract Theory } & 61\end{array}$

3. General Framework 65

3.1. Model with legal covenant: Earno ut 65

3.2. Model with Legal Covenant: Anti-Dilution 70

3.3. Model with legal covenant: liquidation preference $\quad 74$

$\begin{array}{ll}4 \text { Numerical applications } & 78\end{array}$

4.1. Model with Legal covenant: Earnout 78

4.2. Model with Legal Covenant: Anti-Dilution 83

4.3. Model with Legal covenant: Liquidation Preference 86

5. Conclusions 92

6 References 96 


\section{List of Figures}

Figure 1: Global M\&A Volume 2001-2017. Source: Dealogic ..............................16

Figure 2: Largest M\&A transactions worldwide. Source: IMAA Institute, 2019 .... 18

Figure 3: The process of an M\&A deal. Source: Adapted from Pawlina, 2012 ... 19

Figure 4: 80-day total shareholder return performance around deal

announcement since 1981. Source: Corporate Insights - Credit Suisse, 2018 .21

Figure 5: Risk allocation between buyer and seller. Source: Tallau (2006) .........30

Figure 6: Asymmetry in the probability distribution caused by flexibility. Source:

Real Options - Managerial Flexibility and Strategy in Resource Allocation,

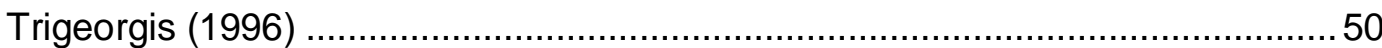

Figure 7: Example of Binomial pricing model. Source: author ............................52

Figure 8: Information asymmetry over the time. Adapted from Lukas et al. (2012)

Figure 9: Deal timeline. Source: author ........................................................... 66

Figure 10: Examples of different earnout models. Adapted from Tallau (2006) ...68

Figure 11: $1 \mathrm{x}$ full-participating example. Source: author .....................................76

Figure 12: Capped participation example. Source: author .................................. 77

Figure 13: FCF average distribution at time 3. Source: author using @Risk

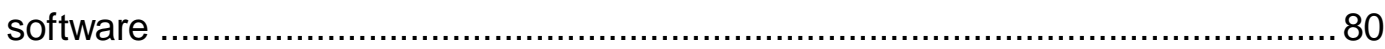

Figure 14: Simulation output of call option. Source: author............................... 82

Figure 15: probability distribution of the new price per share ................................ 85

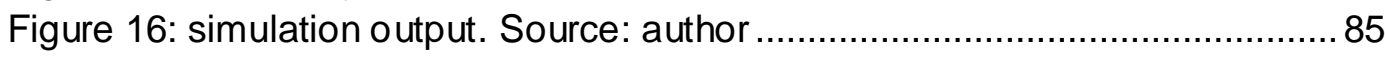

Figure 17: valuation distribution for $t=1$. Source: author ................................... 87

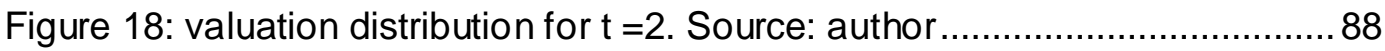

Figure 19: valuation distributio $\mathrm{n}$ for $\mathrm{t}=3$. Source: author .................................... 88

Figure 20: Investor's payoff simulation at time 3. Source: author ......................... 89

Figure 21: Investor's capped payoff simulation. Source: author .......................... 90 


\section{Introduction}

The Merger and Acquisition (M\&A) process is an effective way for companies to expand. Buying other companies, competitors or not, is a vital manner to grow and to increase shareholder value. The relationship between buyer and seller is complex and full of risks, because usually the seller is better informed than the buyer and, sometimes, after the transaction, the buyer needs the seller's best behavior. This thesis aims to explore this relationship by analyzing three common contractual covenants used in M\&A transactions and how the parties' behavior, during the negotiation and post-deal, may affect the transaction value.

The 2018 Global M\&A Outlook provided by JP Morgan highlights the magnitude of the $M \& A$ market in the world. In 2017, the global $M \& A$ market announced transaction volumes reaching US\$3.7 trillion, comprising more than 2,183 deals greater than US $\$ 250$ million in size. North America again leads in M\&A volumes by value with more than US $\$ 1,5$ trillion worth deals, most of which occur within its own borders. The largest deal of 2017 has yet to be resolved, as Broadcom pursues a hostile $\$ 130 \mathrm{bn}$ bid for rival chipmaker Qualcomm. The same publishing shows several highly strategic transactions occurred in 2017 , as companies looked for opportunities to innovate core business models and mitigate technology disruption.

On the other hand, M\&A are some of the most complicated events an organization can face. M\&A transactions can be complicated because of economic concerns related to information asymmetry, agency problems and risk allocation. The transaction is complex and time-consuming. There are seemingly endless moving parts to consider. Executives need to integrate or restructure entire business systems, set strategic goals, and assign the right people to direct projects and programs throughout the process. Not to mention that a merger or acquisition often involves transitioning hundreds of employees, and thousands of contracts. If contracts get neglected, they can introduce dangerous risks for the business. As a straight consequence of their relevance and complexity, M\&A deals have been drawing the attention of the academic researches.

Transactions evolving privately held target companies may be deemed a special case (for instance, Venture Capital deals). More precisely, valuing earlystage (or high technology growth-oriented) companies is a challenge for the traditional valuation methodologies. According to Bureau van Dijk 2017 report, a positive trend was recorded in terms of private equity and venture capital (PE and 
VC) investment. Although volume was still down year-on-year, value hit its highest level in ten years. In all, there were 23,103 deals worth a combined US $\$ 752,791$ million announced during 2017, compared to the US\$588,028 million invested across 23,947 deals in 2016.

The pioneering work of Sahlman (1990) pointed the way to a solution concerning valuation on VC/PE settings, or at least a first attempt of a framework to be used: instead of expending useless amounts of time and effort coming up with a better estimate of an inherent uncertain future, efforts are redirected towards (1) the design of investment contracts which materially skew the distribution of payoffs in favor of the venture investors and (2) an active involvement in the development process of the invested company. As a matter of fact, limitations in valuation abilities are addressed by designing the investment contracts as baskets of real options instead of linear payoff functions and by directly intervening on the underlying processes. The key items outlined by Sahlman (1990) is the relationship between venture capitalists (buyer) and entrepreneurial ventures (target) includes (1) the staging of the commitment of capital; (2) the use of convertible securities instead of straight equity investments and the presence of liquidation preference for the buyer; and (3) anti-dilution provisions to secure the investor's equity position in the company.

Several circumstances must be tackled and decided upon by the participating parties in the course of a company transaction. The main problem for the concerned parties (valuation subjects) is obviously the valuation of the company in question (the valuation object). Apart from a variety of possible valuation methods at their disposal, the aspired goals of the transaction, the subjective decision fields, and the expectations of the future performance of the company measured by its related future payments all play a decisive role in its valuation (Hering et al., 2016)

Many types of contractual mechanisms are used in M\&A deals aiming to mitigate the risk as a consequence of the information asymmetry between buyer and target. Coates (2016) stresses that over 20 years, M\&A contracts have more than doubled size - from 35 to 88 single-spaced pages. The list of M\&A clauses typically used in the industry is long: tag along, drag along, earnout, lock-up, vesting, material adverse change (MAC), anti-dilution, among others. This study focuses on earnout, liquidation preference and anti-dilution covenants.

One mechanism frequently used is the earnout, which is designed aiming to reduce the difference of expectation between the buyer and the target companies. Under an earnout, the parties will agree upon post-closing performance targets, 
using measures such as earnings, net income, or number of customers, and the additional amount of consideration that the target shareholders are entitled to receive will depend on whether such performance goals are met over the earno ut period, which typically lasts from one to five years.

In 2005, eBay has taken the control of Skype Technologies using earnout clause. At that time, US\$2.6 billion were paid upfront and US\$1.5 billion was conditioned to future performance, including metrics on active users, gross profit and revenue. More recently, in 2014, Facebook has used the earnout covenant as well. After a down payment of US\$16 billion (cash and stock), US $\$ 3$ billion were settled as contingent payment if a goal of a number of users is met.

Most research on contract design makes two fundamental simplifying assumptions, which are useful for rendering contracting problems more tractable for game theoretic methods. First, it is commonly assumed that agreements are fully customized, and therefore the terms of a contract are direct reflections of the parties' preferences, capacity to foresee future contingencies, risk tolerances, and bargaining positions (Choi et al. 2017).

In many mergers and acquisitions transactions, one or both parties may have better information about the underlying value of the assets. While there are many possibilities and several reasons for this asymmetric information, we may consider that the seller, usually, knows more about the true conditions and the earnings potentials of the asset than the buyer. Another possibility is that the seller may be better aware of potential liability issues, such as products or environmental liability associated with the business than the buyer. For instance, when the seller is subject to tort or environmental liability, the seller may be (much) better aware of the extent and the nature of such liability compared to the buyer, who, by the operation of the law, would assume that liability after the deal. In such a setting, the result that there could be some transactional failure can also lead to suboptimal deterrence against the seller.

When one party is better informed of the true value of the assets, even though both parties can be aware of the transactional surplus, they will no longer be able to consummate the transaction with certainty when they are relying on a single payment mechanism.

While there could be different mechanisms, including more extensive due diligence by the buyer before closing and broader indemnification protection in favor of the buyer, one very useful tool of overcoming this issue is the idea in which the buyer pays to the seller to some post-closing signal. Rather than paying the entire purchase value at the time of closing, the earnout will condition payment on 
a post-closing performance metric, hence the parties can more successfully overcome the problems of asymmetric information. Also, public buyers modify deal structures by using stock as a form of contingent payment. Doing this can help mitigate the problem of information asymmetries because the value of the stock offer is partially contingent on the value of the target (Hansen, 1987; Fishman, 1989; Eckbo et al., 1990).

In contrast, a private buyer cannot use stock as easily as the public buyer because sellers face post-transaction liquidity constraints and valuation difficulties. Also, private firms lack the same level of transparency, quality of financial statements, and requirements for disclosure that we observe with public firms. The combination of these factors provides an ideal setting for studying contracts under asymmetric information (Jansen, 2016). Asymmetric information issues in venture capital deals can be even more relevant, especially because an early-stage company is more sensitive to external shocks, the post-deal entrepreneur performance or to the delay in launching a new product. This situation may impact negatively the company and anticipate the need for new investments.

A difficult issue in a venture capital financing transaction is how to protect the interests of the venture capital investor if additional rounds of financing are required. Therefore, another mechanism frequently demanded by the buyers is anti-dilution protection, which may appear in different forms in venture capital agreements. The purpose of this provision consists of protecting the earlier investors from future dilution. Stock splits, stock dividends, any new financing at a lower price per share than the previous one, all drive the value of the initial investors down. As highlighted by Cossin (2002), the way that anti-dilution provision protects the buyer from dilution effect depends on the methods or the provision written in the contractual agreement. In general, this can be done by (1) decreasing the conversion price to the price level of the new financing issue (full ratchets). The seller/entrepreneur must issue as much as necessary free shares to the buyer, to bring the old conversion price down to the lowest price level; or (2) both parties agree on a new conversion price, which would be the weighted average of the old conversion rate and the price level of the last round (weighted average formula).

In a nutshell, the full-ratchet method is the harshest and most punitive venture capital investor protection against a down round. The full-ratchet method reduces the venture capital investor's conversion price of its preferred stock from the purchase price paid by the venture capital investor to the purchase price paid by the new purchaser (or, if the venture capital investor has already converted its 
preferred stock, or has purchased common stock, the venture capital investor will be issued additional shares of common at that lower price). On the other hand, a fairer approach to protect the venture capital investor against dilution is the weighted-average method. This method also reduces the venture capital investor's conversion price to a lower number, but that lower number depends on the number and price of new shares issued in the subsequent offering.

Some founders detest the apparent unfairness of the venture capital investor receiving the downside adjustment of its conversion price with no risk or obligation to participate in the subsequent round. The founder with significant bargaining power may require the venture capital investor, therefore, to exercise its preemptive rights in order to avail itself of the dilution protection. Some "pay or play" provisions require the venture capital investor to convert its preferred shares to common at the higher original price if it refuses to participate in a new round of financing.

Finally, the third and last legal covenant we aim to evaluate in this study is the Liquidation Preference. Typically, venture capital transactions are structured with liquidation preferences in favor of the investor. In other words, the investor will receive (partially or entirely) its investment back first, before any return to prior investors.

The use of specific liquidation preference dispositions is popular when venture capital firms invest in startup companies. The investors often make it a condition for their investment that they receive liquidation preference over other shareholders. This protects venture capitalists from losing money by making sure they get their initial investments back before other parties.

In these cases, there does not need to be an actual liquidation or bankruptcy of a company. In venture capital contracts, a sale of the company is often deemed to be a liquidation event. As such, if the company is sold at a profit, liquidation preference can also help venture capitalists be first in line to claim part of the profits. Venture capitalists are usually repaid before holders of common stock and before the company's original owners and employees.

Given this complex context between seller and buyer, sometimes to evaluate the target company becomes a tough task and not fully understood by the main methods of asset valuation. This task becomes harder when there is a complex contract moderating the relationship between seller and buyer - for both situations, pre and post-deal terms.

In general, in investment analysis and M\&A markets, the Discounted Cash Flow (DCF) method is the most used one. This methodology consists of forecasting 
the free cash flow and discount it, using a rate that reflects the business risk. The DCF is very accepted by analysts and academics, nevertheless, its limitations are already known as well, in special because it does not catch the value of the managerial and strategic flexibilities. Thus, using the DCF in M\&A valuation can ignore an important party of its value, because it is based only on static analysis of cash flow. DCF method is not able to model and evaluate legal covenants, as they have options features.

An alternative approach to understanding the value of contractual mechanisms used in M\&A transactions is the Real Options Theory (ROT) that undoubtedly evaluates with more expertise flexibilities inherent in projects or companies.

Therefore, this research intends to purpose a closed-form valuation model for legal covenants in M\&A deals, under Real Options Theory and Contract Theory. The aim of our study is to provide a systematic economic analysis and an overall understanding of the economic value of legal covenants used in M\&A contracts. By integrating ROT and contract theory in the same framework, we are seeking:

- Modeling legal covenants as options, under Real Options lens, and analyzing the impact of parties' behavior on these options.

- Testing different calibration on the purposed model, using both ROT under Contract Theory perspective;

- Bringing contributions on valuation models applied to mergers and acquisitions, especially drawing attention to the value of contractual mechanisms on the fair value of the deal and how the agent's behavior may impact it.

Technically, we show that the pricing of an M\&A contract is similar to that of a complex package of financial options. Each contractual mechanism separately is an option or a bundle of options.

This study proceeds as follows: Chapter 2 locates this research at the intersection of different strands of literature on M\&A, Real Options and Contract Theory. Chapter 3 presents the three independent and closed-form models used to evaluate contractual options. Chapter 4 presents a numerical application to the model, aiming to assess its main features. Finally, chapter 5 concludes the study. 


\section{2}

\section{Context and Literature Review}

This research lies at crossroad of three kinds of literature: (1) M\&A literature in order to exploit its motivations and benefits, (2) Real Options as technical tool for modeling contracts and (3) Contract Theory literature aiming to break new ground and bring them together in a way not attempted before for equity investments contracts. This study goes through the intersection of Economics, Finance and M\&A Law.

\section{1.}

\section{Context}

\subsection{1.}

\section{Mergers \& Acquisitions: concepts and trends}

Mergers and acquisitions have increasingly become an important part of the corporate strategy of many companies. How M\&A fits into a company's strategy and complements organic growth depends very much on the industry the company operates in, its market position and its strategy for value creation. Through M\&A companies can make necessary leaps in the competitive marketplace. M\&A can, for instance, help companies to take advantage of the benefits of scale that result from consolidation in mature markets and to gain access to new technology, markets, products and distribution channels. It can also help companies respond to the unprecedented disruption in industries such as financial services, technology and energy.

M\&A is not only about acquisitions, but also about divestitures. Multibusiness corporations should review their business portfolio on a regular basis for divestiture candidates. Divestitures should not only be considered for poorly performing activities but also when new owners can add more value to a business.

As per the Global M\&A outlook by JP Morgan, the M\&A market in 2017 maintained its momentum. Companies across sectors leveraged M\&A to boost growth and access new markets while benefiting from a continued low cost of capital. Notable transactions include Broadcom's proposed merger with Qualcomm, Disney's acquisition of Twenty-First Century Fox, CVS Health's merger with Aetna, United Technologies' acquisition of Rockwell Collins, the Bain Capital-led consortium's acquisition of Toshiba Memory, Discovery Communications' acquisition of Scripps Networks Interactive, Alstom's merger with 
Siemens' Mobility division and Amazon's acquisition of Whole Foods. Figure 2 shows the global M\&A volume for the period between 2001 and 2017.

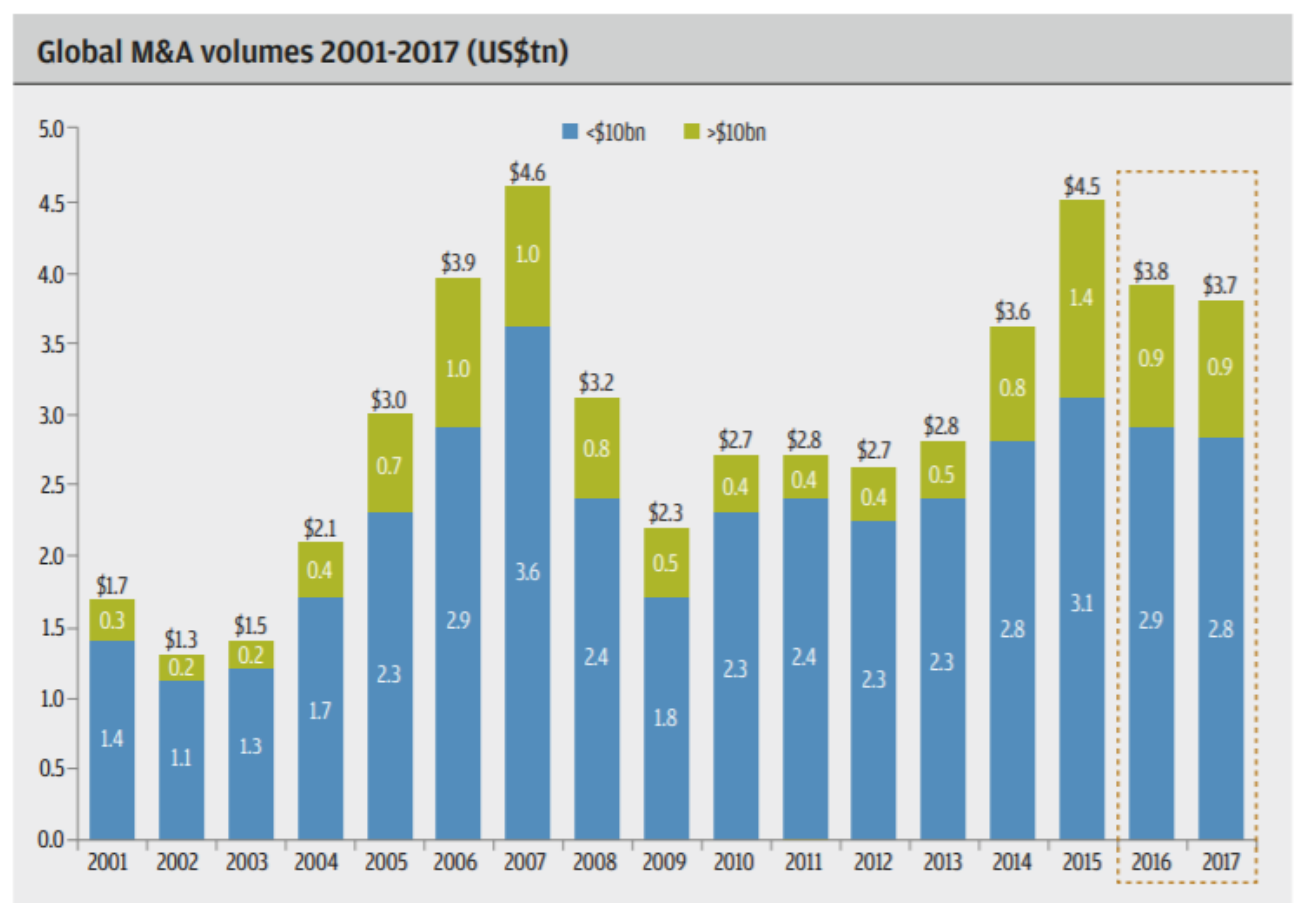

Figure 1: Global M\&A Volume 2001-2017. Source: Dealogic

According to the consultancy company Boston Consulting Group (2017 $M \& A$ report), embedded in the worldwide investment climate are three major trends:

- China goes shopping: China embarked on a global shopping wave in 2016, more than doubling, to almost US\$200 billion, its 2015 announced deal value. About two-thirds of Chinas' M\&A activity today in outbound, with Europe and North America emerging as the most attractive target regions. Several factors are fueling deal activity, including rising consumption by growing middle class and the fact of $M \& A$ is an important way of gaining access to strategic technologies and expanding the country's commercial capabilities. Health care and Private Equity buyers have been particularly active. For example, the acquisition of Playtika by a consortium of several private equity players led by Shanghai Giant Network Technology, allowed the Chinese firm to enter the online gambling market overseas.

- Private Equity keeps buying: Private Equity firms racked up another record year of deal-making while increasing their reserves. However, we can see an increasingly challenging environment for private equity buyers as they face both record-high target multiples and more competition from cash-rich corporate acquires. Despite low interest 
rates, this market environment challenges private equity buyers to execute operationally in order to achieve their target returns.

- Tech M\&A resurges: "Digital disruption" has evolved from a tech term to a boardroom reality in industry after industry. Often, acquisitions of tech-driven, and especially digital, business models have become the instrument of choice to acquire needed technologies, capabilities and products and to close innovation gaps. Though the overall M\&A market has grown significantly over the past five years, the share of deals involving a tech target has been rising even faster. Nowadays, one out of every five transactions have a clear link to some form of technology and the value of these deals as a percentage of the overall market is even greater. Deals involving technology targets differ in many aspects from traditional M\&A. Corporate lenders contemplating tech transactions need to reconsider how they pursue M\&A. Their review should take in all aspects of deal-making, including strategy, execution, valuation, synergies, contracts and post-merger integration.

As mentioned in Figure 1, Global M\&A market evolves a relevant amount and play an important role in international Financial Market. Figure 2 shows the largest M\&A transactions worldwide: 


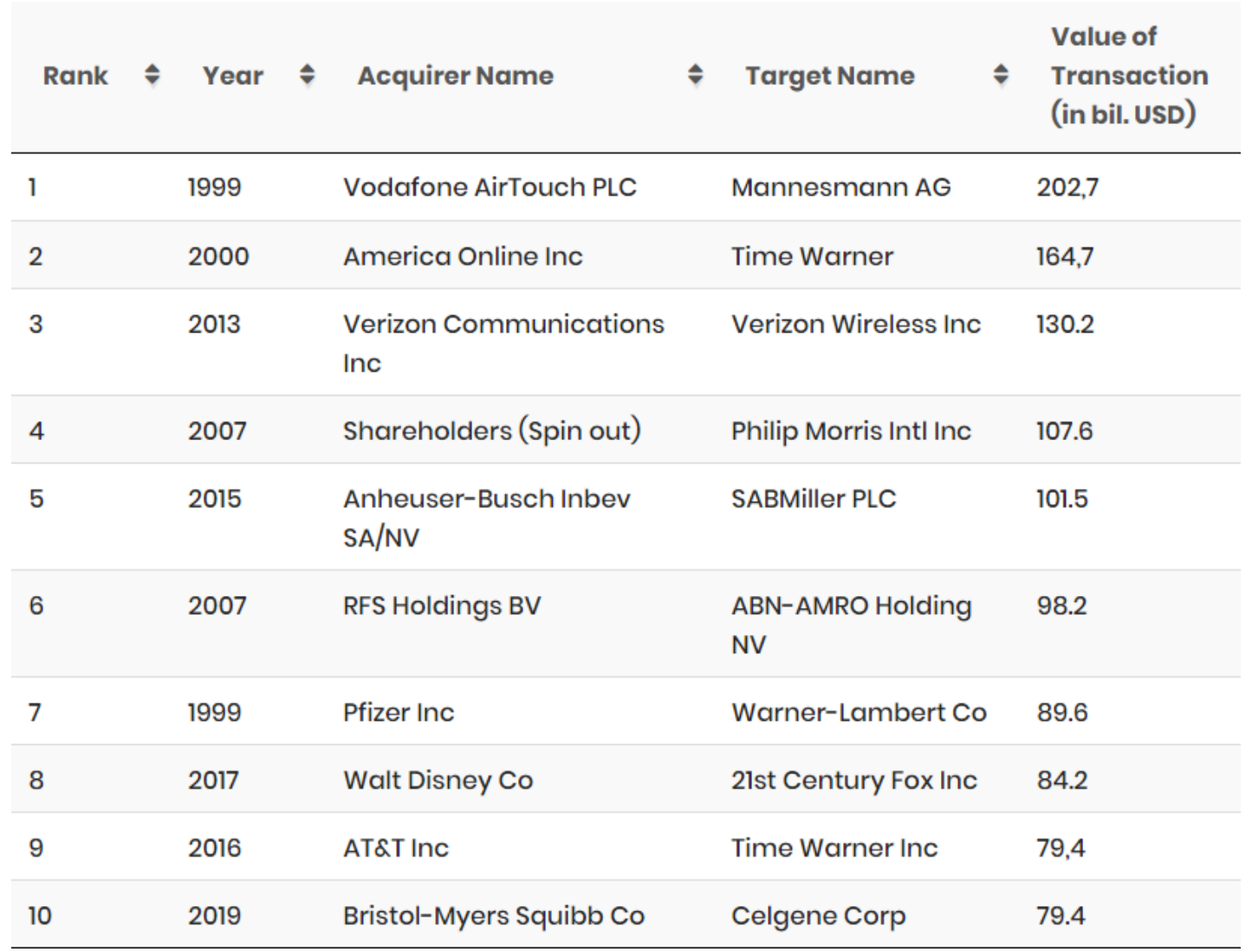

Figure 2: Largest M\&A transactions worldwide. Source: IMAA Institute, 2019

One of the biggest steps in the M\&A process is analyzing and valuing acquisition targets. This usually involves two steps: valuing the target on a standalone basis and valuing the potential synergies of the deal.

When it comes to valuing synergies, there are two types of synergies to consider: hard and soft. Hard synergies are direct cost savings to be realized after completing the merger and acquisition process. Hard synergies, also called operating or operational synergies, are benefits that are virtually sure to arise from the merger or acquisition - such as payroll savings that will come from eliminating redundant personnel between the acquirer and target companies. Soft synergies, also called financial synergies, are revenue increases that the acquirer hopes to realize after the deal closes. They are "soft" because realizing these benefits is not as assured as the "hard" synergy cost savings.

Another critical and challenging aspect in an M\&A deal is matching the price expectations of the buyer and the seller. The parties may differ on the future revenue or costs after the deal closing, becoming a hard hurdle to be overcome. In this way, some contractual mechanisms are necessary to enable the transaction, which can affect the deal value. In general, the M\&A process can be summarized according to Figure 3: 


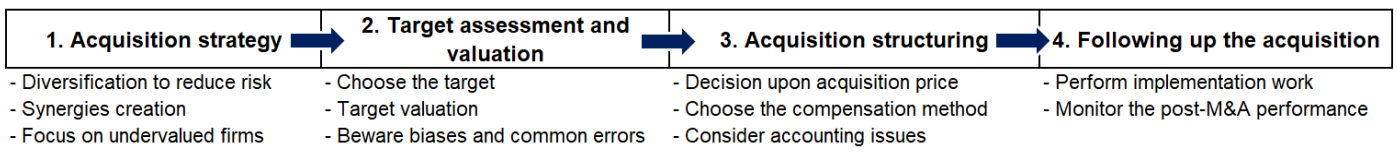

Figure 3: The process of an M\&A deal. Source: Adapted from Pawlina, 2012

The identification and selection of a target firm is followed by due diligence, an important investigation that may require external consulting, aiming at a more detailed analysis and valuation towards an accurate picture of the target. Furthermore, due to its importance, it should be given high attention, because at this stage we still can control and predict but yet not guarantee on the outcomes of this deal (Gomes et al., 2013). Thorough evaluation and investigation of the strategic, financial and cultural fit of both entities during due diligence could be a determinant of M\&A's outcomes as analysis reveals that detailed evaluation of the target firm's employees and business capabilities improves M\&A performance (Ahammad \& Glaister, 2013).

The third step - acquisition structuring - is very rich for the transaction design. At this moment, several managerial flexibilities are possible and used in the deal, in special to enable the transaction or to reduce risks. It is crucial for the success of any transaction to determine the optimal structure in advance, often reflecting not only the interests of the parties but also the interests of the company whose shares are being sold. This depends not only on the discretion of the investor, but also on the current legal and tax solutions and other external circumstances (such as the fulfillment of certain conditions, obtaining the required permits, or carrying out certain preliminary or restructuring measures to prepare the company or enterprise for ownership changes).

After the deal closing comes the most important stage of the transaction which is the post-M\&A integration, holding a huge impact on determining the deal's outcomes because the potential success, as well as the actual realization of the expected synergies, will surface after the deal closes. The integration phase is a complex task, and, in many cases, insufficient integration was a major contributor to an M\&A failure. Therefore, the organizational and cultural fit of the target should be considered and how those two different cultures and business models could be actively integrated, and integration should proceed quickly as competition will not stand aside (Sudarsanam, 2010).

In M\&A deals there are typically two types of acquirers: strategic and financial. Strategic acquirers are other companies, often direct competitors or 
companies operating in adjacent industries, such that the target company wo uld fit in nicely with the acquirer's core business. Financial buyers are institutional buyers such as private equity firms that are looking to own, but not directly operate the acquisition target. Financial buyers will often use leverage to finance the acquisition, performing a leveraged buyout (LBO).

Typically, financial buyers are not planning on benefitting from synergies or keeping the business forever. They usually acquire a target firm to add to their fund, planning to sell the company after 5 years or so in order to get a return. With this exit in mind, they will have a high-growth model in place in order to realize this return. On the other hand, it is not rare a Private Equity fund which looks for a target company that can generate synergies to another firm in its portfolio.

Measuring the success of an M\&A transaction may vary. There are numerous ways in which the relative success or failure of a merger can be defined. Success may be defined in terms of short-term measures of performance, such as an improvement in turnover during the year immediately after the merger. Alternatively, success can be considered in terms of long-term measures of performance such as a sustained increase in average share value during the 10 years after the merger. In many cases, success is measured in terms of a combination of short and long-term performance.

There are several well-documented short-term effects of a merger announcement. In most cases, when the announcement is made the value of the target company shares will increase while the value of the acquiring company shares will remain static or fall. In many cases, the prices of the target company shares will increase prior to the announcement because of pre-announcement rumors. Shareholders may, therefore, have two different views of success in the context of an acquisition. Target shareholders who sell shares to the acquirer at the premium rate make more money than they otherwise would have done in selling the shares. For target shareholders who sell, the short-term view of the acquisition may be one of success. Shareholders who remain with the target and continue to hold shares of the merged company may have a different long-term view (Robert, 2016).

M\&A from the point of view of a buyer is more nuanced and is thus where most of the debate arises. The acquirer not only pays a premium but also carries execution risk. The short-term value created for the acquirer (and its shareholders) is best measured by the market's collective reaction around the announcement of a deal. The Figure below shows an 80-day total shareholder return, comparing all public-to-public transactions of the acquiring and selling companies to the 
performance of the MSCI World Index, from 40 days pre-announcement to 40 days after the announcement.
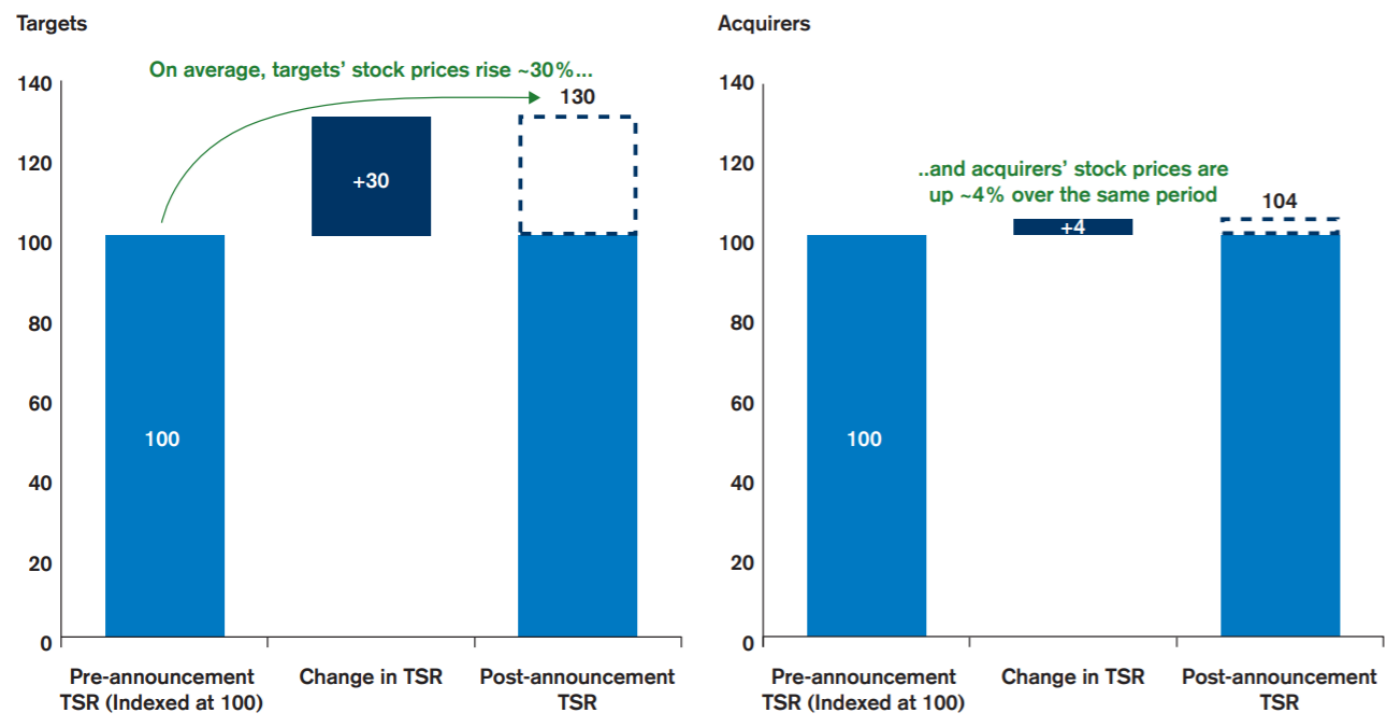

Figure 4: 80-day total shareholder return performance around deal announcement since 1981. Source: Corporate Insights - Credit Suisse, 2018

The ideal analysis would compare the total shareholder return (TSR) of the acquirer post any acquisition to the TSR of the acquirer had the deal not occurred. Unfortunately, the latter is not observable. The simplicity of an M\&A analysis from the seller's point of view is mirrored by the more complex analysis of a buyer's point of view. From the buyer's point of view, each deal can be quite challenging to measure value creation or destruction.

The longer-term view tends to be more complex and less clearly defined. The literature suggests that long-term performance can depend on a wide range of variables. In straightforward financial terms, the long-term success of the merger appears to depend on two main areas: payment method and implementation. The merger deal itself is generally financed either by a cash deal, or by a share deal, or by a combination of the two. In a cash deal, existing shareholders sell their shares for a cash sum. In a share deal, existing shareholders receive new shares for their existing ones. In some cases, the deal may use a combination of both in what is sometimes referred to as a combined deal.

\subsection{2. \\ M\&A contracts}

Contracts constitute the backbone of any financial transaction. However, only in recent years has some light been shed onto the structure of these contracts 
and their implications for theory. Understanding the factors that impact contract design is a central issue in many areas of economics. In finance, contracting theories explore how agency and information problems can be mitigated by the contingent allocation of cash flow and control rights between managers and investors.

M\&A contracts play a crucial role in specifying the terms of a deal, which are often complex, and for communicating deal terms to agents and other third parties. Also, M\&A contracts are always useful tools for management of disputes, which are fairly common, given the complex terms and lengthy duration of many $M \& A$ deals. A typical M\&A transaction involves not one but a suite of contracts. Preliminary to a deal, confidential information is typically shared, and negotiations or auction-like bidding are conducted, generating the need for confidentiality and exclusivity agreements, standstills, letters of intent and joint defense agreements. Collateral to a deal, employment and other ongoing contractual arrangements must be adjusted, generating the need for employment and non-competition agreements. All of these contracts can be understood as "M\&A contracts," but they all also lead to or are required by the core M\&A contract, the "definitive" deal agreement.

M\&A transactions are typically important - and worth the investment in a tailored and negotiated contract - because they represent a substantial investment for the buyer, a change of control and ownership (or even the "end of corporate life") for the target, and a significant transformation in the assets of the seller. They are also typically complex because the subject of the transaction is not simply a collection of assets but - by definition - control over a business. The variety of assets typically included in an M\&A deal include types of assets that raise complexities on their own: intellectual property, real estate, regulatory licenses. The transfer of this mix of tangible and intangible assets is typically coupled with changes in or transfers of contractual and non-contractual relationships with a variety of individuals, from shareholders, directors and managers to employees and agents, from customers and suppliers to lenders and regulators. M\&A transactions are also commonly significant for buyers because they require collateral or bundled financing transactions and changes in a buyer's capital structure, because they can change a buyer's post-deal control and governance, and because they often have a bigger impact on the operations and reputation of the buyer and its managers than other strategic investments.

Another distinct function provided by M\&A contracts is to specify how the parties will share control and information, at signing, between signing and closing, 
and in some deals after the deal closes. Nearly all M\&A contracts address moral hazard by containing interim covenants, as noted above, and address asymmetric information and improve pricing by setting forth factual representations, but both covenants and representations also reinforce the other's more obvious function. Negative covenants serve an information-forcing function because the negotiation process typically involves the buyer proposing tight restrictions and the target having to ask and explain the reasons for exceptions. Representations generally concern past and knowable facts, but also implicitly affect control because they are typically "brought down" to closing as a condition to the other party's obligations to close, and so function similarly to interim covenants. In private target deals, representations also customarily are linked to indemnities, and sometimes address unknowable facts, or make promises about facts in the future, giving them a riskallocation function. In private target deals, representations are also typically tied to detailed schedules, containing extensive information that the buyer can use in planning for integration as well as to firm up pricing (Coates 2015).

The first paper to study contracts is Kaplan and Stromberg (2003). Based on a sample of 213 investments, they provide evidence that the observed contract terms are consistent with both principal-agent and control-rights theories. Hsu (2004) finds that more reputable VCs invest in startups at more investor-friendly terms, consistent with our results. Cumming (2008) uses a sample of 223 investments in European VC-backed startups and shows that stronger VC control is associated with lower probability of an IPO, while Kaplan and Stromberg (2004) study investment analyses of $11 \mathrm{VC}$ firms and associate VC board control with VC interference.

Bengtsson and Sensoy (2011) find that more experienced VCs obtain weaker downside-protecting contractual cash flow rights than less experienced VCs. Their explanation is that experienced VCs have superior abilities and more frequently join the boards of their portfolio companies, but the result is also consistent with more experienced VCs matching with higher quality entrepreneurs. A recent, complimentary paper by Gornall and Strebulaev (2017) also considers the impact of certain contract terms on valuations, using a contingent claims model in the spirit of Merton (1973). 


\subsection{3.}

\section{Legal Covenants}

Before discussing M\&A contracts' particulars, it is worth reviewing the basic purposes of contracts generally. Kaplow and Shavell 2004 identify five economic reasons that exchanges can be socially valuable, arising from differences in (a) valuations; (b) risk preferences and risk-bearing capacities; (c) productive abilities, such as economies of scale or specialized skills arising from the division of labor; (d) complementarities of ownership or control of assets, giving rise to economies of scope; and (e) financing capabilities. Valuations can vary due to differences in raw preferences, information, and expectations. Finance, whether in the form of cash for debt or equity or some hybrid, is valuable whenever people with capital differ from those with business opportunities requiring investment. Risk sharing (i.e., insurance) can be valuable whenever people differ in their risk preferences, as altered by economies of scale in the form of diversification and pooling of risks (Coates, 2015).

One of the main factors that motivate companies to pursue an M\&A operation is the search for efficiency or new markets. In some situations, the central objective also can take on monopolist position, confirming the expectations of larger gains. However, the details behind a transaction of this type are complex and typically involve many uncertainties. There are distinct types of uncertainties, which will be detailed deeply when financial issues are addressed.

Some of these uncertainties are related to market risks, operational risks, financial risks, diversifiable or not. In the acquisition process, for example, the buyer invests an amount of money on the target firm, aiming to get return compatible with its future risk. There is intrinsically divergent positioning, different expectations between target and buyer, or even stalemate in the negotiations on values. To address these questions, at least partially, there are some contractual tools frequently inserted in the shareholder's agreement or additional covenants during the closing phase.

Economists have applied theories of uncertainty, information and moral hazard to contracts of various kinds. Gilson (1984) applies insights from finance and economics to develop a theory of how M\&A lawyers can add value. Gilson argues lawyers add value with contracts that respond to deviations from assumptions in asset pricing models: common time horizons, common value expectations, and full information. 
VCs face four generic (agency) problems in the investment process. First, the VC is concerned that the entrepreneur will not work hard to maximize value after the investment is made. In such a case, when the entrepreneur's effort is unobservable to the VC, the traditional moral hazard approach, pioneered by Holmstrom (1979), predicts that the VC will make the entrepreneur's compensation dependent on performance. The more severe the information problem, the more the contracts should be tied to performance (Kaplan, 2004).

Second, the buyer may also be concerned that the seller knows more about his or her quality/ability than the investor. The model in Lazear (1986) shows that the buyer can design contracts with greater pay-for-performance that good entrepreneurs will be more willing to accept. Ross (1977) and Diamond (1991) show that investor liquidation rights - the ability to liquidate and the payoff in the event of liquidation - can also be used to screen good entrepreneurs.

Third, the buyer/VC also understands that after the investment, there will be circumstances when the buyer disagrees with the seller and the buyer will want the right to make decisions. Control theories (such as Aghion and Bolton (1992) and Dessein (2002)) show that the solution to this problem is to give control to the VC in some states and the entrepreneur in others.

Lastly, the VC is concerned that the entrepreneur can "hold-up" the VC by threatening to leave the venture when the entrepreneur's human capital is particularly valuable to the company. This is the hold-up problem analyzed in Hart and Moore (1994). The VC can reduce the entrepreneur's incentive to leave by vesting the entrepreneur's shares.

A contrasting view is that investors negotiate for certain complex contract terms not to grow the size of the pie that is divided between the contracting parties, but mainly to change the distribution of the pie in their favor. This is possible because VCs have unique talents, are repeat players in the market, and as a result wield greater bargaining power, while lawyers and regulators do not have strong incentives to correct this imbalance. The resulting contracts are favorable to the VC, even if they reduce value overall, at the expense of the entrepreneur, who experiences poor returns (e.g., Moskowitz and Vissing-Jørgensen, 2002; Kaplan and Stromberg, 2004; Hall and Woodward, 2010; Cestone, 2014).

Most agency problems are directly related to asymmetric information, i.e., uncertainties about which the entrepreneur is better informed than the VC. For example, agency problems will be more severe when the entrepreneur's ability is unknown because of inexperience when the operations of the venture are hard to 
observe and monitor, and when the entrepreneur has more discretion in actions and in the use of funds.

Berglöf (1994) mentions that in a venture capital arrangement the possibility to sell control is of importance. Conflicts can arise between venture capitalist and the entrepreneur with the possibility of a sale. In the good state about private benefits, in the bad state about firm value. On the one hand, the capital structure choice is, from the VC's perspective, a trade-off between having protection against dilution (debt) and, on the other hand, free riding by a buyer on potential value improvements (prevented by having equity). In general, Berglöf (1994) describes two optimizing mechanisms, bankruptcy optimizes between insiders and a takeover optimizes between insiders and outsiders. Therefore, debt and equity are complementary from the perspective of exit-decisions. However, debt converting into non-voting equity is in this model optimal to extract as much value as possible from a potential acquirer.

\subsection{4. \\ Earnout}

When compared to the extant literature of other areas of $M \& A$, we notice that the literature on earnouts is more recent and basically involves empirical tests on the use of these flexibilities in M\&A transactions. Even being a recent mechanism, its use has been increasing every year, totalizing more than 7,000 cases in $2000^{1}$. More recently, FTI Consulting and ReedSmith has shown the growth on earnout use, from $19 \%$ in 2006 to $38 \%$ in 2010.

An earnout is a mechanism for risk allocation in an M\&A transaction, where part of the call price is delayed and measured based on the business performance, over a period specified in the contract. This payment instrument helps in removing the information uncertainty and ex-post moral hazard problem. If the company's success is highly dependent on the subject-specific human capital, this can be called a risky transaction, since the workers may leave any time the company (Caselli et al., 2006). Basically, earnouts intend to bridge the gap between an optimist seller and a skeptical buyer, allowing the business to prove its value over time.

The computed marginal price as a maximal (minimal) willingness to pay (demand for payment) of the buyer (seller) is a crucial figure to evaluate the

\footnotetext{
${ }^{1}$ ZEPHYR Database. Bureau van Dijk Electronic Publishing
} 
advantageousness of a company transaction (Hering and Toll, 2015; Hering et al., $2015 b)$. If the marginal price of the seller is below the marginal price of the buyer, the area of agreement is positive, and there is a chance to reach a negotiation settlement. If, however, the minimum demandable price of the seller is higher than the maximum payable price of the buyer, there is no potential area of agreement in the initial round of negotiations. In this case, it is not as simple for the negotiating parties to yield an acceptable outcome for both sides of the negotiation.

Earnouts can be useful if the parties' views on the value of the business are too divergent for the parties to reach an agreement on a fixed purchase price. Most often, this situation arises when the seller's information about the value of the business is superior to the information available to the buyer, such as when the target is a smaller, private company in a different industry from the acquirer. Although the basic concept is relatively straightforward, an earnout, if not carefully structured, can lead to major disagreements between the parties when it becomes time to make the pay-outs.

The disagreement on a fixed purchase price is more likely under the following circumstances:

- The target has experienced a recent drop in earnings or expects an unusual increase in earnings. Naturally, the buyer will hesitate to accept the seller's likely assurances of higher future earnings.

- The target does not possess a meaningful history of operations. It may be newly formed but have exciting prospects, such as the patent rights to an unexploited invention or a new product under development. Because the company has no record on which to base meaningful projections, the buyer may be unwilling to pay a significant amount in an outright acquisition.

- The target is highly dependent on one or relatively few customers. The buyer may discount anticipated earnings if there is a perceived risk of losing key customers.

- The target has a small asset base. Example: a service business.

- The seller is closely held. The seller may claim not to have endeavored to maximize earnings or minimize expenses. For example, if the seller is an individual, he or she may have been causing the target to pay him or her a salary that exceeded the level that would have been given to a thirdparty employee in the same position.

Under the buyer's perspective, there are some key advantages, as follows: 
- Reducing the risk of overpayment: the buyer can offer to pay more because earnouts reduce the risk of overpaying that exists when the entire purchase price is paid upfront.

- Deferred payment: the buyer can finance in part an acquisition made today with tomorrow's dollars, allowing the buyer to expend capital when it may be easier to do so. Technically, the use of an earnout clause in an acquisition also provides the buyer with an additional option to fund the operation. For example, the buyer can use the earnings of the firm (proportional of his shares) to pay off the rest of the payment.

- Goodwill deferred: Although goodwill on the buyer's balance sheet is an asset, it does not impart additional borrowing power. Because the acquisition-minded company may desire high leverage, anything that will soften the impact of goodwill on its books is very attractive. In an outright purchase, all the goodwill of the target is booked immediately, but in a contingent payout scenario, the buyer can gradually increase the goodwill from the transaction as payments are made over the life of the contract.

- Management Performance Incentive. If the seller participates in management post-closing, the earnout can be a powerful incentive tool because the seller is paid based on performance. Furthermore, since the seller is on view not only by top management but also by the other subsidiary or division heads, pride may motivate him or her to perform well.

- Grace Period. If the seller participates in management post-closing, the contingent payout allows the buyer a time to learn the seller's business. It also gives the buyer time to evaluate the seller's executives and decide if they should be retained after the earnout period. If the decision is negative, the buyer can use the interval to search for and prepare new management.

- Limited Fraud Protection. It is often much more difficult for the buyer to assess the accuracy of the financial statements and projections of a closely held company than of a publicly owned company. If the seller has misrepresented its earnings or projections, the use of an earnout protects the buyer by forcing the seller to use its financial statements as the standard against which the business will be measured later. 
- Indemnity Protection. Rather than require the seller to deposit a portion of the purchase price into an escrow account for the purpose of guaranteeing the seller's indemnification obligations, the buyer with a high degree of confidence that a certain earnout payment will be made may elect to negotiate for the right to withhold a portion or all of any earnout payments that would be payable to reimburse it for any indemnifiable losses it has suffered.

On the other hand, it is worth highlighting that earnouts also play an important role in the seller's perspective:

- Increased Purchase Price: the most significant benefit to the seller is that the contingent payout generally enables the seller to receive a larger total payment for its business than it would receive in an outright purchase.

- Autonomy: Generally, when an earno ut is used, if the seller participates in management post-closing, the acquired company remains a relatively autonomous unit within the buyer's organization so that the performance of the target can be accurately measured. This autonomy may be important to the managers who get satisfaction from exercising their entrepreneurial instincts and retaining control over profit-and-loss responsibility.

Crimmins, Gray e Waller (2011) define the following issues as a basic script to build a professional operation using an earno ut:

1. Business objectives definition;

2. Performance indicators choice (how to measure);

3. Goal definition, comparing with a benchmark;

4. Values and period of validity of earnout definition;

5. Responsibilities between buyer and seller definition;

6. Earnout formalization.

If the period of validity of the earnout is extremely short, the risk may be distorted due to short-term issues, or even, the seller may sacrifice long-term interests to enable the clause exercise. On the other hand, a longer period will allow the seller to prove the business is profitable and it makes sense in the longterm perspective.

According to Crimmins, Gray e Waller (2011), the performance indicators most commons to earnout exercise are (i) revenue, (ii) net income, (iii) EBITDA and (iv) earnings per share (EPS). 
In some situations, when there's no track record (e.g: startup acquisition), non-financial indicators are used, such as new products development milestones, number of clients or number of goods sold. In general, custom performance indicators and non-financials tend to have few comparables (benchmarking).

Also, the deal becomes feasible if the upfront payment - at the closing summed to the expected value of the earnout clause is greater than the minimum value required by the seller, as follows in Figure 5:

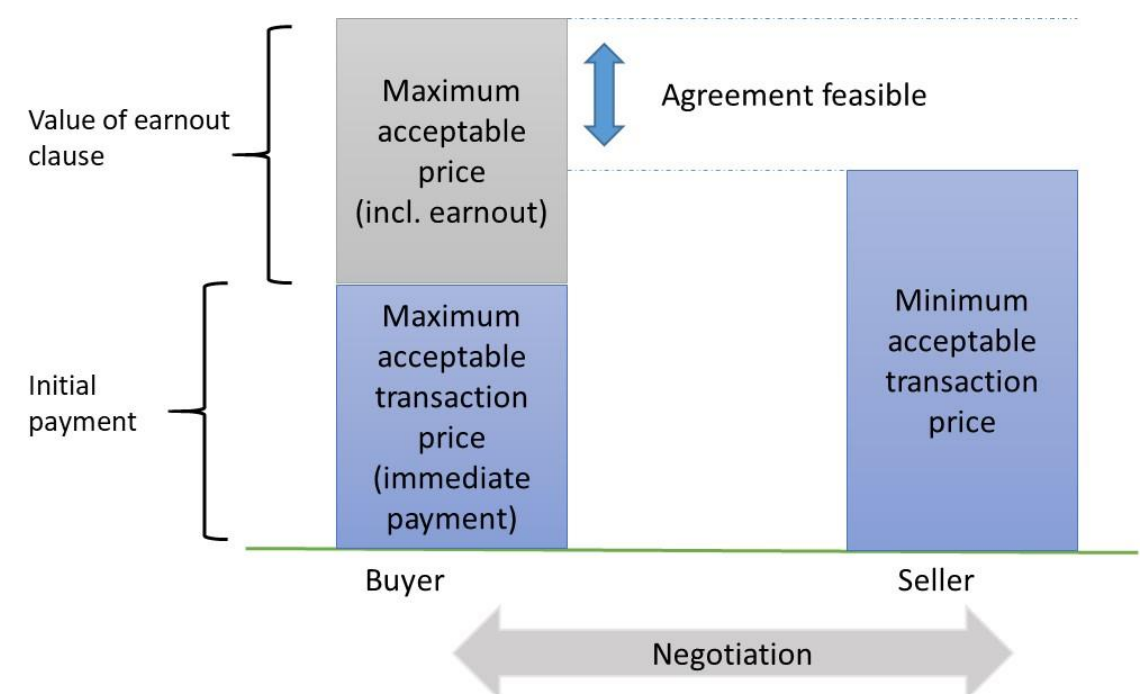

Figure 5: Risk allocation between buyer and seller. Source: Tallau (2006)

The existing academic literature on earno uts, also known as post-closing contingent payment (PCP), not only is relatively thin but also focuses almost exclusively on empirically investigating the uses and structures of earnouts. Kohers and Ang (2000), using sample data over the period 1984-1996, show that earnouts are more likely to be used when the target is a high-tech or service company that is privately held and that acquisition premiums are larger when earno uts are used. Both results suggest that earnouts are being used to deal with the problems of uncertainty and asymmetric information. Datar, Frankel and Wolfson (2001), using a survey data from period 1990-1997, similarly demonstrate that earnouts are more likely used when the acquirer and target are from different industries or when fewer acquisitions take place within an industry. Also, Ragozzino and Reuer (2009) uncover similar findings with a more extensive dataset. They show that earnouts and stock consideration function as substitutes: when the acquirer uses stock as payment, earnout is less likely to be used.

More recent studies attempt to examine the details and settings of earnout contracts. Cain et all (2011), for instance, examine the terms of earno ut contracts 
using a sample about 1,000 acquisition transactions between 1994 and 2003. They show, among others, that earnout size is associated with the uncertainty of target valuation, earnouts period are longer when valuation uncertainty is likely to be resolved over a longer period; and the choice of performance measure is associated with the informational content and the verifiability of the measure.

Bruner and Stiegler (2001) report that the amount paid immediately reflects how strong the agreement is and the future payment reflects how large the gap between buyer and seller is. This is the concept of "earno ut ratio".

Earno ut ratio is defined as the percentage of the total maximum payout that is attributed to the earnout rather than the fixed portion of the purchase price. An increase in the earnout ratio reduces the buyer's risk. On the other hand, an increase in the initial payment reduces the seller risk. Cain et al (2011) report that the earnout constitutes $33 \%$ of the total transaction value, on average, with a median of $28 \%$. The same authors found a positive correlation between the earno ut ratio and the level of uncertainty or growth opportunity.

For valuation purposes, earnout can be compared to a traditional financial option. The seller has a long position on a call-option and the trigger is the company value or the performance metric. Another feature that makes earnout even more like the financial option is that usually, earnouts have a cap, in other words, beyond this threshold the excess of value goes to the buyer. Caselli et al (2006) suggest that the earnout payoff used to be evaluated under DCF methodology. Moreover, if an option pricing model was used, the buyer would propose to reduce the earnout period (other things equal) and sellers would suggest increasing the period. This reflects the fact that, under options perspective, the time period impacts its value. In addition, the volatility will also impact the option value, having a positive relationship.

The Table 1 summarizes the parameters of earnouts:

\begin{tabular}{|l|l|}
\hline Earnout premium & $\begin{array}{l}\text { The amount paid to the seller that is } \\
\text { dependent on the target's performance. } \\
\text { This parameter is also referred to as the } \\
\text { contingent payment, the deferred } \\
\text { variable payment or simply earnout } \\
\text { payment. }\end{array}$ \\
\hline Earnout ratio & $\begin{array}{l}\text { The earnout premium in proportion to } \\
\text { the overall maximal acquisition price } \\
\text { (fixed upfront payment acquisition } \\
\text { plus earnout premium). }\end{array}$ \\
\hline Earnout period & $\begin{array}{l}\text { The prespecified time frame over which } \\
\text { the target's performance is measured. }\end{array}$ \\
\hline
\end{tabular}




\begin{tabular}{|l|l|}
\hline Performance measure & $\begin{array}{l}\text { The prespecified measure of the } \\
\text { target's performance. It can be free } \\
\text { cash flow, EBITDA, net income, net } \\
\text { revenue or any other performance } \\
\text { indicator agreed. }\end{array}$ \\
\hline Performance goal & $\begin{array}{l}\text { The prespecified goal in terms of the } \\
\text { performance measure that the target } \\
\text { has to reach in order to receive the } \\
\text { earnout premium. }\end{array}$ \\
\hline Required performance increase & $\begin{array}{l}\text { The increase in the performance } \\
\text { measure compared to the pre-closing } \\
\text { performance that is required in order to } \\
\text { reach the performance goal. }\end{array}$ \\
\hline
\end{tabular}

Table 1: The earnout parameters. Source: author

Earno ut arrangements are also subject to a host of other issues, including (1) reconciling the target's and buyer's differing accounting practices; (2) delay of integrating the target's assets into buyer's operations due to the (often) requirement that the target remains an independent entity; (3) engendering disputes over management, earnings and valuation; (4) dealing with unforeseen contingencies such as change of control during the earnout period; and (5) tax considerations.

Given that the buyer will have the ultimate ownership over the assets, compared to the seller, the buyer will be more concerned abo ut the long-term value of the acquired company. The buyer's incentive will be more about minimizing the earno ut payment to the seller. The difference in the incentives and how that could affect the optimal design is one of the overlaps between earnout mechanisms and contract theory.

In fact, earnout provisions may give rise to numerous issues between a buyer and seller, which typically result in protracted negotiations. Earnout may require that a buyer and seller collaborate closely over a period after a closing. Once a buyer and seller have endured the negotiation and closing of a complex transaction, such collaboration may be problematic.

\subsection{5.}

\section{Anti-dilution}

Venture-funded businesses often need to keep going back to investors to seek multiple rounds of funding as business grows. Therefore, Venture Capital (VC) financing is deemed a specific case in M\&A industry, which frequently 
includes anti-dilution protection that protects the investor/buyer against future financing rounds at a lower valuation than the valuation of the current round.

In a frictionless Modigliani-Miller (1958) world, the use of downside protection in a financial contract is irrelevant in the sense that the combined payoff to VC investor and entrepreneur is unaffected by contract design. This irrelevance does not hold if the outcome of the start-up company depends on the entrepreneur's willingness to exert unobservable effort. As shown by Holmstrom (1979), the presence of this agency problem implies that the entrepreneur's payoff should optimally be higher when the company has a successful outcome. With limited liability, and in the absence of other contracting frictions, the optimal contract would then always give the entrepreneur a zero payoff if the company is not successful. This contract gives investors the maximum possible downside protection.

On the other hand, downside protections differ in an important way from pre-money valuations: their cash flow implications differ depending on whether company performance is good or bad. From an agency perspective, this property suggests a tradeoff. While downside protections provide incentives to the entrepreneur by penalizing him in bad states of the world (they give the VC a more "debt-like" claim), they are costly from a risk-sharing perspective (Holmstrom, 1979).

Price-based anti-dilution clauses are really arrangements that recognize that the founders and the entrepreneurs are responsible for maintaining and increasing the value of the company and if they are unable to deliver on their promises and subsequent rounds of funding happen at lower valuations, they should compensate the initial investors by giving them more shares in the company to reduce the losses to the investors from reduced valuations. Reduced to their core, anti-dilution clauses are really nothing but the means of determining how losses in value between two rounds of funding get shared between the investors and the entrepreneur.

Following Holmstrom (1979), one plausible friction is the difference in risk preferences between a risk-averse entrepreneur and a well-diversified investor who has more capacity to absorb risks. The presence of both a moral hazard problem and risk sharing costs implies that the optimal contract will include contractual terms that give investors some but not full downside protection, and the extent of downside protections will be negatively related to VC abilities to reduce agency costs through mechanisms that do not incur such costs. A 
distinguishing feature of the VC industry is that VCs actively monitor their portfolio companies and almost always stage investments.

Kaplan and Stromberg (2002) report that almost 95\% of the VC financings in their sample include some type of anti-dilution clause and outlined that, in the extreme case, known as full ratchet protection, the protected security receives a claim to enough additional shares in the subsequent financing to reduce the price of the protected issue to the price of the new issue. In a convertible issue, this is accomplished by decreasing the conversion price on the protected issue to the conversion price of the new issue. The other common type of anti-dilution protection is the weighted average ratchet. Under a weighted average ratchet, the reduction in the conversion price (or common stock price) of the protected issue is a function of the existing shares, the new shares issued and the conversion price of the new issue.

Bengtsson (2009) also shows that anti-dilution in some form is almost always included in VC contracts. Only $2 \%$ of contracts in his sample have no antidilution. Weighted average is most common and found in $89 \%$ of all contracts, while only $10 \%$ of contracts have full ratchet anti-dilution.

The anti-dilution feature is like a long-put position, which guarantees to the buyer an additional value in case of the share price drops below the old conversion rate. The additional value that the buyer receives consists in free shares to compensate for the dilution effect of the negative change in company value.

Dilution may take the form of percentage dilution (i.e. a decrease in the percentage of the entity an investor owns) or economic dilution (i.e. a decrease in economic value of his investment in the entity). While economic dilution has a direct impact on the value of an investor's holding, percentage dilution may have an important indirect impact by altering non-economic features such as veto rights and other control rights (Onimus, 2010).

Depending on the type and amount of adjustment, holders of common stock, options, warrants or other junior securities are diluted more than they otherwise would be by the down round. Their securities receive no adjustment while the preferred stockholder with price protection does. Therefore, the value of their securities as a component of the company's overall capitalization is decreased into a shrinking sliver of the pre-money valuation for the down round, and the preferred stockholder's conversion price adjustment further dilutes the percentage ownership of the common stockholders and option holders, who are typically the founders, managers and employees of the company. This can make it difficult to obtain their stockholder approval for the financing (if needed) without 
readjusting the conversion price upwards and make it difficult to attract and retain employees unless "top-up" option grants, "in-the-money" option arrangements, cash bonuses or other concessions are made (Curtis, 2004).

A financing round under a lower valuation may occur due to different reasons. For instance, in several deals, companies desperate for financing aiming to survive are accepting venture financing at drastically reduced valuations, leading to dramatic dilution of existing security holders. The pre-money valuations are so low that preexisting stock and options are virtually worthless.

Under Contract Theory perspective, the entrepreneur has better information about the project's commercial viability than the investor. Anti-dilution provisions penalize entrepreneurs with bad projects because the current VC investment will be repriced (at the expense of the entrepreneur) if future financing is completed at a lower price.

\subsection{6.}

\section{Liquidation Preference}

Start-up firms are key drivers of innovation and employment growth, and the efficient allocation of capital to early-stage firms is crucial to their success (Solow, 1957). Financial contracting plays a key role at this stage, as information asymmetries and agency problems are severe (Hall and Lerner, 2010). The theoretical literature explains the observed complex contracts between entrepreneurs and venture capitalists (VCs) by the improved incentives and information sharing that they engender, typically assuming that investors are competitive and thus lack self-interest (Cornelli and Yosha, 2003; Kaplan and Stromberg, 2003; Schmidt, 2003; Repullo and Suarez, 2004; Hellmann, 2006).

VC investments are high-risk investments, where many ventures fail. Also, VCs are often the only ones who put in hard cash. VCs engage in sophisticated contracting and structuring of their investments. VC contracts ensure both that (1) the entrepreneur does very well if he or she performs well and (2) that investors 3 can take control if the entrepreneur does not perform. Thus, it is common that venture capitalists ask for protection of their investments in the form of preference rights.

A very common contractual right may also affect the company valuation: liquidation preference. Liquidation preference is typically defined as the right of the investor (usually holding preference shares), to receive its investment amount plus a certain agreed percentage of the proceeds in the event of a "liquidation" of the 
company, in preference over the other shareholders. Prevents the "take-themoney-and-run" problem.

A "liquidation event" is typically defined to include not only winding up of the company but also any "liquidity event", which could include a sale of shares or substantial assets, an acquisition or merger of the company or in some cases even a 'nonqualified' IPO.

Typically, the liquidation preference clause appears in two shapes: nonparticipating and full participation. The "non-participating" type is the one which grants the investors the right to recover an amount equal to their investment in the portfolio company or a multiple of it (for example, twice or three times the investment). After receiving the preferred amount, the remaining proceeds are distributed among the rest of the shareholders and, therefore, the investor does not participate in that distribution. This type of liquidation preference tends to be the most favorable to the founders of the company since it gives investors a seniority position in liquidation.

The full-participation type gives the investors the right to recover their investment (or a multiple of it) and, in addition, to participate in the distribution of the remaining liquidation proceeds, on a pro-rata basis with the rest of the shareholders. This type of liquidation preference is the most favorable to the investors of the company.

Also, there is an especial case of full-participation, the "capped participation", which grants the investors the right to recover the amount of their investment with priority over the rest of the shareholders, and subsequently, to participate in the distribution of the remaining proceeds, on a pro rata basis with the rest of the shareholders, until a maximum amount is reached, which tends to be a multiple of the investment (usually between 2 times and 3 times the invested amount). Once the cap is reached, the funds will be distributed exclusively among the common shareholders, without the preferred shareholders participating in the distribution.

Often the investor gets a guaranteed return of $1 \mathrm{x}$ its investment, which may impact the future founders' income in case of a new deal. So, let us imagine an investor that buys $50 \%$ of a company for $\$ 50$ million, for a $\$ 100$ million post-money valuation. If that company then sells for $\mathrm{R} \$ 75$ million, the investor gets more than $50 \%$ of the $\$ 75$ million. The investor gets his $\$ 50$ million out first, and then half of the remaining $\$ 25$ million ( $\$ 12.5$ million) for a total return of $\$ 62.5$ million. The other shareholders split the remaining $\$ 12.5$ million. That's an example of $1 x$ liquidation preference. 
In line with the concern about the return for the investor, an important question for the company when working through the deal with the $\mathrm{VC}$ is how much money the entrepreneur sho uld raise. Raising less mo ney in a more capital efficient fashion reduces his dilution while increasing his exit options. A company that has raised $\$ 5$ million on a $\$ 10$ million pre-money for a $\$ 15$ million post-money valuation will typically make their VCs happy if they sell for any price above $\$ 75$ million, or a fivefold return for the invested capital. However, if that same company chooses to raise $\$ 15$ million on the same $\$ 10$ million pre-money valuation, they now have a post-money of $\$ 25$ million. The same fivefold multiplier would require a sale of $\$ 125$ million.

Bengtsson (2009) reports that $92 \%$ of his sample contracts have $1 x$ liquidation preference and $6 \%$ have above $1 \mathrm{x}$ and up to $2 \mathrm{x}$. Only $1 \%$ have a liquidation preference above $2 x$. In addition, $29 \%$ of the contracts have "nonparticipating", while $25 \%$ have capped participating liquidation preference. Finally, $46 \%$ of the sample have uncapped participating rights.

Furthermore, as a start-up grows and negotiates multiples rounds of financing, liquidation rights may accumulate. In the aggregate, these rights can create a misalignment of interests and a suboptimal outcome for investors, the management team, and employees. The source of this problem is the sequential nature of the contracts involved; each round of investment involves a new negotiation of liquidation rights. As new investors negotiate their rights, however, earlier investors' rights are rarely renegotiated. In order to protect themselves from the impact of later investors' liquidation rights, earlier investors often seek rights that turn out to be counterproductive.

Under Contract Theory lens, liquidation rights may have a detrimental effect on the incentives of the management team and employees, and they can create conflicting interests among investors, resulting in a failure to maximize the firm's value. A challenge to producing an optimal set of liquidation rights for an earlystage company is the divergence of interests among the parties from the start. Investors' interests, which tend to be related to the stage at which they invest in a start-up, are reflected in the liquidation rights they seek to negotiate and in their decisions regarding exit. 


\section{2.}

\section{Literature Review}

\subsection{1.}

\section{Mergers and Acquisitions}

Depending on the way the merger and acquisition is conducted, it can be friendly or hostile. According to Hirschey (1986), the friendly takeover can be defined as the change on the corporate ownership, without a change on the managerial control, whereas the hostile ones can be defined as an unsolicited takeover, resulting on the administration replacement of the target firm.

The motivations for M\&A transactions are supported by Firm Theory and its deployment, the Agency Theory, that explain the born and existence of the firm: Transaction Economy Costs (Coase, 1937); Administration Economy Costs (Alchian and Demsetz, 1972); Monopoly (Stingler, 1950); Asymmetric Information (Myers e Majluf, 1984); Modern Corporation (Berle Jr. and Means, 1932), Ownership Structure (Jensen e Meckling, 1976); Corporate Control Market Theory (Manne, 1965) e Free Cash Flow Theory (Jensen, 1986).

Firth (1980), based on these theories, affirms that most of M\&A transactions occur due to the followed Firm theories:

a) Neoclassical Firm Profit Maximization Theory: the market power motivates the managers to make a decision to maximize the firm value and the shareholder's wealth. Companies will engage in mergers and acquisitions if they result in increased shareholder's wealth, arising from increases in profitability. These gains can be a result of the creation of monopoly power and synergies, or by replacing inefficient managers in the acquired companies.

b) Theory of Managerial Utility Maximization: in addition to a satisfactory level of profit, the managers will try to maximize the utility (intending to reduce the risk of unemployment or to ensure an increase in wages), at the expense of maximizing shareholder's wealth. These objectives can be reached increasing the firm's size in and the $M \& A$ processes are a fast manner to get it.

Under the concepts mentioned, the economic and financial literature shows several M\&A motivations, as demonstrated in the Table 2: 


\begin{tabular}{|c|c|}
\hline Asymmetric expectations & $\begin{array}{l}\text { Different expectations about the future lead the } \\
\text { investors to assign different values to the same } \\
\text { firm, causing deals opportunities. }\end{array}$ \\
\hline $\begin{array}{l}\text { Individual irrationality in } \\
\text { managerial decisions }\end{array}$ & $\begin{array}{l}\text { Hypothetical rationale for mergers. Under } \\
\text { conditions of uncertainty, individuals do not } \\
\text { always make rational decisions. } \\
\text { This irrationality is diluted or canceled when } \\
\text { considered in aggregate on the interaction of } \\
\text { various economic agents (ROLL, 1986) }\end{array}$ \\
\hline Compensation and tax benefits & $\begin{array}{l}\text { Arising from tax credits related to the fact that } \\
\text { accumulated losses by one of the firms involved } \\
\text { may be offset in future years by another firm that } \\
\text { has been presenting profits. }\end{array}$ \\
\hline $\begin{array}{l}\text { Reposition costs and Market } \\
\text { Value }\end{array}$ & $\begin{array}{l}\text { Available situation when the reposition costs of } \\
\text { the assets are larger than their market value; in } \\
\text { other words, when the ratio "Tobin's Q" (market } \\
\text { value/book value) of a firm is smaller than the unit } \\
\text { ("Tobin's Q" < 1). }\end{array}$ \\
\hline $\begin{array}{l}\text { Search of Economies of scale } \\
\text { and scope }\end{array}$ & $\begin{array}{l}\text { Arising from possible reduces on costs caused } \\
\text { by increasing in production levels, larger } \\
\text { rationalization of the research \& development } \\
\text { effort, joint use of specifics inputs and knowledge } \\
\text { transfer. }\end{array}$ \\
\hline $\begin{array}{l}\text { Anticompetitive effects and look } \\
\text { for Monopoly Power. }\end{array}$ & $\begin{array}{l}\text { Deriving gains from the increase in market } \\
\text { concentration and consequent reduction in } \\
\text { competition. }\end{array}$ \\
\hline Reduction of Insolvency Risk & $\begin{array}{l}\text { From the merger of two or more firms with no } \\
\text { perfect correlation of cash flows. }\end{array}$ \\
\hline Managerial reasons & $\begin{array}{l}\text { Mergers and acquisitions can occur aiming both } \\
\text { to increase the wellness of firm's Directors - } \\
\text { even if the operation causes a negative impact } \\
\text { on the value of their stocks - and the } \\
\text { replacement of directors that do not reach market } \\
\text { value improvement. }\end{array}$ \\
\hline $\begin{array}{l}\text { Additional Capabilities and } \\
\text { Operational Synergies. }\end{array}$ & $\begin{array}{l}\text { Resulting from the growth of demand and } \\
\text { expected increase in shareholder wealth as a } \\
\text { result of the merger. }\end{array}$ \\
\hline
\end{tabular}

Table 2: Manne (1965), Mueller (1969), Gort (1969), Jensen (1986), Roll (1986), Scherer \& Ross (1990) e Kloeckner (1994).

Acharya et al. (2013) investigate the value creation of buyout transactions and focus on operational performance. They document that the improvement of sales and operating margins during the holding period significantly adds to the abnormal performance of buyouts. Wilson et al. (2012) find empirical proof that portfolio companies of private equity funds outperform non-private equity related companies in profitability as well as productivity improvement. 
Given the conflict of interest between managers and shareholders, an acquisition may be one way by which managers spend firm resources on negative net present value projects. However, if the market for corporate control is efficient, such a firm will become a takeover target rather than being an acquiring firm. As a result, a takeover is both evidence of conflict of interest between managers and shareholders and a solution to the problem. This is the free cash flow theory of takeovers formalized in Jensen (1986). It predicts that managers of firms with unused borrowings power and large free cash flow are more likely to undertake value-destroying mergers. Furthermore, these mergers are more likely to be diversifying mergers. Harford (1999) provides empirical evidence supportive of the free cash flow theory.

Abraham \& Dijcke (2002) present an overview of the main motives of banking mergers. At this point, it is important to mention that M\&A within the financial industry have similar patterns 11 (Focarelli \& Pozzolo 2008). Cost saving and the realization of economies of scale are the main reasons for domestic $M \& A$, whereas cross-border deals are driven by a firm's desire to grow further (Abraham \& Dijcke 2002; Focarelli \& Pozzolo 2008). When a firm outgrows its home market, it often intends to expand to foreign markets. Generally, another driving force for cross-border M\&A are market imperfections.

Moreover, companies within the financial sector can better diversify their risk when merging with or acquiring firms outside their home country. This is due to the assumption that capital markets of different countries are not perfectly correlated (Miller \& Parkhe 1998). Allen N. Berger et al. (2001), for example, find a low correlation between bank revenues of Japan, the US and the EU. Thus, financial firms can reduce their risk exposure (e.g. insolvency risk) by doing $M \& A$ (Amihud et al. 2002; Díaz Díaz et al. 2002).

Shleifer and Vishny (2003) and Rhodes-Kropf and Vishwanathan (2003) theoretically show that merger waves will be observed when managers synchronize their acquisitions so that they occur when the market overvalues their firms. Empirically, Dong et al. (2006) find evidence supportive of this prediction while Mitchell and Mulherin (1996) show that merger waves are the result of the firm's reaction to economic regulatory or technological industry shocks.

Theories related to information asymmetry around $M \& A$ deals usually relate to target valuation uncertainty, reducing the risk of buyer overpayment, and signaling buyer value or quality. Hansen's (1987) model predicts that stock is more likely to be used by acquiring firms when there is considerable uncertainty (which Hansen refers to as asymmetric information) about the value of the target. By using 
stock, the risk of overpayment is reduced since post-takeover acquiring and target shareholders will share in any losses attributed to overpayment. On the other hand, Fishman's (1989) model predicts that bidders can signal confidence in their valuation of the target by offering cash.

The intention of creating and realizing potential synergies is considered as one of the top underlying motives from the perspective of corporate managers indenting to pursue an M\&A strategy. Additionally, it is often the primary reason why firms tend to M\&A activity to begin with since the realization of synergies directly can lead to extensive value generation for the firm. Hence, the concept of synergies refers to the additional value created by combining two firms in order to create new opportunities that would not have been possible, if the firms were operating separately (Damodaran, 2005).

Concerning the regulatory environment, Berger et al. (2003) provide evidence that corporations prefer to expand to countries where the legal and regulatory barriers are low. Further, corporations are familiar with the regulatory environment. These factors make M\&A relatively easy, more rapid and less capitalintensive (Allen N Berger et al. 2001). Consequently, it can be argued that the harmonization of the regulatory and supervisory environment within the EU leads to more successful $M \& A$.

Globalization has forced many companies to explore M\&A as a mechanism towards developing an international presence and increasing their market share (Sherman, 2011). Cross border M\&As increased from $23 \%$ of total mergers volumes in 1998 to 45\% in 2007 (Erel, Liao \& Weisbach, 2013).

Regarding the size of the target firm, in literature, it is agreed that when a rather small firm is acquired, the takeover is less complex and it is, hence, easier to create value (Campa \& Hernando 2006). Hawawini \& Swary (1990) also find that when buying a target firm, which is relatively small, the potential to increase efficiency is higher. Further, Kuehn (1975) argues that integrating a small target requires less effort and might be cheaper for the acquiring company. However, the creation of scale effects and the possibility of gains from synergies might be smaller (Beitel et al. 2004).

Finally, the choice of payment method does as well have tax implications, which need to be considered. When the mean of payment is stock, an M\&A is generally tax-free for the target stockholder. Possible capital gain taxes must be paid at a later point in time once a shareholder decides to sell its stock holdings. However, cash acquisitions create an immediate tax obligation for the target shareholders. Consequently, the acquirer will have to compensate for the tax 
burden and, thus, the acquisition price increases (Travlos 1987; Wansley et al. 1983). There are several examples in $M \& A$ literature that highlights the value creation under the target shareholder perspective (Langetieg, 1978; Mandelker, 1984; Andrade et al., 2001). The method of payment has a strong impact on the target firm's cumulative abnormal returns (CAR). CAR is significantly larger if the buyer firm uses its stock as payment to the target firm rather than cash (Huang and Walkling, 1986; Travlos, 1987; Servaes, 1991; Andrade et al., 2001).

Huang and Walkling (1987) argue that the form of payment will influence bidding strategy if it affects the anticipated net present value of the acquisition. Typically, payment methods may affect net present value through interrelations with either acquisition cost (i.e., premium size) or the probability of success, or both.

\subsection{2.}

\section{Valuation methods in M\&A}

No matter the motivation or the M\&A type, the primary goal of this process is to help businesses increase shareholder value over their current pre-M\&A valuation. The value of the combined firms must always be the sum of the values of the independent firms and any synergy gains. Most of the empirical studies on this subject have found that M\&As have not been as successful as expected, and the main factor that had a negative effect on financial performance was the inaccurate determination of company value (Agrawal, 1992; Bruner, 2002; Brotherson, 2014). Valuation is one of the most complicated topics of financial theory. Determining the accurate and realistic value of companies in M\&As has a major effect on the success in both negotiations and in the aftermath of the M\&A (Rhodes, 2004).

Synergy gains also play an important role in this context. Synergy is the additional value that is generated by combining two firms, creating opportunities that would not be available to these firms operating independently (Devos et al, 2012; Shleifer \& Vishny, 2003; Damodaran, A. (2005).

Building a valuation model for M\&A purposes is also challenging. Since there are always underlying assumptions on which business valuation is made, there is no universally a single correct way to estimate the value of a company. Different parties, different stakeholders will have their own views and perspectives, as such, their own underlying assumptions when it comes to appraising a particular business or company. From the perspective of an acquirer, there are many factors 
determining the value of a firm, ranging from the target's product, technology advancement, market readiness, to its management and culture's commonality. Assuming that those factors are thoroughly examined in the due diligence process, the remaining tasks of building a valuation model are forecasting based on those analysis and applying those projected figures into a model using the valuation methods.

Additionally, it is necessary to distinguish the terms "value" and "price." Price is the amount of money paid to obtain a good or service, and it may not necessarily reflect the value of that goods or service all the time. Price varies based on supply and demand, and economic and political conditions. In other words, a price may be higher or lower than the value of the goods or service it is paid for. In M\&As, similarly, there may be a significant difference between the value of a company and the price to be paid for it. The important point here is the realistic determination of the company's value. The more accurate and realistic the valuation is, the more accurate will be the price to be paid. There are a bunch of methods used in business valuation, with different methods more suitable in different conditions. For instance, if a company has low profitability, yet high-value permanent assets, these assets will become more important than its profitability in the valuation process. One method will not be suitable for all M\&As. Below, we summarize the main methods that can be used to determine the values of companies and then we introduce the Real Options approach, which is the focus of this research.

\subsubsection{1.}

\section{Balance-sheet based methods}

As highlighted by Aydin (2017), Balance-sheet-based methods attempt to identify the value of a business by examining the balance-sheet values of their assets. This is a traditional approach dictating that the value of a business is determined considering the assets owned by that business, regardless of the future. These methods ignore intangible assets like brand names, patents, technical know-how and management competence (Gabehart, S.1998; Damodaran, A. 2005). Balance sheet-based methods comprise book value, adjusted book value, liquidation value, and replacement-cost value. 


\subsubsection{2.}

\section{Income Statement and Market-based methods}

In the income statement and market-based method, the value of the company is determined considering the income statement and market data, rather than the data on the balance sheet.

The market price of a company is usually calculated considering the market prices of their shares. The market price of shares is a value that varies by supply and demand conditions on the market. The market price may change in relation to economic conditions, the activeness rate of the company, and other conditions outside the company, although there is no change in the activeness of the company itself. Thus, the price of the shares in the market may be higher or lower than the real value of the company. Here are the main disadvantages of using the market price of shares in M\&As: (1) when most of the company's shares are not traded in the market, the market price does not reflect the real value of the company. (2) Economic and political conditions may give a high or low price for the company's shares. (3) the prices created on the market will not be consistent as the activeness of the markets decreases. (4) when news about M\&As is heard in the market, there can be abnormal changes in the market price.

In M\&As, the earnings/price ratio (E/P) is commonly used, particularly in the valuation of non-public companies, as it is easy to apply. The E/P for non-public companies is unknown because there is no market price for their shares. In these situations, the reference is the $\mathrm{E} / \mathrm{P}$ of another company which is active in the same sector as the company to be valued, has similar characteristics, and is traded in the stock exchange. In this method, the current or future values of the establishment are multiplied by the E/P rate of the reference company, which creates the value of the establishment. If there are no companies similar to the establishment to be valued using E/P, the E/P rate of the sector can also be used, which is a more practical way as well. Whether the E/P of a similar company or the $\mathrm{E} / \mathrm{P}$ of the sector is used, this approach is not suitable for M\&As as it is based on the current or past values of the establishment. However, it is accepted as an applicable and practical method where there is insufficient information about the establishment or the uncertainty about the future is high. 


\subsubsection{3. \\ Discounted Cash Flow Method}

The most common valuation technique used in M\&A is the Discounted Cash Flow (DCF), which is based on capital budgeting theory. Essentially, the discounted-cash-flow approach in an M\&A setting attempts to determine the value of the company by computing the present value of cash flows over the life of the company (Schill et al.2008; Mukherjee et al.2004; Luerhman, 1999; Damodaran, A. 2005; Steiger, 2010; Brotherson et al.2014). Whereas the methods previously mentioned in this study consider current or past values, DCF determines the company value according to the future performance and risks of the company.

$M \& A$ requires considering other factors besides the assets that are being merged, including the establishments' debts, managers and other employees, customers, and corporate culture. For this reason, the decisions to perform $M \& A$ should be made after highly meticulous analyses. In both M\&As and decisions to go public, it is necessary to determine the free cash flow expected in the future, the suitable discount rate, and the period over which to make the predictions in order to use the DCF method in company valuation.

As a consolidated method in the M\&A industry, the step-by-step is straightforward, as follows:

\section{Step 1: Determine Free Cash Flows}

"Free" refers to those cash flows that are available equity and debt holders after consideration for taxes, capital expenditures and working capital needs. Cash flow should be considered as the cash flow the target company is expected to make to the acquiring company. The formula used to calculate the free cash flows is the following:

$$
\begin{array}{r}
F C F=E B I T(1-T)+\text { non-cash expenses }-C A P E X-\text { incremental working } \\
\text { capital }
\end{array}
$$

Where EBIT is earnings before interest and taxes and $T$ is the marginal tax rate of the firm. Non-cash expenses include items such as depreciation and amortization. These must be added back since they do not affect the company's cash position. Capital expenditures (CAPEX) are purchases of fixed assets that are not reflected in the firm's Income Statements, but rather are accounted for through depreciation and amortization over the life of the asset. However, as CAPEX does represent cash outflow, they are subtracted from EBIT. Incremental working capital is the amount of additional cash that will be tied up in items such 
as account receivable and cash required for the operations of the merged/acquired firm. Increased working capital is often estimated as a percentage of the increase in sales.

At this point, it is critical to make an accurate identification of the synergy to be created by the M\&A. Mostly, the company value is not calculated accurately due to the fact that the synergy expected from the M\&A is unrealistic. The synergy resulting from the increase in the effectiveness of activities after the M\&A is called the "operating synergy." When establishments merge their activities, they can obtain operating synergy by increasing their sales and reducing their fixed costs, such as marketing expenses, research and development expenses, and management expenses.

\section{Step 2: Calculate the cost of capital}

The cost of capital is the minimum acceptable rate of return on new investment based on the return that investors can expect to earn by investing in alternative, identically risky securities.

The cost of capital of any firm is the combination of the cost of equity capital and cost of debt. There is a vast literature concerning new techniques to estimate the cost of equity. According to Capital Asset Pricing Model (Sharpe,1964), the required return on an asset is equal to the sum of the risk-free rate and risk premium. The risk-free rate must be stable, certain and free of default risk.

Concerning the cost of debt, the estimation must reflect the current market interest rates and default risk. The default risk indicates the probability that the company fails to pay interest and principal in time, and probably goes into bankruptcy.

Weighted average cost of capital (WACC) is the discount rate that is commonly used in M\&As, which is the combination of the cost of equity capital and the cost of debt. In M\&As, however, the WACC should be calculated for the company that is created by the merger, instead of the WACC of the buyer or the target company. This is due to the fact that there will be a different capital cost after the merger related to the operating and financial synergy. The determination of the WACC has a variety of challenges, including whether the company is public or nonpublic, most of the shares being traded in the market, and the development rate of the capital markets. 
Step 3: Calculate the present value of the Cash Flows

Calculate the present value of the cash flows based on the cost of capital, by discounting the amounts back to year zero. Generally, only one cost of capital rate is used throughout the entire forecast period, although it is possible that this value may change over the forecast period.

\section{Step 4: Add the present value of Terminal Value}

At this point, what is not accounted for are the cash flows that will be generated by the company beyond the forecast period. In order to account for this, the present value of the terminal value is added to the present value of the cash flows. The terminal value is the present value of the resulting cash flow perpetuity beginning one year after the forecast period. Usually, a constant rate of growth of cash flows is used.

\section{Step 5: Subtract debt and other obligations assumed}

When valuing equity in a firm, it must be recognized that the shareholders, as owners of the firm, have an obligation to pay any debtholders. Consequently, repayment of these obligations (the market value of the debt and any other similar obligation) must be subtracted from the present value of the cash flows of the firm.

The following equation summarizes the five steps above detailed:

$$
\text { Value }=\sum_{n=1}^{t} \frac{C F_{n}}{(1+W A C C)^{n}}+\frac{T V}{(1+W A C C)^{t}}
$$

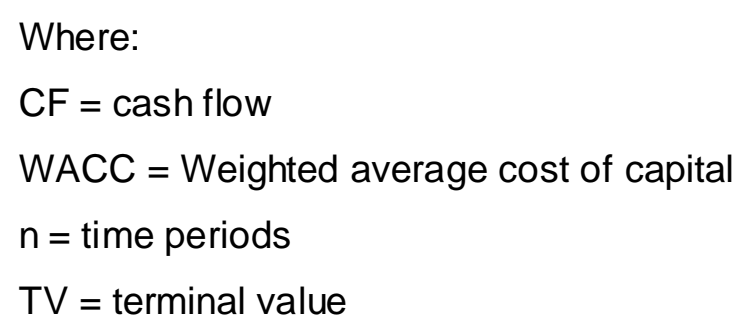

Valuations must consider the impact of future changes in the structure of the Investment, which may materially impact the Fair Value. These potential impacts may take several different legal forms and may be initiated at the buyer's option, automatically on certain events taking place, or at the option of another party. Common clauses include, but are not limited to:

- $\quad$ stock options and warrants; 
- anti-dilution clauses;

- ratchet clauses;

- convertible debt instruments;

- liquidation preferences;

- guaranteed IRR; and

- commitments to take up follow-on capital Investments.

These rights should be reviewed on a regular basis to assess whether these are likely to be exercised and the extent of any impact on the value of the investor's Investment.

As mentioned, the DCF method is widely used for M\&A purpose, although there are a couple of limitations. The DCF does not comprise the flexibility that managers have while running the company. Making decisions throughout the forecast period is completely possible, whereas new information is received, or any uncertainty is addressed. This issue may affect the financial model and hence the value of the deal. The Real Options Theory (ROT) becomes an alternative to bridge this gap and then evaluate the managerial flexibility hold by the managers.

\subsection{3. \\ General background on Real Options Theory}

Companies are included in a highly competitive scenario, characterized by changes and uncertainties about the facts initially considered by the administrators. As additional information is received, the uncertainties about scenarios and the cash flows are beginning to be better understood, offering valuable flexibility to be able to change the operational strategy improving profits or reducing losses (Santos, 2005).

The pioneering research from Black and Scholes (1973) and Merton (1973) - dedicated to the pricing of financial options - has offered a foundation to use the aforementioned considerations on projects that hold uncertainties. This method, named Real Options Theory (ROT), proposes to capture the value of managerial flexibilities (options) in several kinds of projects. Dixit and Pindyck (1994) posit that three conditions are necessary, so a project can have a real option: (i) the investment must be irreversible, (ii) there must exist flexibility that allows the manager to change the path set to the project and (iii) there must exist uncertainty on the generation of future cash flows. 
The Real Options model is an extensio n of the traditional market of financial options, consisting in a right (not mandatory) to buy (call) or sell (put) an asset by previously set price in a specific period (Hull, 2002).

According to Dixit and Pindyck (1994) a firm is able to have a Real Option value if three conditions are met:

- The investment is partially or totally irreversible. In other words, the initial cost is at least partially lost at the moment of the project beginning.

- There are uncertainties about the return on investment. The investment may depend on several variables, under investor domain or not.

- There is some managerial or strategic flexibility (option), on the operation, or by delaying the investment or even on the possibility to abandon the business.

The option premium varies according to two parameters: uncertainties at the analysis period and the value of money over time. According to Newton, Paxson e Widdicks (2004), the staging options for investments add value to the Project, since they allow the evaluation of its technical and economic feasibility at each stage of the process, enabling a new evaluation as the new information are obtained and solve certain technical uncertainty (Childs \& Triantis, 1999). Thus, the manager can limit the expenses in a project doomed to fail, reducing losses and redirecting its reso urces to more promising projects.

The types of Real Options defined by Trigeorgis (1996) are related:

1. Option to defer investment;

2. Option to temporarily shut down (and re-start) operations;

3. Option to expand or contract;

4. Option to abandon staged investment;

5. Option to switch use (e.g inputs or outputs);

6. Corporate growth option.

Synthetically, the project value with options is given by the present value of the expected cash flows (NPV), added to managerial flexibilities that create more value to the project (Trigeorgis, 1999).

\section{Expanded NPV = static NPV + options (flexibility) value}

According to Trigeorgis (2000), the asymmetry created by the adaptability requires a rule for an "expanded NPV" that reflects both components: traditional NPV and the option value, according to the Figure 6: 


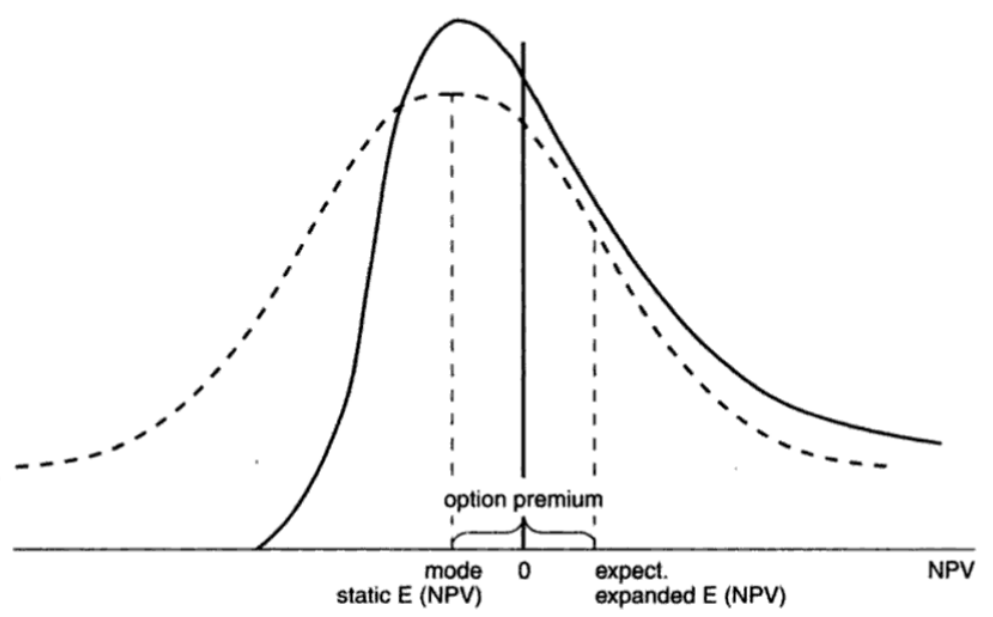

Figure 6: Asymmetry in the probability distribution caused by flexibility. Source: Real Options Managerial Flexibility and Strategy in Resource Allocation, Trigeorgis (1996)

In many real-life situations, there is not just one type of Real-Option related to a project. Besides the classification by type of flexibility, Copeland and Antikarov (2001) add some more Real-Options categories to the list, which are classified by type of combination of options. These sorts of Real-Options are primarily concerned with the modeling structure.

1. Switching options, e.g. a portfolio of American call or put options that allow their owner to switch at a fixed cost between to modes of operation.

2. Compound options, i.e. options on options, e.g. phased investments or sequential investments. A classic example of a compound option comes from Brealey, Myers, and Allen (2011), where they consider an investment in a computer model called the "Mark I". When evaluating the option to build the Mark I, one could also take into account the option to build his successor in the future, the "Mark II". This latest option could be structured as a compound American call option, where one has the right to build the Mark II, the successor of the Mark I.

3. Rainbow options, i.e. options driven by multiple sources of uncertainty, where the option value is dependent on two or more underlying variables, e.g. price of a unit of output and the quantity that might be sold.

Kester (1984) considered that under the traditional decision-making methods, even the negative NPV projects, so much as there is long-term strategic value, they may be worthwhile investments. In the evaluation of such projects, the real options approach should be used. When competitors have the same options, 
the enterprise should implement options as soon as possible in order to prevent losses. Kulatilaka and Marks (1988) studied the strategic value of flexibility options. They constructed two companies to make comparative studies; the assumptions were that one enterprise can use only a certain technique, while another enterprise has several choices of technology. This flexibility option gives the later one a strategic value.

Kellogg and Charnes (2000) found that many high-tech biotechnology companies have a high stock price despite having no product revenue because their products are in early stages of development. They use the decision-tree method and binomial-lattice method to value the high-tech company's share price and found that the real options evaluation methods reflect the high-tech company's early value more accurately. Schwartz and Moon (2000) apply real options theory and capital budgeting methods to assess the value of Internet companies. They established a real options model based on the continuous time, estimate model parameters, perform sensitivity analysis and apply the results to the valuation of technology companies.

As claimed by Mun (2006), the real options can be calculated by many methodologies, including the use of closed-form models, simulations of pathdependent partial differential equations and multinomial approximation (binomial, trinomial, etc.).

Another mandatory issue to the Real Options valuation is the modeling the uncertain variable that can assume different behaviors. According to Hull (2006), any variable whose changes over time are uncertain can be model by a stochastic process. The stochastic processes can be divided into two groups: discrete and continuous. The first one presupposes that the variable value oscillates in specifics moments over time. In contrast, continuous time views variables as having a particular value for potentially only an infinitesimally short amount of time.

Despite the financial assets follow a discrete stochastic process, in other words, the prices vary according to the price of fractions and variations depend on the occurrence of business, continuous models work very well for most of the models used in finance.

Although being attractive from a theoretical point of view, the practical application of the methods of real options has been limited by the high level of mathematical complexity, lack of intuitive appeal and by the restrictive assumptions that these approaches have (Brandão et al., 2005).

The binomial model, developed by Cox, Ross and Rubinstein (1979), is a discrete time option valuation model. In each period, the asset can only assume 
one of two value alternatives. As shown in Figure 2, the upward and downward movements determine the possible paths. Considering that the initial asset value is $V_{0}$, on the next period, it can be $V_{u}$ due to an upward movement or $V_{d}$ in case of downward, whre $u$ is the growth multiplier and $d$ is the decrease multiplier. Figure 7 represents an example of Binomial Pricing Model:

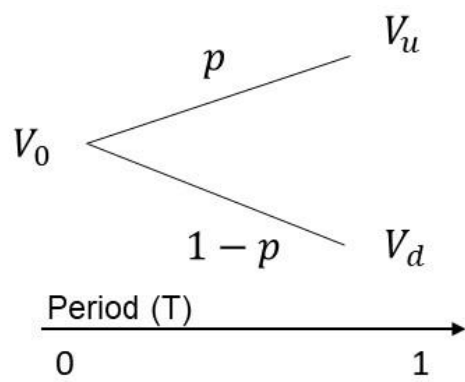

Figure 7: Example of Binomial pricing model. Source: author

In this way, the binomial model may be used to approximate discrete solutions to continuous time model developed by Black, Scholes and Merton for financial options valuation, with additional advantage to allow that this solution can be applied to American Options, while the Black-Scholes-Merton model can evaluate only European Options.

In practical issues, this model considers that, in each period, an asset price $S$ can go up (u) or go down (d). The upward movement has the probability $q$ to occur and it shifts the price to $V_{u}$, while the downward movement has probability (1-q) and it reduces the asset price to $V_{d}$. The values of $u$ and $d$ are defined based on the asset value volatility $(\sigma)$, as following equations:

$$
\mu=e^{\sigma \sqrt{\Delta \tau}} \text { and } d=e^{-\sigma \sqrt{\Delta \tau}}
$$

The valuation method based on this tool, also known as Decision Tree Analysis (DTA), tries to catch the value of the managerial flexibility in future decision moments, mapping possible managerial actions in response to determined situations. Each tie of the tree represents a decision to be taken by the management that, based on available information at that moment, can try to maximize the project value or to reduce losses.

Considering the flexibility that management has over the useful life of the project to respond to market conditions, the DTA allows that some limitations of DCF are overcome, in special the static characteristic of this traditional valuation method. However, the optimization that occurs in each moment changes the cash flows expected and then, changes the project risks as well. Therefore, the standard 
deviation of the project's cash flows considering flexibility differs from the standard deviation of no option project cash flows. Therewith, the discount rate adjusted by the risk used in a non-option project cannot be used in models that include real options. As stated by Brandão et al. (2005), this issue about the DTA has led several authors mistakenly to conclude that this method cannot be used for the evaluation of real options.

Indeed, there are solutions that can be applied to the DTA limitation. One of them is the use of a replicating portfolio, which can determinate the right discount rates $(\mathrm{k})$ and consequently catch the market risks related to this investment. Such an approach consists in the creation of a portfolio of securities whose payments are equal to the asset payments in all states of nature and in all future periods. According to the principle of non-arbitration, the asset and the portfolio that replicates your payments must have the same present value, which allows the project value is determined from the known values of its replicating portfolio.

Nevertheless, the need to create a replicating portfolio for each node of the decision tree makes this non-intuitive method and difficult to apply, especially in more complex situations involving simultaneous or compound options. In addition, this method assumes that there are securities in the market in sufficient variety to enable the creation of portfolios that replicate the payments of the underlying assets. However, the market is incomplete and, for most projects involving real assets, there is a portfolio whose payments amount to the underlying asset payments in each state of nature and in every future moment. An alternative to the replicating portfolio is the approach to risk-neutral probability, according to which the project risk is regarded by adjusting the range of probabilities in the price of the asset, $q$ and $(1-q)$, instead of the adjustment by the discount rate adjusted (k).

The adjustment of those probabilities leads to the risk-neutral probability $p$ and $(1-p)$, so called because the asset is priced as if there was a representative investor who was indifferent to the risk, and estimates the probability $p$ of increase in asset price. Considering the neutrality to risk, the risk-neutral model evaluates the future cash flows of the asset using a risk-free discount rate ( $r$ ).

Therefore, according to this approach, the project's present value can be obtained by the following equation:

$$
V=\frac{\rho V_{u}+(1-\rho) V_{d}}{1+r}
$$


As the risk-free rate is smaller than the adjusted discount rate $k$, the derived probability $p$ is also smaller than the probability of upward movement $q$. This probability can be obtained by:

$$
\rho=\frac{(1+r-d)}{(u-d)}
$$

Thus, in line with this approach, the project's present value is equal to the expected returns times the probabilities that adjust them to the risk, discounted by the risk-free rate. Therewith, the challenge to find a discount rate adjusted by the risk is replaced by the challenge to find the risk-neutral probabilities.

However, according to Brandão et al. (2005), this second challenge tends to be more easily solved, since the risk-neutral probabilities can be determined from market information or from theoretical assumptions regarding the stochastic process associated with the value of the project. Among these assumptions, the most common is this stochastic process follows a Geometric Brownian Motion (GBM) with constant volatility, meaning that the values of the probabilities $p$ and $(1-p)$ are constant and should be applied in the same manner over the decision tree.

Another limitation of the binomial model is on the scenarios with many uncertainties. The DTA structure, sometimes, can become barely functional (barely friendly), due to the high number of possible paths in each node. For the cases where there is more than one uncertainty, both for American and European Options, there is a possibility to use the Monte Carlo Simulation method with Least Squares (LSM) of Longstaff and Schwartz (2001).

\subsection{4.}

\section{Modeling uncertainties: The Geometric Brownian Motion}

The uncertainties are inherent to the great majority of projects or firms and, so, they are the main source of risks. These uncertainties can be a commodity price, market-share, sales growth, etc. Therefore, the correct modeling of the motion is fundamental to evaluate of existing real options.

According to Dixit and Pindyck (1994), the Wiener Process, or Brownian Motion, is a particular type of Markov Process, often used in physics to describe the motion of a particle that is subject to a large number of small molecular shocks.

The Wiener process is a continuous-time process with three important properties: 
1. It is a Markov Process. Therefore, all we need to make a prediction of the future value of the variable is its probability distribution and its current value.

2. It has independent increments.

3. Changes on the process over any time interval are normally distributed, with variance increases linearly with the time interval.

These three properties can seem restrictive, because it is known, for example, that stock prices follow a log-normally distribution (stock prices are never smaller than zero). To solve this problem, we just have to model the logarithm of the price as a Wiener Process.

Since the seminal work by Pindyck $(1980,1984)$, the GBM process has also been largely used in natural resource applications. One example is Olsen and Stensland's optimal shutdown problem (Olsen and Stensland, 1988), which reveals one of the main advantages of using a GBM process: its mathematical simplicity. In particular, the GBM assumption results in differential equations whose analytical solutions are relatively easy to find and interpret. Another advantage of using a GBM is that its parameters are very easy to find by maximum likelihood estimation.

Dias (2009) presented the following summary on different stochastic models used in real options:

\begin{tabular}{|l|l|l|}
\hline $\begin{array}{l}\text { Types of Stochastic } \\
\text { Process }\end{array}$ & Model Name & References \\
\hline Unpredictable Model & $\begin{array}{l}\text { Geometric Brownian } \\
\text { Motion (GBM) }\end{array}$ & $\begin{array}{l}\text { Paddock, Siegel \& Smith } \\
(1988)\end{array}$ \\
\hline Predictable Model & $\begin{array}{l}\text { Pure Mean Reversion } \\
\text { (MR) }\end{array}$ & $\begin{array}{l}\text { Dixit \& Pindyck (1994), } \\
\text { Schwartz (1997, model 1) }\end{array}$ \\
\hline \multirow{3}{*}{ More realistic Models } & $\begin{array}{l}\text { Two or Three-factor } \\
\text { models, and Mean } \\
\text { reversion to an } \\
\text { uncertain long-term } \\
\text { mean }\end{array}$ & $\begin{array}{l}\text { Gibson \& Schwartz } \\
\text { (1990), Schwartz (1997, } \\
\text { models 2 \& 3), Baker, } \\
\text { Mayfield \& Parsons } \\
\text { (1998), Schwartz \& Smith } \\
\text { (2000) }\end{array}$ \\
\cline { 2 - 4 } & $\begin{array}{l}\text { Mean Reversion with } \\
\text { Jumps }\end{array}$ & $\begin{array}{l}\text { Dias \& Rocha (1999, } \\
\text { 2001), Aiube, Tito \& } \\
\text { Baidya (2008) }\end{array}$ \\
\hline
\end{tabular}

Table 3: More usual Stochastic Processes. Source: Ozorio et al (2012) 
GBM has two components; a certain component and an uncertain component. The certain component represents the return that the stock will earn over a short period of time, also referred to as the drift of the stock. The uncertain component is a stochastic process including the stocks volatility and an element of random volatility (Sengupta, 2004). Brewer, Fend and Kwan (2012) show that only the volatility parameter is present in the Black-Scholes (BS) model, but the drift parameter is not, as the BS model is derived based on the idea of arbitrage-free pricing. For Brownian motion simulations both the drift and volatility parameter are required, and a higher drift value tends to result in higher simulated prices over the period being analyzed (Brewer, Feng and Kwan, 2012).

A stochastic process $d x$ is said to follow a Geometric Brownian Motion if it satisfies the following stochastic differential equation:

$$
d x=a(x, t) d t+b(x, t) d z
$$

Where $\mathrm{dz}$ is a Wiener Process (Brownian Motion) and $\alpha(x, t)$ and $b(x, t)$ are non-random functions. The variables $\alpha$ and $b$ are the percentage drift and variance (volatility).

Let us assume $F$ as a function of $\mathrm{x}$ and $\mathrm{t}, F(x, t)$, using Taylor expansion, we have:

$$
\begin{gathered}
d F=\frac{\partial F}{\partial x} d x+\frac{\partial F}{\partial t} d t+\frac{1}{2 !} \frac{\partial^{2} F}{\partial x^{2}}(d x)^{2}+\frac{1}{2 !} \frac{\partial^{2} F}{\partial t^{2}}(d t)^{2}+\frac{1}{2 !} \frac{\partial^{2} F}{\partial x \partial t} d x d t \\
+\frac{1}{3 !} \frac{\partial^{3} F}{\partial x^{3}}(d x)^{3}+\frac{1}{3 !} \frac{\partial^{3} F}{\partial t^{3}}(d t)^{3}+\cdots
\end{gathered}
$$

By applying the equation (5) in the equation (6), we have:

$$
\begin{gathered}
d F=\frac{\partial F}{\partial x} a(x, t) d t+b(x, t) d z+\frac{\partial F}{\partial t} d t+\frac{1}{2 !} \frac{\partial^{2} F}{\partial x^{2}}(d x)^{2} \\
+\frac{1}{2 !} \frac{\partial^{2} F}{\partial t^{2}}(d t)^{2}+\frac{1}{2 !} \frac{\partial^{2} F}{\partial x \partial t} d x d t
\end{gathered}
$$

Considering that:

$$
(d x)^{2}=a^{2}(x, t) d t^{2}+2 a(x, t) b(x, t) d t d z+b^{2}(x, t)(d z)^{2}
$$


Also, assuming that:

$$
\begin{gathered}
d z=\varepsilon \sqrt{d t} \\
(d z)^{2}=(\varepsilon \sqrt{d t})^{2} \\
E\left[(d z)^{2}\right]=E\left[\varepsilon^{2} d t\right]=d t . E\left[\varepsilon^{2}\right] \\
E\left[\varepsilon^{2}\right]=1
\end{gathered}
$$

Therefore:

$$
\begin{gathered}
(d z)^{2}=d t \\
(d x)^{2}=a^{2}(x, t) d t^{2}+2 a(x, t) b(x, t) \varepsilon d t^{\frac{3}{2}}+b^{2}(x, t) d t
\end{gathered}
$$

Also, any $d t$ tending to zero, all $d t$ terms raised to any power greater than one, will tend to zero, thus:

$$
\begin{gathered}
(d x)^{2}=b^{2}(x, t) d t \\
d x d t=a(x, t)(d t)^{2}+b(x, t) d z d t=a(x, t)(d t)^{2}+b(x, t) \varepsilon d t^{\frac{3}{2}} \\
=0
\end{gathered}
$$

Finally, we come up with the following:

$$
d F=\left[\frac{\partial F}{\partial t} d t+\frac{\partial F}{\partial x} a(x, t) d t+\frac{1}{2} \frac{\partial^{2}}{\partial x^{2}} b^{2}(x, t)\right] d t+\frac{\partial F}{\partial x} b(x, t) d z
$$

We also can find the discrete equation of simulation. Thus, at the moment $\mathrm{t}$ (future), the asset price $X_{t}$ is given by:

$$
X_{t}=X_{0} \cdot e^{\left[\left(\alpha-\frac{\sigma^{2}}{2}\right) \cdot \Delta t+\sigma \cdot \sqrt{\Delta t} \cdot N(0,1)\right]}
$$

The simulation of real prices using the equation above is done choosing random values and getting their standard Normal distribution $(\mathrm{N}(0,1))$, and then we find the matching price $X_{t}$. The main restriction of GBM is this process can lead $x(t)$ to the infinite and, so, some models that follow a GBM can be unrealistic.

The expected value and the variance can be used to estimate the discounted present value of $x(t)$ at any time: 


$$
E\left[\int_{0}^{\infty} x(t) e^{-r t} d t\right]=\int_{0}^{\infty} x_{0} e^{-(r-\alpha) t} d t=\frac{x_{0}}{r-\alpha}
$$

This equation will be useful to calculate the discounted present value of cash flow, considering the uncertainty follows a GBM.

Although the GBM process is well-supported, there is a growing amount of literature that focuses on testing the validity of the model and accuracy of forecasts using Brownian motion. For example, Abidin and Jaffar (2014) use GBM to forecast future closing prices of small-sized companies in Bursa Malaysia. The study focuses on small-sized companies because asset prices are lower and more affordable for individual investors. The study looks into the accuracy of forecasts made using the model over different horizons, and also at the time horizon needed for data inputs into the model, that is, past stock prices. According to Abidin and Jaffar (2014), GBM can be used to forecast a maximum of two weeks closing prices. It was also found that one week's data was enough to forecast the share prices using GBM.

Marathe and Ryan (2005) discuss the process for checking whether a given time series follows the GBM process. They also look at methods to remove seasonal variation from a time series, which they claim is important because the GBM process does not include cyclical or seasonal effects. They found that of the four industries they studied, the time series for the usage of established services met the criteria for a GBM process; while the data form growth of emergent services did not.

\subsection{5.}

\section{Real Options applied to M\&A}

Real Option valuation has been applied notably to some specific industries and contexts, such as mining, energy, information technology and corporate strategy. Likewise, ROT has also been found to be a useful tool when framing problems found within the environment of corporate acquisitions and mergers.

According to Myers (1978), growth opportunities can be viewed as real options, whose value depends on future investment by the firm. Smith and Triantis (1995) discuss strategic acquisitions that create real options able to increase upside potential while truncating downside risk. They argue that synergies influence the growth options that an acquirer has on an acquired firm. 
In an M\&A deal, for instance, the parties have the flexibility to exchange an asset or stock for another risky asset or stock (Margrabe, 1978). Pawlina (2002) also suggests the Real Options approach in M\&A deals, in special considering the option to pay in cash (cash-for stock) or in stock swap (stock-for-stock). Pawlina (2002) found that structuring the deal in the form of exchange ratio swap held by the acquiring firm can lead to the $25 \%$ increase in the value of the acquisition opportunity. Alternatively, incorporating the managerial flexibility on the side of the target alone leads to its fair valuation being $23 \%$ lower than obtained with a simple NPV rule.

Lambrecht (2004) provides a setting in which mergers are driven by economies of scale and shows that the merger takes place once the price of the industry output raises to a sufficiently high threshold, thereby providing a rationale for the procyclicality of mergers. Morellec and Zhdanov (2005) build on the framework of Lambrecht to study mergers in a setting with incomplete information between the market and the merging firms.

Smit et al (2005) investigate the distribution of value gains in acquisitions with a real options game model that examines the bidding process, the likelihood of bidding contest and the expected value distribution for the acquirer. Also, Alvarez (2006) discuss the different types of real options available in corporate $M \& A$, including the option to divest parts of the acquired company. They also present a compound real options model that considers the different phases of an acquisition: divestment, synergy, consolidation and takeover. The model can be used to calculate the optimal timing and price of the acquisition.

Collan (2008) outlined different types of real options connected to $M \& A$, such as options to postpone and to stage the acquisition, synergies as options, option to split the existing business into parts and option to abandon a non-core part of the target.

Kinnunen (2013) presented a two-component portfolio selection problem under two types of uncertainties, i.e., probabilistic risk and possibilistic risk. He studied the portfolio selection problem in mergers and acquisitions and modeled synergies as a real option. Collan et al. (2011) discussed how a rapid preacquisition screening of target companies can be performed with pay-off method for real option valuation, treating the acquisition synergy as a real option available for the acquirer.

Zhu et al (2017) develop a real options model to analyze the timing of bank mergers motivated by the incentive to obtain too-big-to-fail (TBTF) status from the government. They show that mergers may occur even in the absence of scale 
economies, which is different from Lambrecht (2004). Moreover, the TBTF incentive lowers the threshold required for bank mergers, and the degree of scale diseconomies that the merging entities can tolerate increases as the probability of obtaining the TBTF status becomes higher. Their findings thus provide a theoretical explanation for the lack of scale economies in bank mergers identified in prior literature.

Yu and $\mathrm{Xu}$ (2011) developed a dynamic analyses model to price that target firm from the perspective of real options integrated with game theory under stochastic surroundings. They introduced the synergy multiplication coefficient into the evaluation model to reflect the synergy management process of $M \& A$ and proposed the equilibrium price formula by applying the famous offer-counteroffer Rubinstein theorem, which is improved to fit for the stochastic surroundings.

Hackbarth and Morellec (2006) developed a real options framework aiming to analyze the behavior of stock returns in mergers and acquisitions. Also, in this framework, the timing and terms of the takeover are endogenous and result from value-maximizing decisions. Another key contribution of this study relates to the change in beta at the time of the takeover. By exercising their real options, firms change the riskiness of their assets and therefore affect their betas and expected stock returns. Hackbarth (2011), also using a real options framework, shows that (i) mergers are more likely in more concentrated industries; (ii) mergers are more likely in industries that are more exposed to industry-wide shocks; (iii) returns to merger and rival firms arising from restructuring are higher in more concentrated industries; (iv) increased industry competition delays the timing of mergers; (v) in sufficiently concentrated industries, bidder competition induces a bid premium that declines with product market competition and (vi) mergers are more likely and yield larger returns in industries with higher dispersion in firm size.

Azevedo et al (2016) analyze the changes in the consumers' and producers' surplus associated with acquisition deals where there is a noncompetition covenant that forbids the seller from re-entering the market over a given time period. Their findings suggest that these acquisition deals can lead to significant negative (positive) changes in the producers' (consumers') surplus, which decreases significantly with the time period of the covenant.

Bates et al (2018) present evidence that earnout agreements in acquisition contracts provide a substantial source of financing for acquirers. Acquirers in transactions with earnouts are significantly more likely to be financially constrained, face tighter credit market conditions, and use less debt and equity to fund 
acquisitions. Financially constrained acquirers also book lower fair values for the contingent claim.

\subsection{6.}

\section{Contract Theory}

An eternal obstacle to human cooperation is that people have different interests. In modern societies, conflicts of interests are often mitigated if not completely resolved by contractual arrangements. Well-designed contracts provide incentives for the contracting parties to exploit the prospective gains from cooperation. For example, labor contracts include pay and promotion conditions that are designed to retain and motivate employees; insurance contracts combine the sharing of risk with deductibles and co-payments to encourage clients to exercise caution; credit contracts specify payments and decision rights aimed at protecting the lender, while encouraging sound decisions by borrowers (Holmstrom, 2016).

Endogenous risk in venture projects is related to agency conflicts between the buyer/investor and the seller/entrepreneur. The seller inhibits the role of contracting agent and owns human capital, such as specific skills or knowledge, essential to realize the venture project (Hart and Moore, 1994). To avoid an inefficient continuation of the project, the investor implements various mechanisms like contingent control allocation (Chan et al., 1990; Kirilenko, 2001), convertible securities (Schimidt, 2003), and staging (Bergemann and Hege, 1998).

Also, exogenous risk in venture projects is related to unexpected market developments, e.g. technological progress within the industry, trending consumer behavior or competitor's response to new products. Exogenous risk is out of control of a decision maker and resolves primarily with the passage of time (McGrath, 1997; Pindyck, 1993; Dixit \& Pindyck, 1994). In this case, the timing of investments can be seen as the decision on whether to hold the current option to invest and wait for informational updates abo ut the market conditions or to invest immediately and capitalize on the informational available ( $\mathrm{Li}, 2008)$.

A simple formal framework can be used to illustrate the basics of Contract Theory. An agent $A$ works a single period for a principal, $P$. The agent takes an action $\alpha$ from some interval $[\underline{\alpha}, \bar{\alpha}]$. This generates a cost $c(\alpha)$ for the agent and a benefit $\beta=b(\alpha)+\varepsilon$ for the principal, where $\varepsilon$ is a random noise term. Since we are concerned with conflicts of interest, we assume $b$ and $c$ are increasing functions of $\alpha$, so that, all else equal, the principal prefers a higher $\alpha$ while the agent prefers a 
lower $\alpha$. We also may interpret $\alpha$ as the agent's "effort". More precisely, we can interpret $\alpha$ as the lowest effort the agent can get away with without being caught shirking. Assume further that both $b$ and $c$ are differentiable, $b$ is concave, and $c$ is convex. For any random variable $x$, let $E(x)$ and $\operatorname{Var}(x)$ denote the expected value and variance of $x$, respectively. Without loss of generality, assume $E(\varepsilon)=0$.

This simple model captures the essence of many real-life settings. For example, the agent could be a worker, a CEO, an entrepreneur or a firm. The principal could be an employer, a board of directors or an investor (venture capitalist). In many such settings, the outcome is random, and risk-sharing is a crucial aspect of the contracting problem.

Let $t$ denote a payment, or transfer, from the principal to the agent. Note $t$ $>0$ indicates a payment from $P$ to $A$, while $t<0$ is a payment in the opposite direction. These payments would be constrained by the financial resources that $P$ and $A$ have. First, we assume both parties have large enough resources so that such financial constrained can be neglected. Moreover, since the principal is often richer or better diversified than the agent, let us assume that $P$ is risk-neutral, and $A$ is risk-averse. Also, let's suppose the principal's expected utility is:

$$
U_{P}=b(a)-E(t)
$$

While the agent's expected utility is

$$
U_{A}=-c(a)+E(t)-\frac{1}{2} r \operatorname{Var}(t)
$$

Where $r>0$ measures the degree of risk aversion.

Therefore, the total surplus from the relation is

$$
U_{P}+U_{A}=b(a)-c(a)-\frac{1}{2} r \operatorname{Var}(t),
$$

Where the last term is the utility cost of A's risk-bearing. We may also assume that a unique action $\alpha^{*} \in[\underline{\alpha}, \bar{\alpha}]$ maximizes $b(a)-c(a)$. Uniqueness of $\alpha^{*}$ is guaranteed if either $b$ is strictly concave, $c$ is strictly convex, or both. Assuming $b^{\prime}(\underline{\alpha})>0$ and $c^{\prime}(\underline{\alpha})=0$ guarantees that $\alpha^{*}>\underline{\alpha}$. It is also convenient to assume that $c^{\prime}(\bar{\alpha})$ is very large, so that $\alpha^{*}<\bar{\alpha}$. The total surplus is maximized when $a=$ $\alpha^{*}$ and $\mathrm{A}$ bears no risk: $\operatorname{Var}(t)=0$. The outcome is then said to be first-best.

A classic contracting problem has the following structure. A principal engages an agent to take certain actions on the principal's behalf. However, the principal cannot directly observe the agent's actions, which creates a problem of 
moral hazard: the agent may take actions that increase his own pay but reduce the overall surplus of the relationship. To be specific, suppose the principal is the main shareholder of a company and the agent is the company's manager. As Adam Smith noted, the separation of ownership and control in a company might cause the manager to make decisions contrary to the interests of shareholders. To alleviate this moral-hazard problem, the principal may offer a compensation package which ties the manager's income to some (observable and verifiable) performance measure (HOLMSTRÖM, 2016).

In the classic moral-hazard model, it is not possible to write a contingent transfer schedule $t(\alpha)$ into the contract. The justification for this is typically the hidden action assumption: $\alpha$ is not observable. However, even if the action could be observed, it may be hard to fully describe it in advance - and even if it could be both described and observed, it might be impossible for a court (or some other contract enforcer) to verify what action was taken. In any case, following the classic moral-hazard literature, we assume the transfer is based on an imprecise performance measure. Specifically, it is based on the benefit the principal derives from the agent's action, $t=t(\beta)$. The benefit $\beta=b(a)+\varepsilon$ is assumed to be both observable and verifiable by a court, but it is only an imperfect indicator of the agent's action (due to the fluctuating $\varepsilon$ ). This is often a realistic situation. For example, while a board of directors may not observe exactly how the CEO runs the company, they do observe the stock price (and a bunch of other accounting measures). Empirically, a typical CEO's payoff is strongly dependent on his company's stock market performance.

If the agent is risk neutral ( $r=0)$ and has eno ugh financial resources, then the contracting problem has a straightforward solution, a "franchise contract", where $\mathrm{A}$ pays a fixed fee $f$ to $\mathrm{P}$ and in return gets all the realized benefit: $t(\beta)=$ $\beta-f$. Since the agent becomes a residual claimant of any surplus he generates, he has the right incentives to trade-off costs and benefits: he will maximize $b(a)-$ $c(a)$ by choosing the first-best action $\alpha^{*}$. The agent has to carry all the risk, but as long as $r=0$ this is not costly. The fixed fee $f$ can be used to divide surplus in any desired fashion. Also, another interpretation of the optimal contract is that $A$ buys the project from $\mathrm{P}$ for a price $f$. This relates to Jensen and Mecklings (1976) insight that having the manager own the equity of the firm alleviates moral hazard. They use this insight to rationalize debt financing, which allows a founder-manager to keep the equity of the firm.

However, let's assume a more interesting and realistic case where the agent is risk averse $(r>0)$, so that it not optimal for him to bear all the risk. The 
gain from high-powered incentives then has to be weighed against the loss from suboptimal risk-sharing. This trade-off between incentives and risk-sharing is a classic problem in incentive theory. To sum up, aiming to solve the moral-hazard problem, parties should write performance-based contracts ex ante and enforce appropriate rewards ex post.

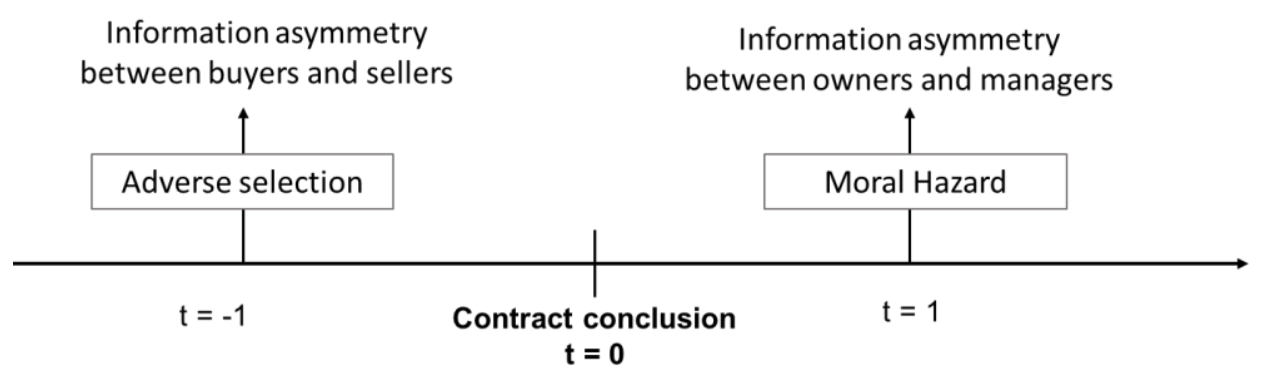

Figure 8: Information asymmetry over the time. Adapted from Lukas et al. (2012)

Nevertheless, measuring performance may not be easy. Even if performance can be evaluated ex-post, it may be difficult to write a sufficiently detailed contract ex-ante, specifying exactly what aspect of performance will be rewarded. Finally, even if such a contract could be written, it may be difficult to enforce it, because a third party (e.g., a judge) may not be able to verify the performance ex-post. In view of the difficulties involved in writing and enforcing detailed contracts, it not surprising that many of the contracts we observe are highly incomplete. This is the motivation behind the incomplete contracts approach to contracting, pioneered by Oliver Hart.

One of the most important application of incomplete-contracts theory is in the corporate finance field. Economists focused on what many practitioners and legal scholars had seen all along, namely that a major purpose of financial contracting is to ensure that entrepreneurs and managers act in the interests of investors. 
3.

\section{General Framework}

This study investigates specifically three common features (covenants) of M\&A contracts: earnout, anti-dilution provisions and liquidation preference. By combining real options and contract theory, we aim to investigate the real value of legal covenants frequently used in M\&A transactions.

The discussion about the model starts from the analysis of the net present value (NPV) of the Company with no option. After applying the contractual flexibilities, we analyze the impact of the option on the deal value using Monte Carlo Simulation.

For each case, we begin with the DCF valuation, making initial assumptions of the model. Then, we identify the uncertainty, defining risk premium, risk-free rate and volatility.

We have chosen the Geometric Brownian Motion as stochastic diffusion to model the uncertainties. Pindyck (1994) showed that for short periods, GBM represents the uncertainty behavior better than Mean reversion. Also, one of the main advantages of GBM when compared to other models is its small quantinty of parameters.

After modeling, we test a numerical application, aiming to understand the behavior of each variable and its impact on the model outcome. Finally, we also verify the effect of changes in the value of key parameters may have on the expected value of the deal.

\section{1.}

\section{Model with legal covenant: Earnout}

Our model with earnout involves a buyer and a target in an M\&A deal. This is a typical principal-agent model, in which the principal (VC/buyer) "hires" the agent (entrepreneur/seller) to run the company. The buyer would like the entrepreneur to work very hard, however, the entrepreneur's actions (effort) are unobservable. On the other hand, signals (firm performance) are correlated with the entrepreneur's actions (effort). These signals can be contracted on. Thus, as the buyer wants to maximize pay-for-performance for the seller, he will want to make the entrepreneur's compensation contingent on as many verifiable signals correlated with the entrepreneur's effort as possible. 
The buyer agrees to pay an upfront payment $\overline{I_{t}}$ to the seller and a contingent payment in the future if the target company reaches the performance measure agreed. For pricing purposes, earnouts resemble options on the target company's fair value. The target company's shareholders hold what amounts to a long position in a call option on their company's value. After the deal closing, the seller will remain as a firm' shareholder and has to put his best effort to makes the company more profitable. The buyer is risk neutral while the seller is risk averse. The following timeline summarizes the steps:

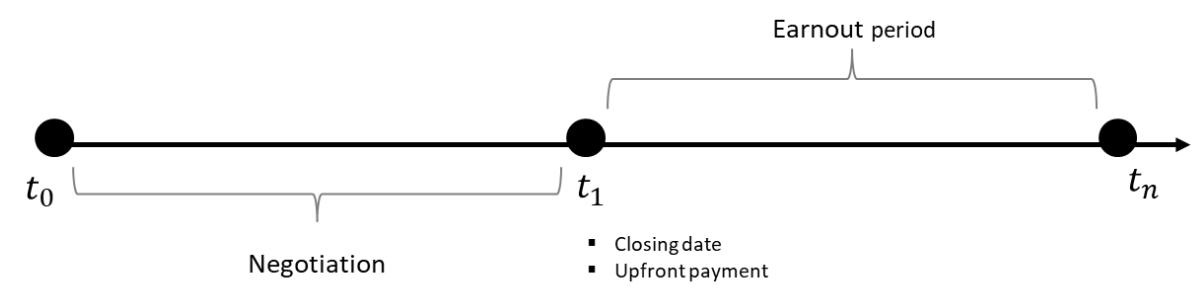

Figure 9: Deal timeline. Source: author

Target firm has free cash flow (FCF) $x_{t}$ and this is the model uncertainty. The FCF follows a Geometric Brownian Motion (GBM) over the time:

$$
d S=\alpha S d t+\sigma S d z
$$

Where, $d z$ is the Wiener Process and the variables $\alpha$ and $\sigma$ are also known as drift and volatility. A function of $S$ and $t, f(x, t)$, follows the process:

$$
d f=\left(\frac{\partial f}{\partial X} \alpha+\frac{\partial f}{\partial t}+\frac{1}{2} \frac{\partial^{2} f}{\partial X^{2}} \sigma^{2}\right) d t+\frac{\partial f}{\partial X} \sigma d z
$$

Applying this to the uncertainty, with $f=\ln (S)$, gives:

$$
\begin{gathered}
d \ln (S)=\left(\frac{1}{S} r S+0+\frac{1}{2}\left(-\frac{1}{S^{2}}\right) \sigma^{2} S^{2}\right) d t+\frac{1}{S} \sigma S d z \\
=\left(r-\frac{1}{2} \sigma^{2}\right) d t+\sigma d z
\end{gathered}
$$

Using a logarithmic transformation and applying the Ito Lemma, we find the following discrete equation of simulation. Thus, at the future time t, the asset $x_{t}$ is given by: 


$$
X_{t}=X_{0} \cdot e^{\left[\left(\alpha-\frac{\sigma^{2}}{2}\right) \cdot \Delta t+\sigma \cdot \sqrt{\Delta t} \cdot N(0,1)\right]}
$$

Considering $\mu$ the project discount rate, so any time $t$, we will have the present value expressed by $V_{\tau}=\int_{t=\tau}^{\infty} E\left[F_{t}\right] e^{-\mu(t-\tau)} d t$, where $F_{t}$ is the cash flow at time t. As $E\left[F_{(\tau)}\right]=F_{0} e^{\alpha t}$, thus the relation between $V_{(\tau)}$ e $F_{(\tau)}$ is $V_{(\tau)}=\frac{F_{(\tau)}}{\mu-\alpha}$, with $\mu>\alpha$. We assumed all transactions costs are irreversible. The model predicts a deal where the free cash flow generation is the performance indicator for earnout clause activation. The transaction costs were modeled according to the following function:

$$
I_{T}(Q)=\bar{I}_{t}+Q \tilde{I}_{t}
$$

Where, $I_{T}, \tilde{I}_{t}$ e $\overline{I_{t}} \in \mathbb{R}^{+}$. Here, $\overline{I_{t}}$ is the fixed transaction cost and $Q \tilde{I}_{t}$ reflects the part of the transaction cost which depends on earnout payment. The $Q$ represents the situations which it is possible to pay only a percentage of the clause value. For purposes of modeling, we also assumed that the earnout payment is an irreversible cost. To estimate the contingency payment, we considerate the uncertain cash flow will follow the option pricing settings. In these settings, the initial value is "in-", "at-" or "out of the money". We assume the option has its initial value "out of the money" and to activate the earnout clause, the cash flow has to surpass the performance indicator.

Under the seller's perspective, greater the earnout ratio, greater the effort post-deal. Likewise, greater the probability of earnout payment, smaller the seller's effort post-closing phase. Under the buyer's perspective, the earnout may be seen as a real option to wait.

The earnout option generates a single payment of size $Q$ once the prespecified performance is met. Otherwise, the earnout option expires worthless. This is a cash-or-nothing option like feature, which means a single cash payment is made, contingent on the future cash flow of the target. We also analyze the sensitivity of any change in these parameters in the option value by simulation.

There are three types of earnouts under real options perspective: 

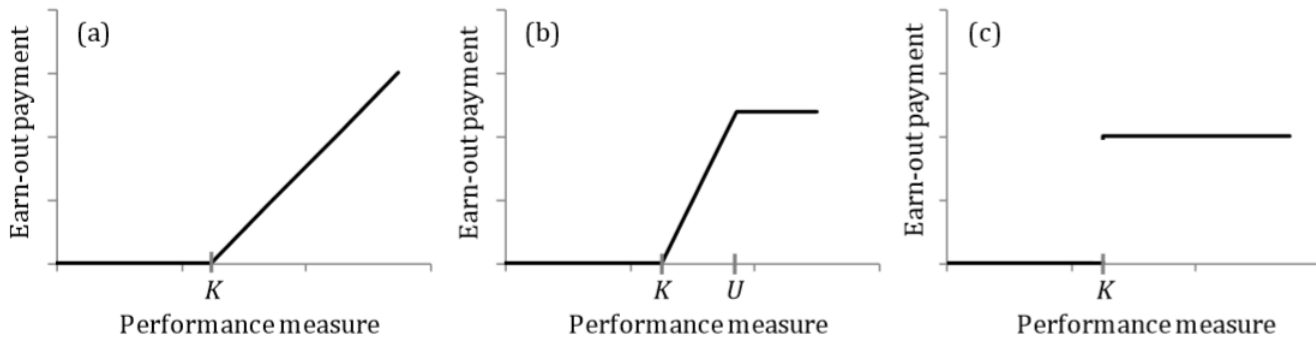

Figure 10: Examples of different earnout models. Adapted from Tallau (2006)

According to Figure 10, there are three pay-offs profiles of possible earnout clauses. In case (a), if the performance measure exceeds the threshold $\mathrm{K}$, it triggers a proportional participation. For case (b), the variable subsequent payment is capped at a level U. Finally, (c) displays a situation where, if the performance measure exceeds the threshold $\mathrm{K}$, it triggers a fixed payment. Furthermore, the case (a) corresponds to the pay-off of a European call option (with strike price $\mathrm{K}$ ), while (b) is may be demonstrated by combining a long call and a short call. Lastly, the pay-off profile (c) corresponds to a binary option, which provides a fixed payment if the stock price exceeds the strike price at maturity.

First, we model the earnout clause as a binary option, in which the payoff has the shape of (c) in Figure 3. In this situation, the contingent payment is a function of the gap between the valuation asked by the seller and the valuation bided by the buyer. Second, we model the earnout as a call option, in which the seller will earn a proportionate value. The following equation summarizes the present value of the call option:

$$
c=e^{(-r t)}\left[\max \left(F C F_{t}-F C F_{e}, 0\right)\right.
$$

Where, $F C F_{t}$ is the free cash flow of the seller at time $t$ and $F C F_{e}$ is the free cash flow goal, which means the earnout performance measure.

We argue that the seller can change his short-term action aiming to speed up the activation of the earnout or at least make the earno ut feasible. In other words, the seller can damage the long-term company's plans trying to overcome the short-term earnout goal. This can happen in different ways, such as the anticipation of sales or sales recognition (accounting issue), short-termism on cost side (lack of efficiency) or by hiding or postponing legal/environmental liabilities and delaying equipment maintenance. Although it can be fairly addressed by adopting free cash flow as the performance goal (or any other), Contract Theory 
(e.g. Incomplete Contracts) supports that it is challenging to predict all events exante, as mentioned in section 2.3.

Therefore, to address this additional risk, we also model earnout as an Asian option. Asian options are securities with payoff which depends on the average of the underlying asset price over a certain time interval (see Ingersoll, 1987). By doing that, we aim to overcome the moral hazard as the seller must deliver consistent results, not "one-time achievement". Thus, for modeling purpose, we set the free cash flow quarterly average as a performance goal.

Furthermore, the average prices can be calculated using either the arithmetic mean or geometric mean. The arithmetic mean does not follow a lognormal distribution and because of that, it is not possible to obtain a closed-form formula to price Arithmetic Asian option. However, since it is possible to approximate the arithmetic mean using the geometric mean, it is possible to derive an approximation of the price of an Arithmetic Asian option. Wiklund (2012) has shown the Arithmetic Asian option formula:

$$
\begin{aligned}
& c=e^{(-r t)} E[E[\max (A-K, 0) \mid G]] \\
& p=e^{(-r t)} E[E[\max (K-A, 0) \mid G]]
\end{aligned}
$$

Where $A$ is the Arithmetic and $G$ is the geometric mean of the underlying asset price. In the case when the averaging period has not yet started, the price for a non-dividend paying Arithmetic Asian option can be approximated by (Wiklund, 2012):

$$
\begin{aligned}
& c \approx e^{(-r t)}\left[\left(\frac{1}{n} \sum_{i=1}^{n} e \mu_{i}+\sigma_{i}^{2} / 2 N\left(\frac{\mu-\ln (K)}{\sigma_{x}}+\frac{\sigma_{x i}}{\sigma_{x}}\right)\right)-K N\left(\frac{\mu-\ln (K)}{\sigma_{x}}\right)\right] \\
& p \approx e^{(-r t)}\left[K N\left(\frac{\mu-\ln (K)}{\sigma_{x}}\right)-\left(\frac{1}{n} \sum_{i=1}^{n} e \mu_{i}+\sigma_{i}^{2} / 2 N\left(\frac{\mu-\ln (K)}{\sigma_{x}}+\frac{\sigma_{x i}}{\sigma_{x}}\right)\right)\right]
\end{aligned}
$$

Where:

$$
\mu_{i}=\ln (S)+\left(r-\frac{\sigma^{2}}{2}\right)\left(t_{1}+(i-1) \Delta t\right)
$$




$$
\begin{gathered}
\sigma_{i}=\sigma \sqrt{\left(t_{1}+(i-1) \Delta t\right.} \\
\sigma_{x i}=\sigma^{2}\left(t_{1}+\Delta t\left((i-1)-\frac{i(i-1)}{2 n}\right)\right. \\
\mu=\ln (S)+\left(r-\sigma^{2} / 2\right)\left(t_{1}+(n-1) \Delta t / 2\right) \\
\sigma_{x}=\sigma \sqrt{t_{1+\Delta t(n-1)(2 n-1) / 6 n}} \\
\widehat{K}=2 K-\frac{1}{n} \sum_{i=1}^{n} e^{u_{i}+\frac{\sigma_{x i}(\ln (K)-\mu)}{\sigma_{x}^{2}}+\frac{\sigma_{i}^{2}-\sigma_{x i}^{2} / \sigma_{x}^{2}}{2}}
\end{gathered}
$$

Because of the real options approach, there are three relationships to be observed, as follows:

1. Greater the asset volatility $(\sigma)$; greater the likelihood of the option becomes in the money.

2. Greater the earnout period (t); greater the likelihood of the option becomes in the money.

3. Smaller the difference between current performance and future performance (performance metric); greater the likelihood of the option becomes in the money.

In Chapter 4, we test our model by applying numerical examples and analyzing the output sensitivities on variables changes.

\section{2.}

\section{Model with Legal Covenant: Anti-Dilution}

We begin our model with an anti-dilution provision by considering a VC investor and an entrepreneur (seller) and a closed-form solution under restrictive assumptions. In this case, an investor aims to be protected against a "down round", which means a subsequent financing event at a lower valuation. In a down round, it is critical for the company to calculate the anti-dilution adjustments to existing series of preferred stock as it considers the terms of the new financing, keeping in mind that the lower the price of the new round, the larger the percentage of the company that will be owned by the existing preferred investors in relation to all other current stockholders after the financing. 
The anti-dilution may work as a guarantee for the investor. Under high uncertainty environment, it is likely that investor demands such protection in order to bridge the gap during the negotiation phase. It is worth mentioning that in VC context, typically the investor depends on entrepreneur performance, which may reinforce agency problems.

First, we choose the weighted average method, as it is more common in venture agreements as documented by Kaplan and Stromberg (2002). Both parties - buyer and seller - agree on a new conversion price, which would be the weighted average of the old conversion rate and the price level of the last investment round. Thus, the conversion price will be reduced on a weighted average formula basis, as follows:

$$
p=\frac{p_{1} q_{1}+p_{2} q_{2}}{q_{1}+q_{2}}
$$

Where:

\begin{tabular}{|c|c|}
\hline$p$ & Conversion price per share following the new issuance \\
\hline$p_{1}$ & Conversion price per share prior to the new issuance \\
\hline$b_{2}$ & Price per share of the new issue \\
\hline$q_{1}$ & Number of shares before the new issuance \\
\hline$q_{2}$ & Number of shares newly issued \\
\hline$k$ & Fraction of newly released shares \\
\hline$q^{+}$ & $\begin{array}{l}\text { Number of free shares offered to the investor after the new } \\
\text { financing round }\end{array}$ \\
\hline$q_{t}$ & $\begin{array}{l}\text { Total number of outstanding shares before the new financing } \\
\text { round }\end{array}$ \\
\hline & Investor ownership stake before a new issue \\
\hline & $\begin{array}{l}\text { Fully diluted investor ownership stake after the new issue } \\
\text { Partially diluted investor ownership stake after the new issue }\end{array}$ \\
\hline${ }^{1} 0$ & Total investor's capital infusion in the company \\
\hline & Additional source of financing \\
\hline
\end{tabular}

The anti-dilution option will be modeled as the difference between the value of investor ownership with and without protection. This protection is valuable only if the price per share of the new issue is lower than the conversion price prior to the issuance.

First, we model the situation in which there is no anti-dilution protection. The outcome of this first step will be $x_{1}^{*}$, the fully diluted investor ownership (shares). By multiplying the $x_{1}^{*}$ by the company valuation $V_{t_{0}}^{+}$, we can find the value of the investor ownership.

The seller may need additional investment $\left(I_{t}\right)$ : 


$$
I_{t}=q_{2} p_{2}
$$

Which is equivalent to:

$$
I_{t}=\left(\frac{k}{(1-k)}\right) q_{1} q_{2}
$$

Where $\mathrm{k}$ is the fraction of newly released shares; $k=\frac{q_{2}}{q_{1}+q_{2}}$.

Therefore, for $q_{1}$ shares, the investor ownership is:

$$
x_{t_{0}}=\frac{q_{1}}{q_{t}}=\frac{I_{0}}{V_{t_{0}}^{+}}
$$

It is easy to notice that the valuation is equal to:

$$
V_{t_{0}}^{+}= \begin{cases}V_{t_{0}}^{+} & \text {if } t<t_{0} \\ V_{t_{0}}^{+}+I_{0} & \text { if } t=t_{0}\end{cases}
$$

Let's consider first the base case of an investor with no dilution protection. At time $t$, the seller/entrepreneur decides to issue more shares aiming to raise funds for the firm to cover its needs of working capital and CAPEX. Let's assume $q_{2}$ as the effective number of new shares issued at the second financing round. Define $x_{1}^{*}$ as the ownership stake of the investor right after the event.

$$
x_{1}^{*}=\left(\frac{q_{1}}{q_{t}+q_{2}}\right)
$$

The investor diluted ownership stake is defined as:

$$
x_{1}^{*}=x_{t_{0}}\left(\frac{p_{2}}{p_{2}+I^{+}}\right)
$$

The dilution protection aims to reduce the dilution impact on the investor holdings in case of new financing round. In other words, the investor is entitled to a certain number of free shares $q^{+}$to compensate for the loss in value of its holdings. Notice that these shares are given to the investor for free.

$$
x_{2}^{*}=\left(\frac{q_{1}+q^{+}}{q_{1}+q_{2}+q^{+}}\right)
$$


Where, according to the weighted average formula:

$$
q^{+}=\left(\frac{q_{1} * p_{1}}{p}\right)-q_{1}
$$

For any new issue at a price lower than the previous conversion price $V_{t} \leq$ $p_{1}$ the dilution protection offers to the investor a larger stake $x_{2}^{*}>x_{1}^{*}$, defined as:

$$
x_{2}^{*}=\frac{p_{1} x_{1}^{*}}{x_{1}^{*} p_{1}+\left(1-x_{1}^{*}\right) p}
$$

If we replace back $q^{+}$, we can rewrite the investor ownership as follows:

$$
x_{2}^{*}=\frac{\frac{q_{1} p_{1}}{p}}{q_{t}+q_{2}+\frac{q_{1} p_{1}}{p}-q_{1}}
$$

Recalling equation 33, the protected ownership can be written as a function of the unprotected ownership, as follows:

$$
x_{2}^{*}=\frac{p_{1}}{p}\left(\frac{q_{1}}{\frac{q_{1}}{x_{1}^{*}}+\frac{q_{1} p_{1}}{p}-q_{1}}\right)
$$

The investor stake after the new investment round is driven by the new investment amount $I_{t}^{+}$, the previous conversion price $p_{1}$, the price per share of the new issuance and lastly the previous investor ownership before the new round.

The anti-dilution right at time $t$ is modeled as the difference between the value of the investor stake with dilution protection versus the ownership in case of no protection multiplied by the valuation of the company.

$$
f\left(V_{t}, t\right)=\max \left(\left(x_{2}^{*}-x_{1}^{*}\right) V_{t}^{+}, 0\right)
$$

We can rewrite the equation above as: 


$$
f\left(V_{t}, t\right)=\max \left(\left(\frac{x_{1}^{*}\left(1-x_{1}^{*}\right)\left(p_{1}-p\right)}{p+x_{1}^{*}\left(p_{1}-p\right)}\right) V_{t}^{+}, 0\right)
$$

Under the option lens, anti-dilution protection is similar to a put option (Cossin, 2002). At the contractual time $t_{0}$, it is difficult to predict $p_{2}$, the price at which new shares are released. If $V_{t}=V_{t_{0}}$ there is no protection $f(V, t)=0$. It is worth noting that $V_{t}, x_{2}^{*}, x_{1}^{*}$ are all stochastic variables.

As $p_{2}$ is an uncertainty of the model, it follows a Geometric Brownian Motion (GBM):

$$
d P=\alpha P d t+\sigma P d z
$$

Where $\alpha$ is the drift rate and $\sigma$ is the volatility. If $p_{2}$ falls to a lower level than the initial price, the anti-dilution protection is activated. Otherwise, the guarantee expires worthless. Since $V_{t}, x_{2}^{*}, x_{1}^{*}$ are functions of $p_{2}$, they also follow a GBM.

We analyze different parameters for $\alpha$ and $\sigma$, hence we also estimate the probability of a down round for each scenario. Based on the literature background, the presence of moral hazard and risk sharing costs implies that optimal contract may include contractual mechanisms that give investors some downside protection.

\section{3. \\ Model with legal covenant: liquidation preference}

As mentioned in Smith (2005), Liquidation Rights (almost) never confer the investor (venture capitalist) a contractual right to liquidate the portfolio company. Therefore, they should be understood as protective exit rights and not as initiatory exit rights. The major function of Liquidation Rights is to protect the VC against opportunistic liquidation by a controlling entrepreneur and to increase his incentive to force liquidation through the exercise of other contractual rights (e.g. via board voting rights) in circumstances when the entrepreneur would like to maintain the status quo. The payment of the Liquidation Amount is effectively triggered by the occurrence of a Liquidation Event or the sale of the Company.

From the investor's perspective, he or she aims to maximize the value of her/his ownership in case the project is successful or recoup the maximum possible value in the case of project liquidation. Typically, the liquidation preference entitles the investor to collect $L_{0}$ (in case of $1 x$ liquidation preference, will be equal to the 
original investment $I_{0}$ ), if there is enough money in the company, or the remaining value $V_{T}$ after creditors and before all the other shareholder's claims. Therefore, the liquidation option value, in case of a liquidation event, is of $\min \left(V_{T}, L_{0}\right)$. As mentioned in Cossin (2002), a merger, consolidation, dissolution, winding up, change of control or sale of the assets shall be deemed to be a liquidation event.

Often, venture capitalists own convertible securities, such as convertible preferred stocks or debentures (Kaplan and Stromberg, 2000). There is an extensive literature on the use of the convertible securities in venture capital finance. Schmidt (2001) gives a complete summary of the papers dealing with the issue of the optimal contract design for an inside investor.

This conversion feature can be understood as a reallocation of control rights in case of success of the project from the investor to the entrepreneur. It is an incentive to perform to the entrepreneur beyond the direct financial incentives offered by the venture capitalist.

We begin our model by considering an entrepreneur who raised money from an investor $I_{0}$, at a valuation of $V_{0}$, at time $T_{0}$. The investment agreement entitles the investor a protection (liquidation rights) in case of any liquidation event at a valuation lower than $V_{0}$. On the other hand, in case of good performance, nevertheless, the investor may decide to convert and obtain conversion value (CV), as follows:

$$
C V=x V_{T}-C_{0}
$$

Where $C_{0}$ is the conversion level and $x$ is the number of shares obtained of the company after conversion.

Thus, the investor payoff at time $\mathrm{T}$ is given as:

$$
\varphi\left(V_{T}\right)=\max \left(L_{0}+x\left(V_{T}-L_{0}\right), I_{0}\right)
$$

Where $V_{t}$ is the liquidation value, $x$ is the investor's ownership, $L_{0}$ is the level of guarantee. $L_{0}$ is a function of $I_{0}$. The equation above shows that the investor will convert his/her holdings only if the upside potential from converting is high enough to pay for the loss of the downside protection linked to the liquidation preference.

In case of $1 x$ full participating liquidation preference, the final payoff at time $t$ $=\mathrm{T}$ can be written as: 


$$
\varphi\left(V_{T}\right)= \begin{cases}V_{t} & \text { if } V_{t} \leq L_{0} \\ L_{0}+x\left(V_{t}-L_{0}\right) & \text { if } V_{t}>L_{0}\end{cases}
$$

The $1 \mathrm{x}$ liquidation preference, fully participating, has the following shape illustrated in Figure 11:

1x Liquidation Preference, Full-Participation

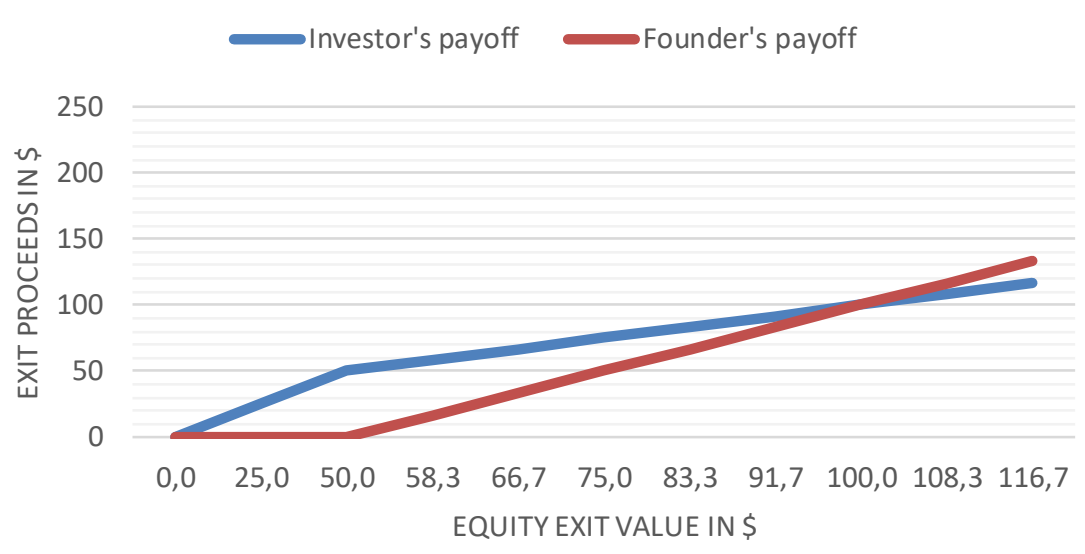

Figure 11: $1 x$ full-participating example. Source: author

The Figure 11 above illustrates, for visual example, the difference between investor and founder's payoff, depending on exit proceeds. Note that until the transaction valuation reaches the liquidation preference threshold, all proceeds go to investor's pocket.

In order to limit the investor payoff, we also can model the option as a capped participation, which has the same shape of full participating but with a maximum amount (cap):

$$
\varphi\left(V_{T}\right)=\min \left\{\max \left(L_{0}+x\left(V_{t}-L_{0}\right), V_{t}\right), C_{t}\right\}
$$

Where $C_{t}$ is the level of the payoff of the cap. Figure 12 represents the shape of capped participation: 


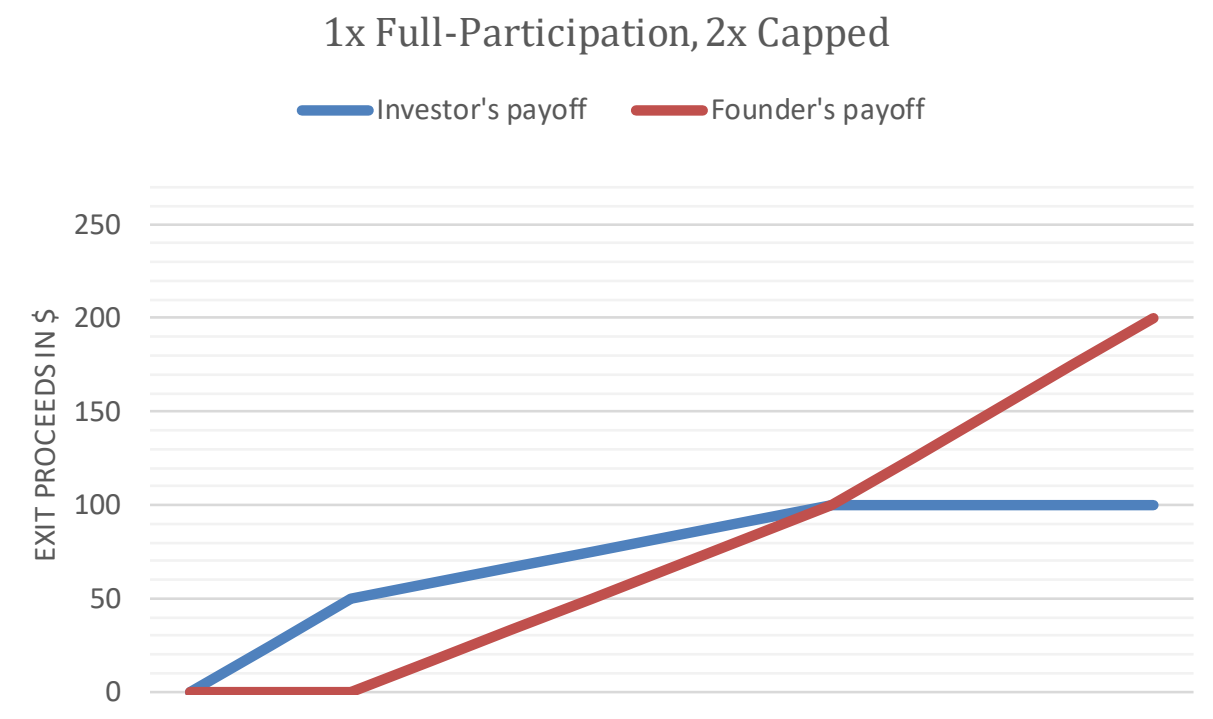

Figure 12: Capped participation example. Source: author

Also, for illustration purpose, Figure 12 shows the shape of $1 x$ fullparticipation, $2 x$ capped, by providing the investor and founder's payoff depending on the Exite Proceeds.

For modeling purpose and in order to provide a closed-form solution, let us assume a finite horizon, in which the investor and entrepreneur enter in contractual agreement which will last up to 3 years $(t=3)$. In this case, the investor may exit only at some discrete events, which will correspond to the end of each year.

The target company valuation $V_{t}$ is the model uncertainty, which follows a Geometric Brownian Motion (GBM), as follows:

$$
d V=\alpha V d t+\sigma V d z
$$

Where $\alpha$ is the drift rate and $\sigma$ is the volatility. At time 0 , investor and entrepreneur meet, and both enter in a contractual agreement until $t=3$. Throughout the contract duration, we also test different liquidation event date and different liquidation preference settings, aiming to understand the impact of those parameters on the model output. 


\section{4 \\ Numerical applications}

After deriving the theoretical models, this chapter presents some numerical results in order to test the proposed framework and to explore the main outputs. Also, aiming to make the reader's understanding easier, the results are presented separately for each model.

\section{1.}

\section{Model with Legal covenant: Earnout}

The earnout model considers a negotiation between a buyer and a seller in an M\&A transaction. There is a deadlock during the negotiation due to a gap in the deal value expectation. Aiming to bridge this gap, the parties agreed in setting a contingency payment mechanism called earnout based on a future performance measure.

For the basic case, let us assume that the valuation asked by the target firm is $\$ 2.500$ and the value desired by the buyer is $19.0 \%$ larger. For our analysis, we built the cash flow implied in this valuation, changing the growth rate. Our understanding is that changing the initial free cash flow is not a good choice, because the first period does not have considerable uncertainty. Therefore, solving this issue by an exogenous solution, we found an implied growth of $4.6 \%$ per quarter, against $2.9 \%$ settled by the buyer.

Thus, considering the negotiation impasse on the deal valuation, the buyer purposes using earnout mechanism, aiming to mitigate the risk of the company not performing well after the closing. To do so, the parties agreed in defining the year 3 free cash flow as the earnout performance measure.

Aiming to model the earnout mechanism, we recall the main firm's uncertainty, which is the seller's free cash flow. Moreover, we will look at the quarterly free cash flow, since we argue that may exist moral hazard. Focusing on earnout activation, the seller may make short-term decisions misaligned with the company's long-term strategy.

Thus, let us summarize the numbers and the terms of the deal in Table 3 : 


\begin{tabular}{lc}
\hline \multicolumn{2}{c}{ Earnout parameters: } \\
\hline Target firm valuation (bided by the buyer) & $\$ 2,100$ \\
Target firm valuation (Asked by the seller) & $\$ 2,500$ \\
Target' stake acquired & $80 \%$ \\
Initial payment & $\$ 1,680$ \\
Contingency payment & $\$ 320,00$ \\
Earnout period & 3 years \\
Performance measure & Free Cash Flow \\
Performance goal (quarterly average) & $\$ 161$ \\
\hline \multicolumn{2}{c}{ Table 3: Earnout settings. Source: Author }
\end{tabular}

As mentioned, the model's uncertainty is the target firm's free cash flow, which follows a GBM. Below, we present the main parameters of process diffusion in Table 4:

\begin{tabular}{cc}
\hline & Parameters GBM - target's FCF \\
\hline Drift rate (\% per quarter) & $2.9 \%$ \\
Volatility (\% per quarter) & $5.7 \%$ \\
\hline Table 4: Geometric Brownian Motion parameters. Source: Author
\end{tabular}

The buyer is acquiring $80 \%$ of the target's stocks, which means that, under the $\$ 2,100$ valuation, the acquirer agrees in paying upfront $\$ 1,680$.

Under the earnout assumption, the seller and the buyer agree that if the company underperforms in the specific deadline, the final valuation will be the smallest one. This agreement means that the seller has up to 3 years to prove its value, in other words, to achieve the performance measure goal. If he does so, the buyer will pay the difference between both initial expectations. Otherwise, the option expires worthless.

We modeled the uncertainty according to the assumptions from tables 3 and 4. Moreover, considering that the entrepreneur will remain as manager and aiming to avoid any short-term detrimental decision, we modeled the performance measure as an Asian option, by using the quarterly average. By doing so, we argue that the management performance must be consistent over time, avoiding any outlier and one-time performance.

We also summarized the descriptive statistics of target's free cash flow for each year, as shown in Table 5: 


\begin{tabular}{lccc}
\hline & Year 1 & Year 2 & Year 3 \\
\hline Minimum & 83.92 & 78.52 & 72.78 \\
Maximum & 136.33 & 172.13 & 234.20 \\
Mean & 106.18 & 116.79 & 128.55 \\
Standard Deviation & 8.54 & 16.19 & 23.93 \\
\hline
\end{tabular}

Table 5: Descriptive statistics of the target's free cash flow for each year. Source: author

Although we are modeling the earnout as a European option with maturity at time 3, we also analyzed the probability of exercise in other periods. According to the simulation done, in the first year, there is zero probability of the earnout goal be reached. About the second period, there is $1.7 \%$ probability of the performance measure to be reached, while in the last period, there is $14.9 \%$ probability of an earno ut successful. The higher the gap between the expectations of seller and buyer, the lower the probability of performance goal achievement. Figure 13 shows the distribution of the quarterly average on time 3 :

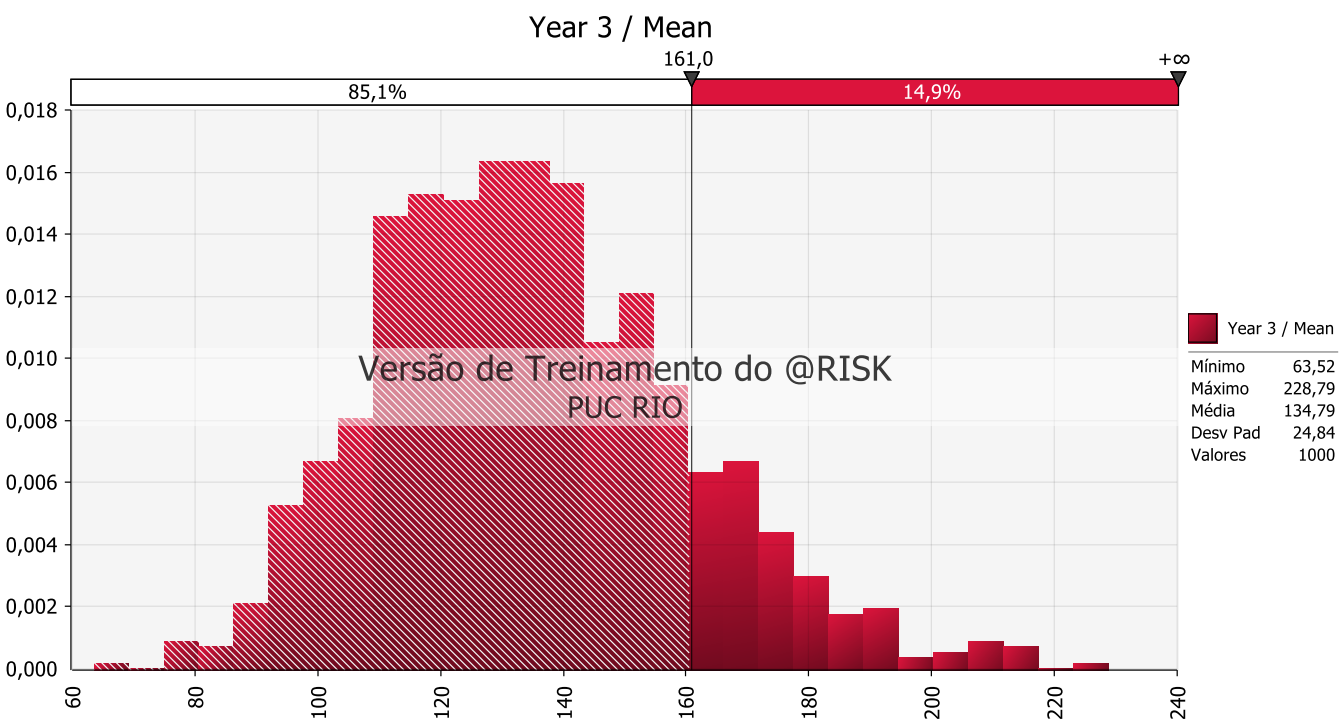

Figure 13: FCF average distribution at time 3. Source: author using @Risk software

Contractually, the Asian Option may be defined as an arithmetic average or a geometric average. For that reason, we also analyzed the impact of changing 
the type of average on performance goal achievement. The use of geometric mean or arithmetic mean generates some discussions in financial theory. Blume (1974) provides a way of using the geometric mean and the arithmetic mean of past returns to form an unbiased estimate of the expected return over any future period. The procedure he proposes is that the expected return over a horizon of $\mathrm{N}$ periods should be formed by a weighted average of the compounded geometric and arithmetic means $G^{N}$ and $A^{N}$. He shows that is an approximately unbiased estimate of $M^{N}$, the true expected return over $\mathrm{N}$ periods. Note, however, that it will not provide an unbiased estimate of $M^{-N}$, the discount factor, which is a non-linear function of expected return, $M^{N}$. In general, the use of the arithmetic mean for time series ignores estimation error and serial correlation in returns. Another disadvantage of the arithmetic average is the probability of achieving the arithmetic average return may be unsatisfactory, in other words, as a prediction of future returns, the arithmetic mean may be too optimistic. One of the main advantages of the arithmetic average is it is an unbiased estimate of the return.

In a nutshell, considering the probability of exercise, the trigger of $\$ 161$ (average free cash flow at time 3 ) and the contingent payment $(\$ 320)$, the table below summarizes the main results. In order to understand the impact of changing the type of average, we also present the results regarding the geometric average for the Asian option, in Table 6.

\begin{tabular}{lcc}
\hline & Arithmetic average & Geometric Average \\
\hline Binary option & $\$ 44.91$ & $\$ 44.93$ \\
Earnout upside & $2.67 \%$ & $2.68 \%$ \\
\hline \multicolumn{3}{c}{ Table 6: Binary option results. Source: author }
\end{tabular}

Accordingly, there is no impact on changing the type of average for valuation purpose under our assumptions. In addition, the option upside is equivalent to $2.67 \%$ for Arithmetic average and $2.68 \%$ in the case of geometric average when analyzed as a proportion of the initial payment.

Lastly, we modeled the earnout mechanism as a call option. In this setting, if the performance measure is reached, besides the contingent payment previously agreed (\$320), the seller will get the value that excesses the performance goal. To do so, we recall the equation 30 and estimate the probability of exercise and the option present value. Table 7 summarizes the main results and compares them to the base case: 


\begin{tabular}{lc}
\hline Scenario & Value \\
\hline Base case (Static NPV) & $\$ 1,680.00$ \\
Static NPV + Binary Option & $\$ 1,724.91$ \\
Static NPV + Binary + Call options & $\$ 1,727.24$ \\
\hline \multicolumn{2}{c}{ Table 7: main results summary. Source: author }
\end{tabular}

We also present the simulation output of the call options, Figure 14:

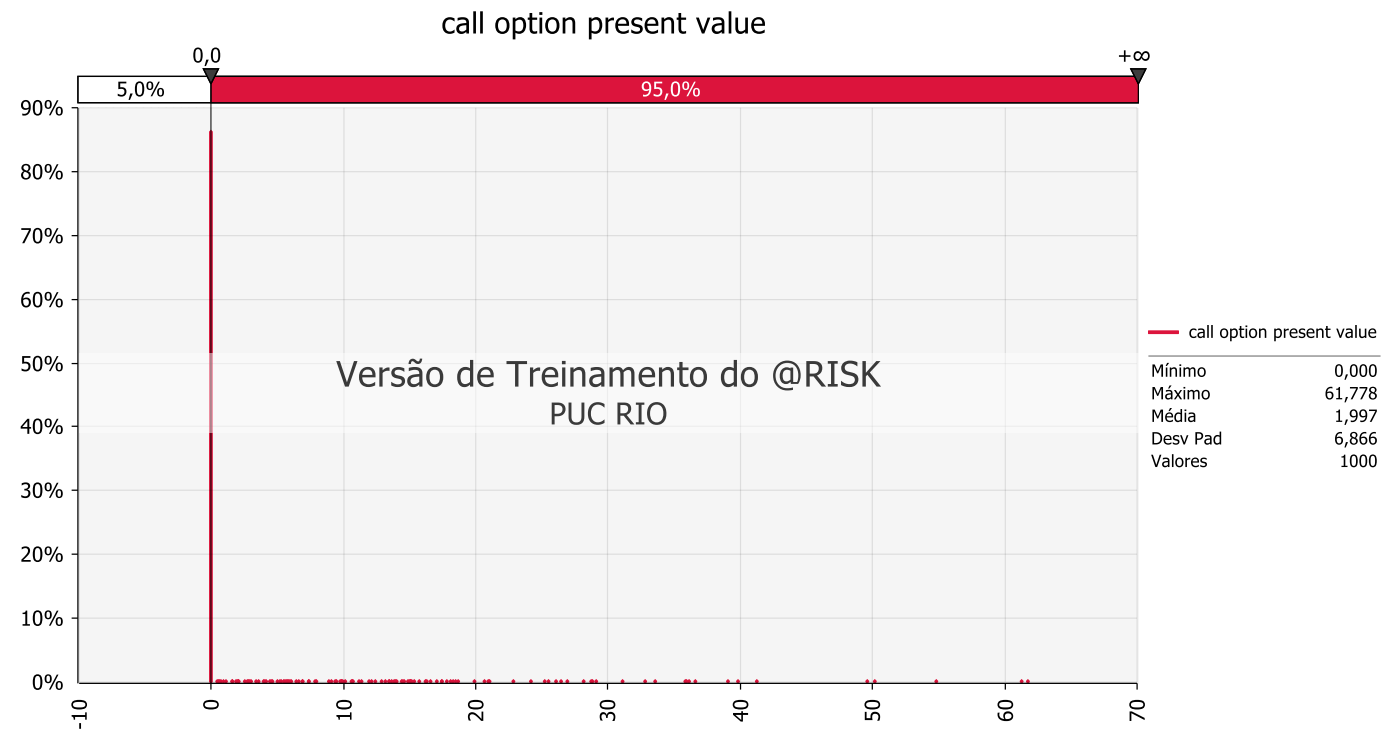

Figure 14: Simulation output of call option. Source: author

After modeling both de binary option and the call option and considering the closed-form model characteristics, we now estimate the output sensitivity on main assumptions changes. By doing that, we aim to draw attention to the main parameters during an M\&A negotiation process. First, we verify the effect that changes in volatility may have on the expected option values. Table 8 summarizes the changes effect:

\begin{tabular}{lrrr}
\hline Volatility & Binary option & call option & Combined \\
\hline $4.0 \%$ & 19,73 & 0,51 & 20,24 \\
$4.5 \%$ & 27,45 & 0,93 & 28,38 \\
$5.0 \%$ & 37,60 & 1,61 & 39,21 \\
$5.5 \%$ & 40,35 & 2,00 & 42,35 \\
$6.0 \%$ & 45,51 & 2,28 & 47,79 \\
$6.5 \%$ & 48,46 & 3,08 & 51,54 \\
\multicolumn{4}{l}{ Table 8: sensitivity analysis of volatility. Source: author }
\end{tabular}

The sensitivity analysis we proceeded confirmed the option shape of the earnout clause. Higher the volatility, the higher the option value. Besides, we verified the impact of changes in the drift rate on option values in Table 9. To do so, we kept the volatility at the same level of base case (5.7\% per quarter). 


\begin{tabular}{lrrr}
\hline Drift rate & Binary option & call option & Combined \\
\hline $1.5 \%$ & 7,76 & 0,10 & 7,86 \\
$2.0 \%$ & 25,88 & 0,64 & 26,52 \\
$2.5 \%$ & 33,04 & 1,35 & 34,39 \\
$3.0 \%$ & 44,19 & 2,19 & 46,38 \\
$3.5 \%$ & 46,05 & 4,14 & 50,19 \\
\multicolumn{2}{l}{ Table 9: sensitivity analysis of drift rate. Source: author }
\end{tabular}

Ceteris paribus, higher the drift rate, higher the option values. We also could test the relationships typically seen in option, such as (1) greater the asset volatility $(\sigma)$; greater the likelihood of the option becomes in the money, (2) Greater the earnout period $(\mathrm{t})$; greater the likelihood of the option becomes in the money and (3) Smaller the difference between current performance and future performance (performance metric); greater the likelihood of the option becomes in the money.

\section{2 . Model with Legal Covenant: Anti-Dilution}

In the anti-dilution scheme, the investor aims to be protected against a down round, which means a subsequent financing event at a lower valuation. As mentioned at the model building in chapter 3, the anti-dilution may work as a guarantee for the investor. Under high uncertainty environment, it is likely that investor demands such protection in order to bridge the gap during the negotiation phase. Typically, in equity investment environment, the investor depends on postdeal entrepreneur performance, which may reinforce agency problems.

At the contractual time $t_{0}$, it is difficult to predict $p_{2}$, the price at which new shares are released. Also, $p_{2}$ is the uncertainty of the model and it follows a Geometric Brownian Motion (GBM). It is important to notice that as $p_{2}$ is uncertain, the variables that are a function of it are stochastic as well. Below, we set the model parameters in Tables 10 and 11 : 


\begin{tabular}{lrr} 
& Value & Description \\
\hline p & 1,96 & Conversion price per share following the new issuance \\
p1 & 2,00 & Conversion price per share prior to the new issuance \\
p2 & 1,89 & Price per share of the new issue \\
q1 & 50,00 & Number of shares before the new issuance \\
q2 & 26,48 & Number of shares newly issued \\
k & 0,3 & Fraction of newly released shares \\
$q^{+}$ & 0,99 & Number of free shares offered to the investor after the new financing round \\
qt & 100,00 & Total number of outstanding shares before the new financing round \\
xt0 & $50,0 \%$ & Investor ownership stake before new issue \\
x1 & $39,53 \%$ & Fully diluted investor ownership stake after the new issue \\
x2 & $40,00 \%$ & Partially diluted investor ownership stake after the new issue \\
I0 & 100,00 & Total investor's capital infusion in the company \\
It+ & 50,00 & Additional source of financing \\
Vt & 200,00 & Valuation before the additional financing \\
Vt+ & 250,00 & Valuation after the additional financing \\
\hline
\end{tabular}

Table 10: model parameters. Source: Author

\begin{tabular}{lr}
\hline GBM Parameters & \multicolumn{1}{c}{$\#$} \\
\hline Risk free & $5,0 \%$ \\
Drift & $6,0 \%$ \\
Volatility & $30,0 \%$ \\
V & $1,3 \%$ \\
\hline able 11: GBM parameters. Source: author
\end{tabular}

Basically, at time 0 , the investor infused $\$ 100$ in the company, acquiring 50 shares at $\$ 2\left(p_{2}\right)$ each. By doing so, the investor owns $50 \%$ of the firm, before the second investment round. Considering that $p_{2}$ is uncertain, at time 0 , both investor and entrepreneur are not able to predict the company's valuation for the future capital raising event.

In a nutshell, we tested whether the price of the new issuance falls at a lower level than the previous one. If it happens, the company offers free shares to the investor to compensate for the dilution effect. In a weighted-average method, the new conversion price will be the weighted average of the old conversion rate and the price level of the last round.

Using simulation, we estimated the frequency with which the protection is activated, by analyzing the price per share of the new issuance, as follows in Figure 15: 


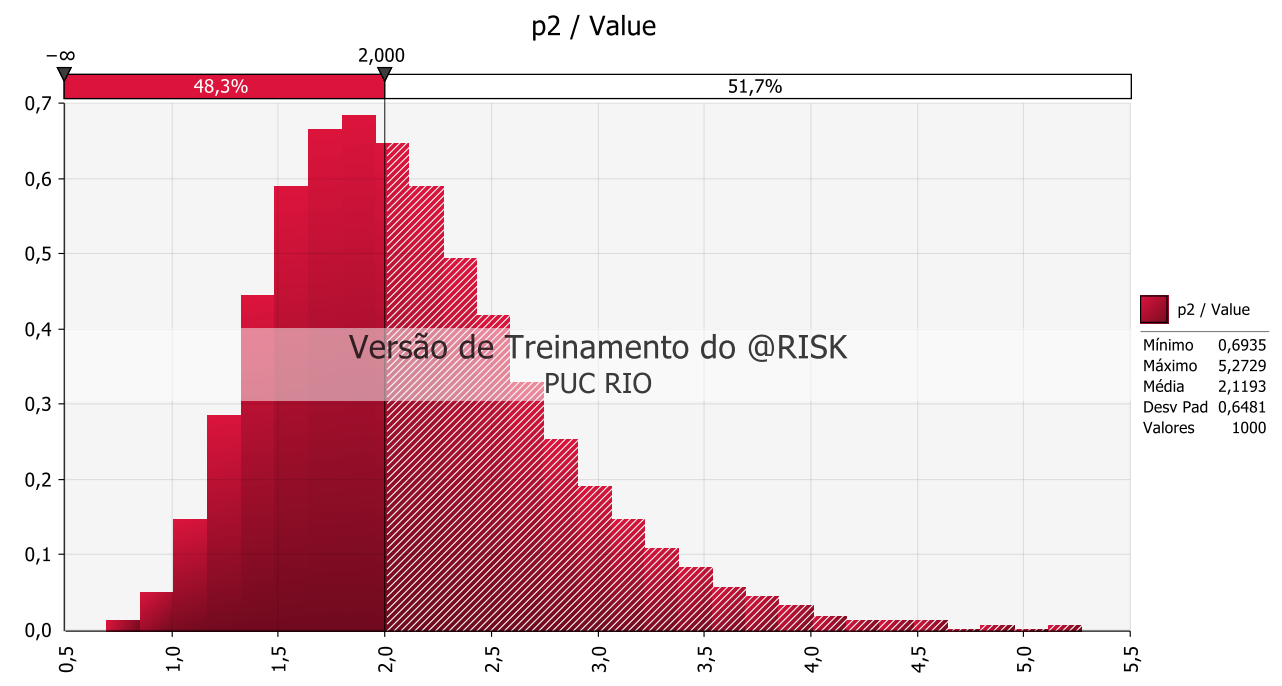

Figure 15: probability distribution of the new price per share

Note that, under those assumptions, there is a probability of $48,3 \%$ the new price per share is smaller than the first issuance, which means that the investor would be protected by the anti-dilution scheme.

According to the weighted-average method, if $p_{2}<p_{1}, q^{+}>0$, in other words, free shares will be offered to the investor. Moreover, for any $p_{2}<p_{1}, x_{2}>$ $x_{1}$. On the other hand, if $p_{2}>p_{1}$, there is no protection.

After the initial numerical application, estimating the option is straightforward. The anti-dilution option value is the difference between both scenarios, with and without protection, as demonstrated in equation 52. Figure 16 presents the simulation output:

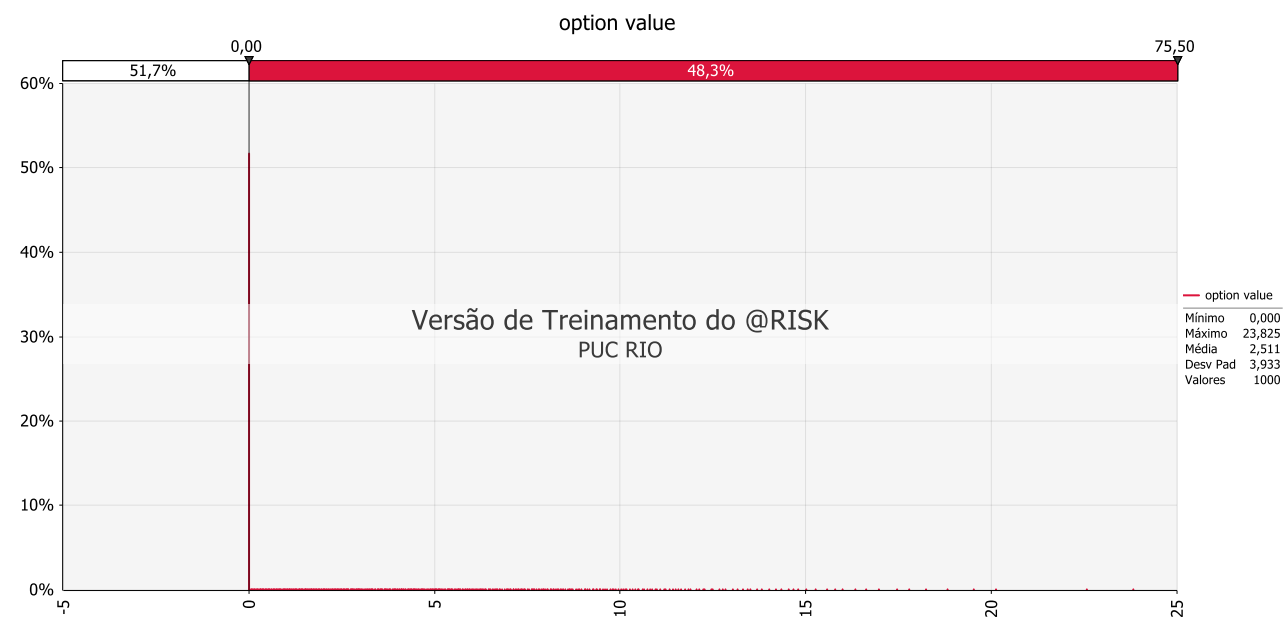

Figure 16: simulation output. Source: author

Although there is $48,3 \%$ likelihood the subsequent valuation is lower than the first one, when it is higher, the option is worthless. Our simulation suggests that the option value is $\$ 2.5$ or $5 \%$ of the initial investment. 
In order to verify the sensitivity of our model's output to changes in our assumptions, we also tested different scenarios. First, we analyzed the impact of changes in GBM parameters and present in Tables 12 and 13:

\begin{tabular}{cc}
\hline Volatility & Option value \\
\hline $20 \%$ & 1,33 \\
$25 \%$ & 1,84 \\
$30 \%$ & 2,51
\end{tabular}

Table 12: Sensitivity analysis. Source: author

\begin{tabular}{cc}
\hline Drift rate & Option value \\
\hline $4 \%$ & 2,49 \\
$5 \%$ & 2,51 \\
$6 \%$ & 2,53
\end{tabular}

Table 13: Sensitivity analysis. Source: author

Moreover, the investment round size may affect our model output. We argue that in case of lower valuation, greater the second round, higher the dilution. Therefore, in this situation, more valuable would be protection. Table 14 summarizes the relationship between additional investment and the option value:

\begin{tabular}{cc}
\hline Additional source of financing & Option value \\
\hline$\$ 10$ & 0,64 \\
$\$ 50$ & 2,51 \\
$\$ 90$ & 3,73
\end{tabular}

Table 14: sensitivity analysis on investment round size. Source: author

According to we can observe, there is a relevant impact on changing the size of the investment round, which means that under a lower valuation, the entrepreneur must be very careful in defining how much he or she need to raise to fund the firm's needs. Any overestimated amount may impact deeply his ownership afterwards.

\section{3.}

\section{Model with Legal covenant: Liquidation Preference}

The third model refers to the Liquidation Preference, which plays an important role in protecting the venture capitalist against the company's poor performance after the first investment round.

Let us assume a negotiation between an investor and an entrepreneur, under a risky environment. Aiming to be protected against an opportunistic liquidation event, the investor asks for a liquidation preference option, which entitles him to recoup a relevant part of his investment in case of a lower valuation. 
The VC invests $I_{0}=50$ for a post-money valuation $V_{0}=150$. Therefore, right after the investment, the investor owns $33,3 \%$ of the target company. The fullparticipating liquidation preference level $L_{0}$ is $1 \mathrm{x}$, which means $I_{0}=L_{0}$. The valuation $V_{t}$ of the future liquidation event is the uncertainty of the model and follows a Geometric Brownian Motion (GBM): $d V=\alpha V d t+\sigma V d z$.

\begin{tabular}{lr}
\hline Deal assumptions & $\#$ \\
\hline Investment (\$) & 50 \\
Post-money valuation (\$) & 150 \\
Investor's equity (\%) & $33.3 \%$ \\
Liquidation preference (multiple) & $1 \mathrm{x}$ \\
\hline \multicolumn{2}{c}{ Table 15: deal assumptions. Source: author }
\end{tabular}

The investor will get back first $I_{0}$ and then will share the balance with the other shareholders. The table below shows the GBM parameters related to the valuation $V_{t}$ of the future liquidation event:

\begin{tabular}{lr}
\hline GBM Parameters & \multicolumn{1}{c}{$\%$} \\
\hline Risk-free & $5,0 \%$ \\
Drift & $6,0 \%$ \\
Volatility & $30,0 \%$ \\
V & $1,3 \%$ \\
Table 16: GBM parameters. Source: author
\end{tabular}

Accordingly, Figure 18 to 20 report the valuation $V_{t}$ simulation output, also considering three different scenarios for liquidation event dates $(t=1, t=2$ and $t=$ $3)$.

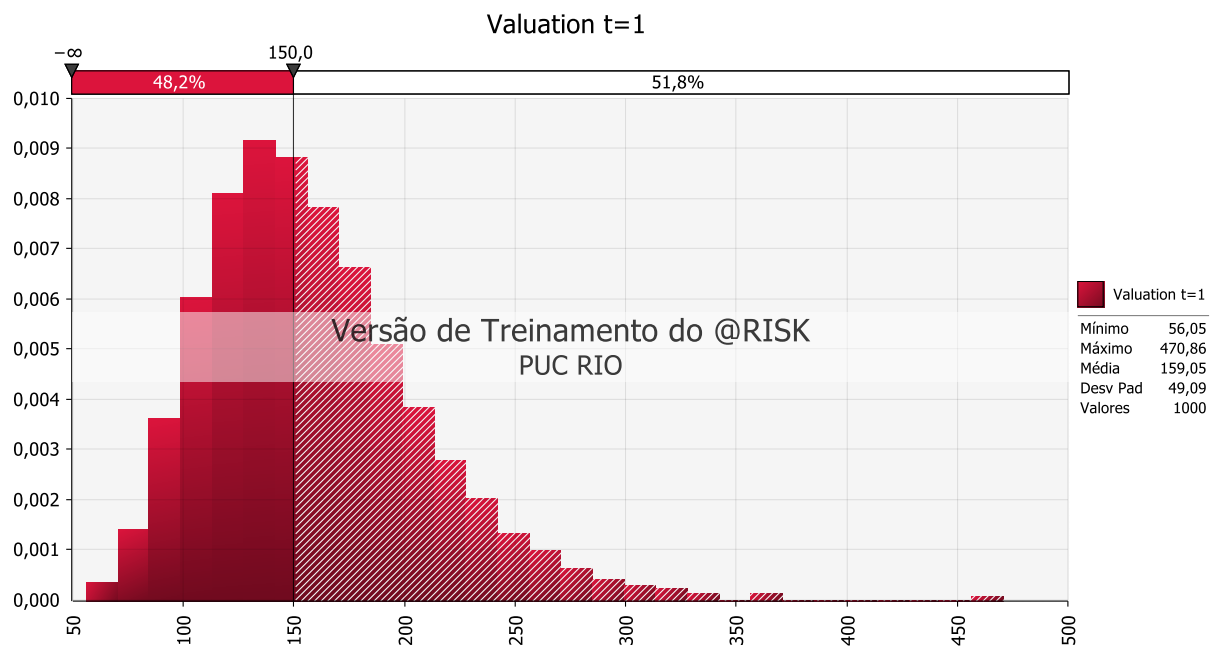

Figure 17: valuation distribution for $t=1$. Source: author 


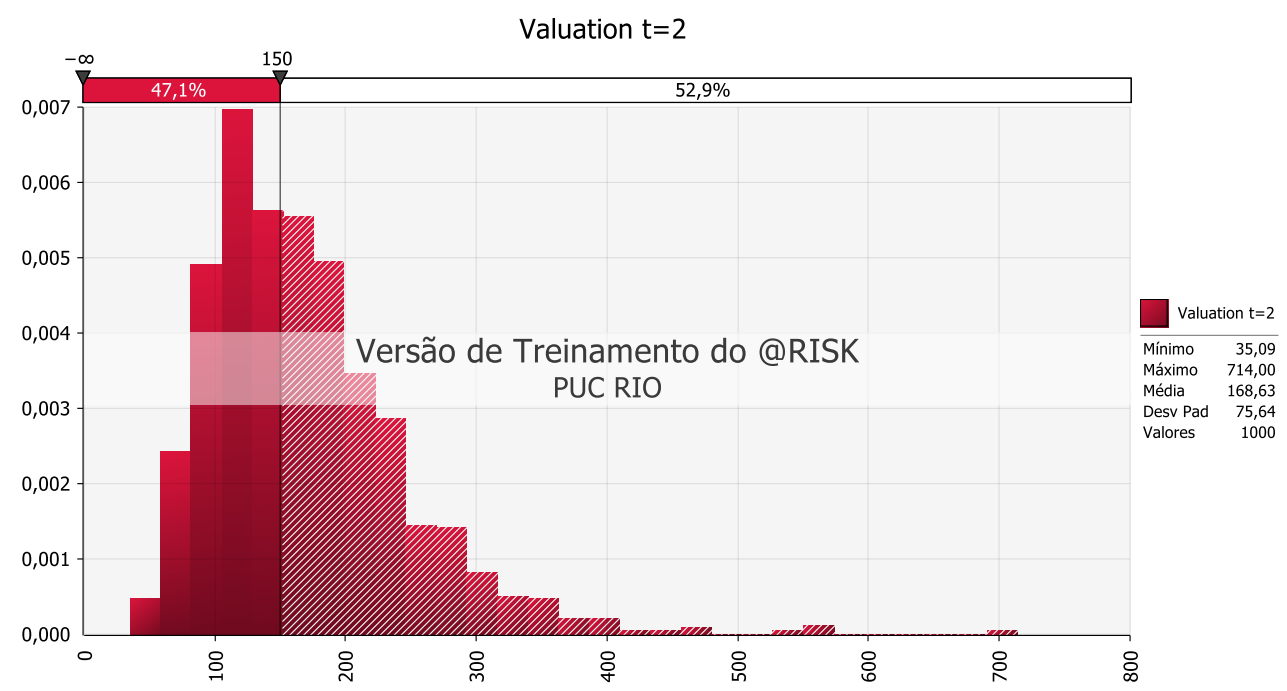

Figure 18: valuation distribution for $t=2$. Source: author

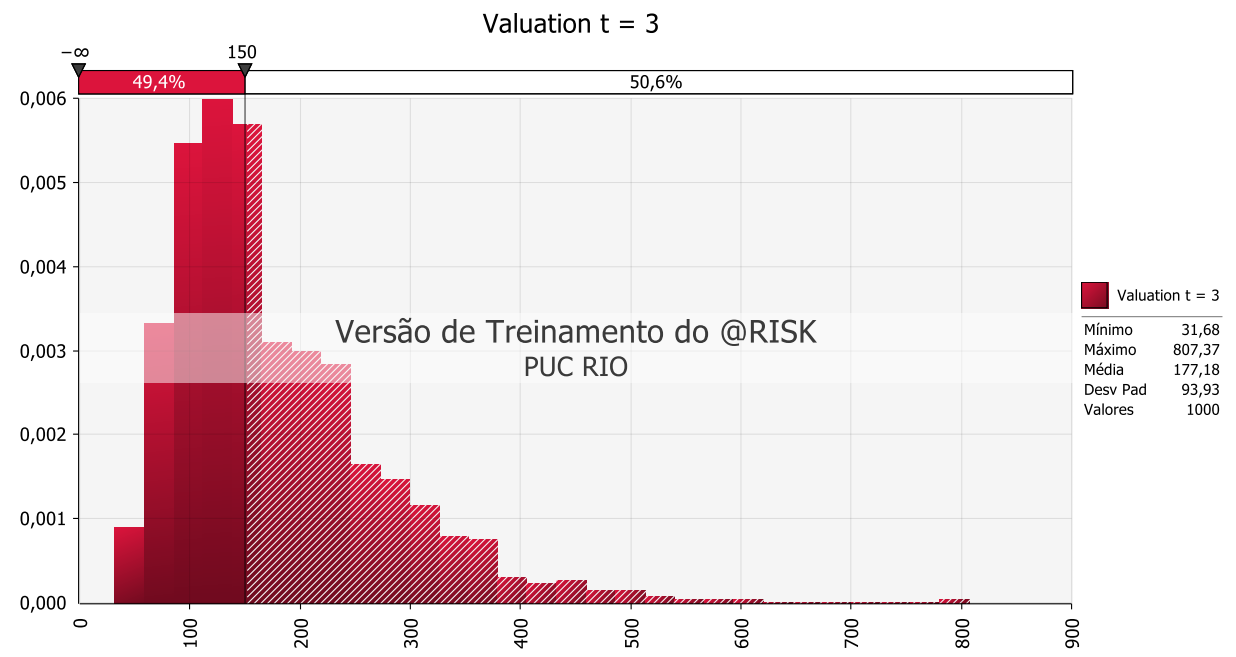

Figure 19: valuation distribution for $t=3$. Source: author

For each scenario, we estimate the probability of a down-round, which means a liquidation event on a valuation lower than the previous one. Moreover, we also present the investor payoff as a proportion of the liquidation event valuation, which highlights the upside potential of this covenant. It is worthy to note that the initial investor's ownership is $33 \%$, however by analyzing the payoff we realize the benefits of the liquidation preference. Considering a liquidation event at time 1 , the probability of a down round is $48.2 \%$. Regarding a liquidation event at time 2 , the probability of a down round is $47.4 \%$, while the probability of a poor performance at time 3 is $46 \%$. Greater the drift rate, lower the probability of a down round after the first investment deal.

Assuming a discrete event at time 3 , the investor is protected against any deal on a valuation lower than the previous one. Following the empirical evidence from Bengtsson (2009), under a $1 \mathrm{x}$ full participating scheme, the investor will get 
$I_{0}=L_{0}=50$ first and then split the rest with the entrepreneur, according to parties' stake. Under the assumptions showed at tables 6 and 7, the average investor payoff (with Liquidation Preference) at time 3 is $\$ 92.85$, which wo uld represent an "artificial" ownership of $57.8 \%$, instead of the original $33.3 \%$. The investor's payoff simulation ( $1 \mathrm{x}$ full participating) has the shape presents in Figure 21 :

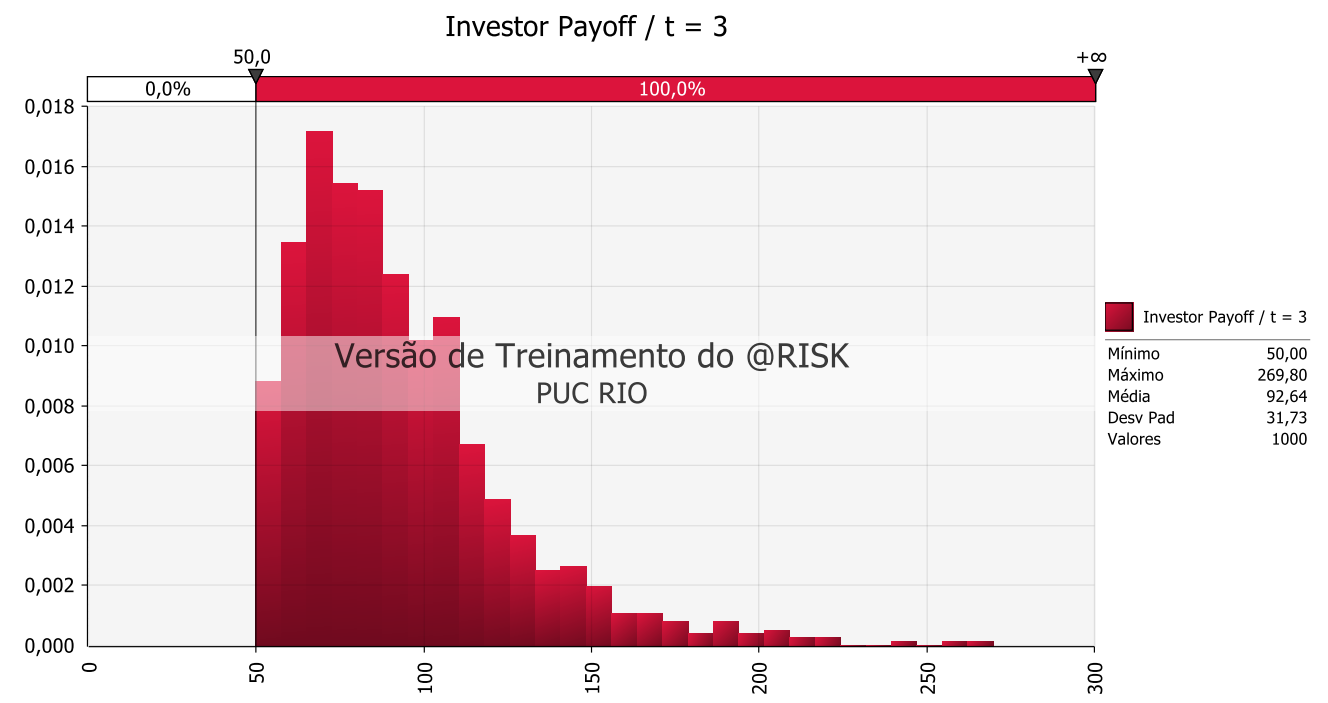

Figure 20: Investor's payoff simulation at time 3. Source: author

We can calculate the option present value by the difference of the ownership on both scenarios, with and witho ut liquidation preference. By doing so, we get an option value of $\$ 28.69$. In order to provide a robustness check, we also provided different scenarios for the liquidation preference, as follows in Table 17:

\begin{tabular}{lc}
\hline Multiple & Option value (\$) \\
\hline $0.5 \mathrm{x}$ & 7.17 \\
$1.0 \mathrm{x}$ & 28.69 \\
$1.5 \mathrm{x}$ & 64.55 \\
$2.0 \mathrm{x}$ & 114.76 \\
\hline Liquidation preference scenarios. Source: author
\end{tabular}

As can be easily observed, greater the liquidation preference multiple, worthier is the option.

Although Bengtsson (2009) reported that vast majority of his sample contracts has liquidation preference, under the entrepreneur perspective, the full participating liquidation preference can be too expensive and generate a lack of incentives for seeking future growth. In other words, in case of high dependence on entrepreneur performance by the investor, the liquidation preference may play 
an opposite role in the context. On account of this, the agents may set a capped liquidation preference, in which the investor is protected against poor performance after the initial investment, however, there is a clear incentive for the entrepreneur in case of outstanding future performance by limiting the investor's payoff. Although the most common covenant is the uncapped participating (Bengtsson, 2009), we also tested the results under a capped scheme. We argue that, under Contract Theory approach, this structure will provide the incentives to the entrepreneur undertake his or her best efforts aiming to improve a firm's future profit. In case of a capped participating liquidation preference, the venture capitalist's payoff will follow the equation $\varphi\left(V_{T}\right)=\min \left\{\max \left(L_{0}+x\left(V_{t}-\right.\right.\right.$ $\left.\left.\left.L_{0}\right), V_{t}\right), C_{t}\right\}$, where $C_{t}$ is the cap level. For numerical application purpose, we assumed the cap level as $2 x$, which means twofold the venture capitalist's investment in the firm. The simulation of the investor's payoff at time 3 in a capped scheme is according to Figure 22:

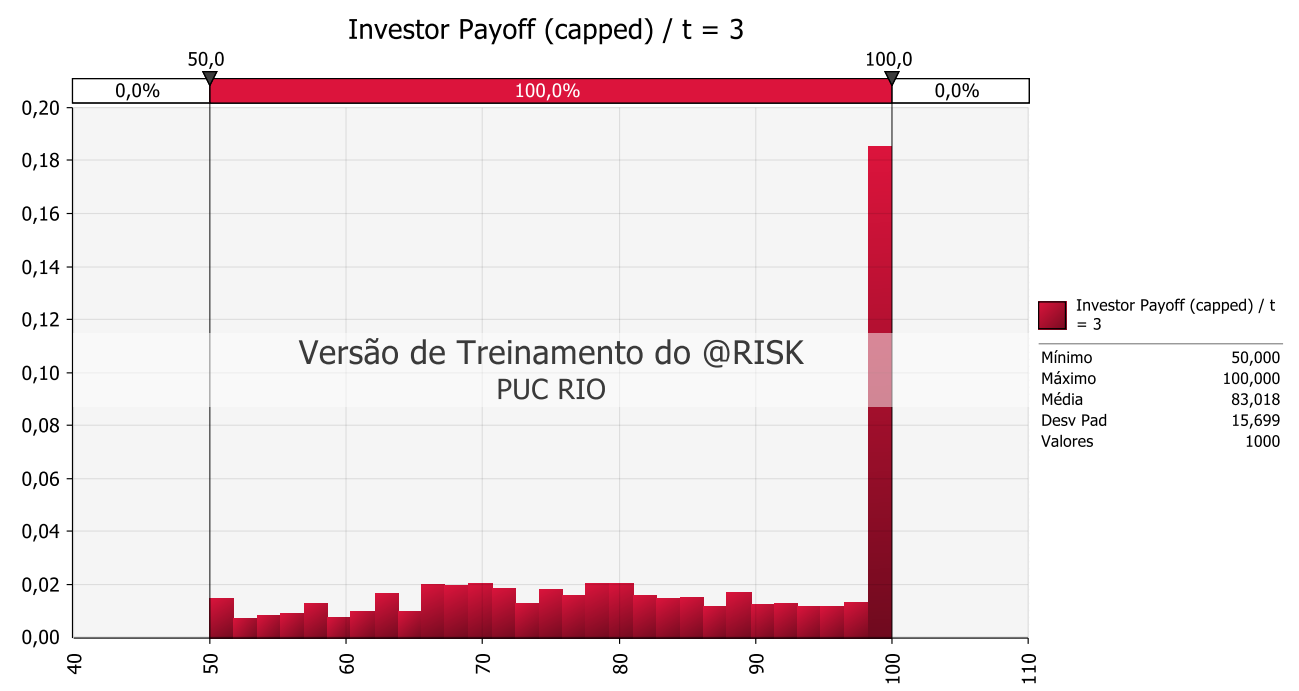

Figure 21: Investor's capped payoff simulation. Source: author

Note that now the option value is lower than that scenario witho ut the cap. For a $1 x$ full participating with $2 x$ cap, the option present value is $\$ 21.36,25 \%$ less than the capless scenario. Furthermore, we can verify the effect that changes in the cap settings may have on the expected value of the project. Thus, Table 18 shows that the higher the cap level, the higher the option value:

\begin{tabular}{lc}
\hline Settings & Option value $\mathbf{( \$ )}$ \\
\hline $1.5 \mathrm{x}$ & 10.00 \\
$2.0 \mathrm{x}$ & 21.36 \\
$2.5 \mathrm{x}$ & 24.84
\end{tabular}

Table 18: capped participating sensitivity analysis. Source: author 
Table 18 shows the relevance of the cap on the option value. Also, the difference of this amount and the table 17 shows that the cap may become the overall structure feasible for the entrepreneur perspective since the option becomes less expensive. 


\section{5 . \\ Conclusions}

The Global M\&A market has been growing year after year and plays an important role in corporate strategy. On the other hand, the relationship between buyers and sellers is complex and has drawn attention to the importance of the use of contractual mechanisms as tools to bridge the gap between the expectations of each side during the negotiation process. In this context, we developed three models to estimate the impact of three common contractual mechanisms on M\&A fair value and show how they can be applied by practitioners and researchers. The presentation of our models was separated into three parts, one for each model, in order to make the reader's understanding easier.

Chapter 2 presented the trends for the M\&A global market, the common process and concepts in a typical M\&A transaction. Also, chapter 2 presented the literature background on the related themes. We developed the models under the Real Options approach, where we evaluate the contractual mechanisms as options. In addition, in order to establish foundations for parties' behavior during the negotiation and post-deal, we analyzed the relationship between seller and buyer under Contract Theory lens. Contract Theory provides the foundation that justifies both the use and the settings of those clauses in a typical M\&A contract. For instance, the presence of a moral hazard problem and risk sharing costs implies that the optimal contract will include contractual terms that give investors some, but not full, downside protection. Also, information asymmetry between seller and buyer and the fact that after the deal closing the entrepreneur will remain running the company, a contingent payment scheme plays an important role in this context.

Chapter 3 presents the models, separated by sub-sections. We proposed three distinct models for three different contractual mechanisms: earnout, antidilution and liquidation preference. We used Monte Carlo simulation method to value the underlying options. First, we modeled the earnout clause, which is a helpful tool to make difficult negotiations feasible. When the seller and the buyer reach an impasse, the incorporation of an earnout clause can help make the deal possible by conditioning part of the payment to a pre-agreed (and future) performance measure. Since an earnout has option-like characteristics, we modeled it as a call option and tested for different parameters in order to verify the impact of our assumptions on the buyer's and seller's payoffs. 
The second model in Chapter 3 was related to the anti-dilution provision, which is a scheme largely used in venture capital deals. Anti-dilution works as an insurance for investors against the firm's poor performance and hence future investment rounds at a lower valuation. Once again, by using the Contract Theory approach, we argued that the information asymmetry between the investor and the entrepreneur is one of the most relevant motivations for the use of this mechanism.

The third and last model in Chapter 3 comprised the liquidation preference mechanism, which also provides a guarantee for the investors. In this scheme, the investor owns the right to receive its investment amount plus a certain agreed percentage of the proceeds in the event of the "liquidation" of the company, in preference over the other shareholders. Essentially, the investor is protected and, in the worst-case scenario, will receive at least its initial investment or the entire exit proceeds.

Chapter 4 provided some numerical applications for the models presented in Chapter 3 and the main results. As we presented the models separately, we also separated the results into the three independent cases. In all of them, there is a negotiation between a seller and a buyer where both want to undertake an M\&A transaction. Moreover, in all the cases, after the close of the deal, the entrepreneur remains on the firm management, which creates a relationship of dependency between buyer and seller. In other words, the buyer/investor depends on the seller/entrepreneur performance after the deal and we covered this topic based on Contract Theory background.

Concerning the results of the first model, we considered an M\&A negotiation between a skeptical buyer and an optimistic seller. In this context, there was a gap between their price expectation for the deal, which could be considered a deal breaker. However, by using the earnout mechanism, the parties were able to fill the gap and closed the deal. Additionally, the parties agreed on the earnout parameters, such as earnout period (three years) and performance measure (free cash flow). Still, the parties agreed on measuring the free cash flow quarterly, aiming to avoid any decision strictly focused on short-term. Thus, the target firm must reach the quarterly average of free cash flow to be able to receive the contingent payment. Lastly, we modeled the earnout as a binary option and a combined binary and call option.

Still, regarding the earnout model, we showed that there is no significant difference in measuring the performance goal as a geometric or arithmetic average. Furthermore, results showed the model output is highly dependent on 
the assumptions made, in particular, the drift rate, volatility and the size of the gap between the value expectation of the seller and the buyer.

In the second model, we considered an M\&A transaction between an entrepreneur and a venture capitalist. Typically, in this type of negotiation, the bargaining power is skewed towards the investor, while there is a clear dependency on the entrepreneur's motivation and performance after the close of the deal. Due to this dependency and because it is common for an early stage company to have a couple of investment rounds in a row to fund its growth, the venture capitalist demanded protection against an eventual poor performance afterward - the anti-dilution provision.

The results of the anti-dilution model showed that under a lower valuation, the second investment round size has a significant impact on option value. In other words, if the company has been facing bad results and needs to raise capital to finance its operations, the entrepreneur will be harshly punished due to the antidilution protection. In a context of poor performance, the higher the investment round, the higher the value of the anti-dilution option. Results suggest that the option may worth $5 \%$ of the investment placed by the venture capitalist, while an increase of $80 \%$ in its capital infusion may represent an increase of almost $50 \%$ of the option value. Additionally, the choice of the GBM parameters has no relevant impact on our model output, even though, all else being equal, higher the volatility, higher the protection value.

As for the last model, we modeled an $M \& A$ deal between a venture capitalist and an entrepreneur with liquidation preference. Like the anti-dilution context, the investor demanded additional protection against the firm's bad results after the deal closing. Empirical evidence showed that liquidation preference became very common in venture capital contracts and have different shapes. In order to address the most common features, we modeled the liquidation preference as fullparticipating and capped participating. The results suggest that full participating can be too expensive for the entrepreneur while the capped participating can be a way to reduce the cost of this protection. In our model, the option provides an increase in NPV of almost $60 \%$, considering the full-participating scenario. On the other hand, when we set the capped option (2x), the liquidation preference showed an increase of $40 \%$.

The three models developed in this work are simple to use and may provide valuable insights to the decision on M\&A deals, especially under uncertainty and moral hazard. Besides, practitioners, investment bankings and potential $M \& A$ players would be interested in these tools, since evaluating M\&A deals is 
challenging and demand the use of more sophisticated approaches than the Discounted Cash Flow method. Also, entrepreneurs could benefit from these models, as they are common in Venture Capital settings. Understanding their impact on deal fair value is critical for investment decision. Finally, researchers may be interested in the models, as they contain cutting edge literature in Finance, Economics and Decision Analysis. Combining real options and contract theory has a rich landscape ahead and may be a promising field.

The findings reveal that these contractual options may overcome a negotiation impasse between the buyer and the seller, by providing alternatives to the parties. On the other hand, depending on the clauses settings, the risk may be too skewed to the seller side, making the deal structure too expensive under his perspective. By testing the model's parameters sensitivity, we provided the inputs the seller needs to evaluate and pursue the optimal contractual terms.

While this study provides new opportunities for further empirical research under real options framework, there are some limitations that might be addressed in future research. First, as mentioned by Coates (2016), M\&A contracts doubled size over the past twenty years. Also, typically, the contractual mechanisms are used in combination, rather than one at a time. For instance, earnout, liquidation preference and anti-dilution may appear together in a real M\&A contract, which can demand a more specific approach. In order to cover this, future research can develop a unified framework, combining several clauses. Notwithstanding the programming complexity, the framework output would fill an important gap in M\&A transactions indeed.

Future works may also include different settings for each contractual mechanism. For instance, concerning the earnout, instead of a fixed quarterly average for the European Asian Option, a moving average could be used to calculate the expected value of an American Asian Option, as the compensation should reflect the seller performance and he or she can overperform before the earnout period. Regarding liquidation preference, future research may include more than one liquidation preference combined, which is likely when the company faces several investment rounds in a row. This can impact the bargaining power of the entrepreneur in future capital raising, as under a bunch of active liquidation preference, few new investors would be interested in undertaking the negotiation. 
6

\section{References}

ABDIN, S.; JAFFAR, M. Forecasting Share Prices of Small Size Companies in Bursa Malaysia using Geometric Brownian Motion. Applied Mathematics \& Information Science. Vol. 8. 107-112. 2014.

AGHION, P; BOLTON, P. An Incomplete Contracts Approach to Financial Contracting. The Review of Economic Studies. Vol 59. 473-494. 1992.

AGRAWAL, A.; JAFFE, J.; MANDELKER, G. The post-merger performance of acquiring firms: A re-examination of an anomaly. The Journal of Finance. Vol. 47. 1605-1621. 1992.

AHAMMAD, M.F. and GLAISTER, K.W. The pre-acquisition evaluation of target firms and cross border acquisition performance. International Business Review, 22 (5), pp. 894-904. ISSN 0969-5931. 2013.

ALCHIAN, A.; DEMSETZ, H. Production, Information Costs and Economic Organization. The American Economic Review. Vol 62. 777-795. 1972.

ALVAREZ, L. Optimal Exit and Valuation under Demand Uncertainty: A Real Options Approach. European Journal of Operational Research, 111: 320-329. 1999.

ALVAREZ, L.; STENBACKA, R. Takeover Timing, Implementation Uncertainty, and Embedded Divestment Options. Review of Finance, 10: 1-25. 2006.

AMIHUD, Y. Illiquidity and stock returns: cross-section and time-series effects. Journal of Financial Markets. 31-56. 2002.

ANDRADE, G.; MITCHELL, M.; STAFFORD, E. New evidence and perspectives on mergers. Journal of Economic Perspectives. 103-120. 2001.

AYDIN, N. Mergers and Acquisitions: A review of valuation methods. International Journal of Business and Social Science. Vol. 8. 2017.

AYRES, IAN. Optional Law. The Structure of Legal Entitlements. The University of Chicago Press. 2005.

BARBOPOULOS, L.; SUDARSANAM, S. Determinants of earnout as acquisition payment currency and bidder's value gains. Journal of Banking \& Finance. Vol.36. 678-694. 2012.

BATES, T.; NEYLAND, J. WANG, Y. Financing Acquisitions with Earnouts. Journal of Accounting \& Economics. 2018.

BEITEL, P.; SCHIERECK, D.; WAHRENBURG, M. Explaining M\&A success in European Banks. European Financial Management. 2004.

BENABOU, R.; TIROLE, J. Bonus Culture: Competitive Pay, Screening, and Multitasking. Journal of Political Economy 124, 305-370. 2016 
BENGTSSON, O.; RAVID, S.A. The Geography of Venture Capital Contracts. 2009.

BERGEMANN, D.; HEGE, U. Venture Capital financing, moral hazard and learning. Journal of Banking \& Finance. Vol. 22. 703-735. 1998.

BERGER, A.; BUCH, C.; DELONG, G.; DEYOUNG, R. Exporting financial institutions management via foreign direct investment mergers and acquisitions. Journal of International Money and Finance. Vol. 23. 333-366. 2003.

BERGLOF, E., A control theory of venture capital finance. Journal of Law, Economics and Organization 10, pp. 247-267, 1994.

BERLE, A.; MEANS, G. The modern corporation and private property. New York: The Macmillan company, 1932.

BLACK, F.; SCHOLES M. The Pricing of Options and Corporate Liabilities. Journal of Political Economy, n. 81, p.p. 637 - 654, 1973.

BOSTON CONSULTING GROUP. 2017 M\&A Report. 2017

BRANDÃO, L.; DYER, J.; HAHN, W. Using Binomial Decision Trees to Solve Real-Option Valuation Problems. Decision Analysis, v. 2, n. 2, p. 69-88, 2005.

BREALEY, R.; MYERS, S.; ALLEN, F. Principles of Corporate Finance. McGraw-Hill/Irwin. 2011.

BREWER, K.; FENG, Y; KWAN, C. Geometric Brownian Motion, Option Pricing, and Simulation: Some Spreadsheet-Based Exercises in Financial Modeling, Spreadsheets in Education (eJSiE): Vol. 5: Available at: http://epublications.bond.edu.au/ejsie/vol5/iss3/4. 2012.

BROTHERSON, W.; EADES, K.; HARRIS, R.; HIGGINS, R. Company valuation in Mergers and Acquisitions: How is discounted cash flow applied by leading practitioners? Journal of Applied Finance. Vol. 24. 43-51. 2014.

BRUNER, R.; STIEGLER, S. Technical note on structuring and valuing incentive payments in M\&A: Earnouts and other contingent payments to the seller. Darden Graduate School of Business Administration, University of Virginia. 2001.

CAIN, M.; DENIS, D.; DENIS, D. Earnouts: a study of financial contracting in acquisitions agreements. Journal of Accounting and Economics. Vol 51. 151170. 2011.

CAMPA, J.; HERNANDO, I. M\&As performance in the European financial industry. Journal of Banking \& Finance. Vol. 30. 3367-3392. 2006.

CASELLI, S., GATTI, S.; VISCONTI, M. Managing M\&A Risk with Collars, Earnouts, and CVRs. Journal of Applied Corporate Finance, 18: 91-104. 2006. 
CESTONE, G. Venture Capital meets Contract Theory: Risky Claims or Formal Control? Review of Finance. 2014.

CHILDS, P.; TRIANTIS, A. Dynamic R\&D investment policies. Management Science. Vol. 45. 1359-1377. 1999.

$\mathrm{CHOI}$, Albert $\mathrm{H}$., Facilitating Mergers and Acquisitions with Earnouts and Purchase Price Adjustments (September 20, 2016). 2 Journal of Law, Finance \& Accounting, 2017.

COASE, R. H. The Nature of Firm. Economica. Vol 4. 386-405. 1937.

COASE, R. H. The institutional structure of production. The American Economic Review, vol. 82, no 4, 1992.

COATES, J. Mergers, Acquisitions and Restructuring: Types, Regulation and Patterns of practice. The Oxford Handbook of Corporate Law and Governance. 2015

COATES, John C., Why Have M\&A Contracts Grown? Evidence from Twenty Years of Deals. Harvard Law School John M. Olin Center Discussion Paper No. 889; European Corporate Governance Institute (ECGI). 2016.

COPELAND, T.; ANTIKAROV, V. Real Options. New York: Texere LLC, 2001

COSSIN, D.; LELEUX, B.; SALIASI, E. Understanding the Economic Value of Legal Covenants in Investment Contracts: A Real Option Approach to Venture Equity Contracts. FAME, n. 63. 2002.

COX, J.; ROSS, S.; RUBINSTEIN, M. Option pricing: a simplified approach. Journal of Financial Economics. 229-263. 1979.

CRIMMINS, P.; GRAY, B; WALLER, J. Earnouts in M\&A Transactions: Key Structures and Recent Developments. Mayer Brown. 2011.

DAMODARAN, A. Valuing Young, Start-up and Growth Companies: Estimation Issues and Valuation Challenges. Stern School of Business, New York University. 2009.

DATAR, S.; FRANKEL, R.; WOLFSON, M. Earnouts: The Effects of Adverse Selection and Agency Costs on Acquisition Techniques. The Journal of Law, Economics, and Organization, Vol. 17, pp. 201-238, 2001.

DESSEIN, W. Authority and Communication in Organizations. Review of Economic Studies. Vol 69. 811-838. 2002.

DIAMOND, D. Monitoring and Reputation: The Choice between Bank Loans and Directly Placed Debt. Journal of Political Economy, 99, issue 4, p. 689-721. 1991.

DIAZ, B.; AZOFRA, S.; GUTIERREZ, C.; Are M\&A Premiums Too High? Analysis of a Quadratic Relationship between Premiums and Returns. Quarterly Journal of Finance and Accounting. 2002. 
DIXIT, A.; PINDYCK, R. Investment under uncertainty. Princeton: Princeton University Press, 1994.

DONG, M.; HIRSHLEIFER, D.; RICHARDSON, S.; TEOH, S. Does investor misvaluation drive the takeover market? The Journal of Finance. Vol. 61. 725762. 2006.

ECKBO, B. Consistent Estimation of Cross-sectional Models in Event Studies. Review of Financial Studies. 1990.

EISENBARTH, I. MECKL, R. Optimizing the timing of M\&A decisions - An analysis of pro-and Anticyclical M\&A behavior in Germany. American Journal of Industrial and Business Management. Vol. 4. 545-566. 2014.

EREL, I.; JANG, Y.; WEISBACH, M. Do acquisitions relieve target firms' financial constraints? Journal of Finance. 2013.

FAMA, E. Agency Problems and the Theory of the Firm. Journal of Political Economy 88, 288-307. 1980.

FIRTH, M. Takeovers, Shareholder returns, and the Theory of the Firm. The Quarterly Journal of Economics, Volume 94. 235-260. 1980.

FISHMAN, M. A theory of preemptive takeover bidding. Journal of Economics 19 (1), 88-101. 1988.

FISHMAN, M. Preemptive bidding and the role of the medium exchange in acquisitions. Journal of Finance 44 (1), 41-57. 1989.

FOCARELLI, D.; POZZOLO, A. Cross-border M\&As in the financial sector: Is banking different from insurance? Journal of Banking and Finance. Vol 32. 1529. 2008.

GABEHART, S. Guide to buying, Valuing and Selling Your Business, Dearborn Financial Publishing, Inc., Chicago, s.191.1998.

GARTNER, M.; PEREIRA, P. BRANDÃO, E. Optimal contingent payment mechanisms and entrepreneurial financing decisions. European Journal of Operational Research. Vol. 270. 1182-1194. 2018.

GENCHEVA, D.; DAVIDAVICIENE, V. Reduction of the information asymmetry in Mergers and Acquisitions through the means of payment. Journal of System and Management Sciences. Vol. 6. 16-21. 2016.

GILSON, R. Value Creation by Business Lawyers: Legal Skills and Asset Pricing, 94 Yale L. J.239. 1984.

GOMES, E., ANGWIN, D. N., WEBER, Y. and YEDIDIA TARBA, S. Critical Success Factors through the Mergers and Acquisitions Process: Revealing Pre- and Post-M\& A Connections for Improved Performance. Thunderbird Int'I Bus Rev, 55: 13-35. 2013 
GOMPERS, P.; LERNER, J. The money of invention: how venture capital creates new wealth. Massachusetts: Havard Business Scholl Press, 2001.

GORNALL, W.; STREBULAEV, I. A., Squaring Venture Capital Valuations with Reality. Journal of Financial Economics, 2018.

GROSSMAN, S.; HART, O. Implicit Contracts under asymmetry information. The Quarterly Journal of Economics. Vol.98. 123-156. 1983.

GROSSMAN, S.; HART, O. An Analysis of the Principal-Agent Problem. Econometrica 51, 7-45. 1983.

DEL, R.; FHUR, J.P. The pros and cons of earnouts. Journal of Financial Service Professionals 55, 88-93. 2001.

HACKBARTH, D.; MIAO, J. The dynamics of mergers and acquisitions in oligopolistic industries. Journal of Economic Dynamic \& Control. Vol. 36. 585609. 2012.

HACKBARTH, D.; MORELLEC, E. Stock returns in Mergers and Acquisitions. The Journal of Finance. Vol. 63. 1213-1252. 2008.

HANSEN, R. A Theory for the choice of exchange medium in mergers and acquisitions. Journal of Business, 60 (1), 75-95. 1987.

HARFORD, J. Corporate Cash Reserves and Acquisitions. The Journal of Finance. Vol 54. 1999.

HARRIS, M.; RAVIV, A. Optimal incentive contracts with imperfect information. Journal of Economic Theory. Vol.20. 231-259. 1979.

HART, O. Financial Contracting. Journal of Economic Literature 39, 1079-1100. 2001.

HART, O.; MOORE, J. A Theory of Debt Based on the Inalienability of Human Capital, Quarterly Journal of Economics 109, 841-879. 1994.

HART, O.; MOORE, J. Foundations of Incomplete Contracts. Review of Economic Studies. Vol.66. 115-138. 1999.

HAWAWINI, G.; SWARY, I. Mergers and Acquisitions in the U.S. Banking Industry: Evidence from the Capital Markets. New York: North Holland, 1990.

HERATH, H. JAHERA JR, J. Real Options: Valuing flexibility in strategic mergers and acquisitions as an exchange ratio. Managerial Finance. Vol. 28. 2002.

HERING, T.; TOLL, C. Application of Alternative Valuation Formulas for a Company Sale. Global Economy and Finance Journal, 8(2), pp.14-30. 2015.

HIRSCHEY, M. Merger, buyouts and fakeouts. American Economic Review, Nashville: American Economic Association, v. 76, n. 2, p. 317-321, May 1986. 
HOLMSTROM, B.; COSTA, J. Managerial Incentives and Capital Management. The Quarterly Journal of Economics. Vol. 101. 835-860. 1986.

HOLMSTROM, B. Moral Hazard and Observability. The Bell Journal of Economics, vol 10, №1. 74-91. 1979.

HOLMSTROM, B. Managerial Incentive Problems: A dynamic perspective. The Review of Economic Studies. Vol. 66. 169-182. 1999.

HOLMSTROM, B.; TIROLE, J. Market Liquidity and Performance Monitoring. Journal of Political Economy. Vol. 101. 678-709. 1993.

HUANG, Y.; WALKLING, R. Target abnormal returns associated with acquisition announcements: Payment, acquisition form, and managerial resistance. Journal of Financial Economics. Vol. 19. 329-349. 1987.

HULL, J., C. Options, Futures and Other Derivatives. Prentice Hall 4th ed, Upper Saddle River, NJ, 1999.

JANSEN, M. How information asymmetry affects contract design: paying for private firms with IOUs. Dissertation approved by University of Texas at Austin. 2016.

JENSEN, MICHAEL C.; MECKLING, WILLIAN. Theory of the Firm. Managerial Behavior, Agency Cost and Ownership Structure. Journal of Financial Economics. Vol 3. No 4. Pp 305-360. 1976.

JENSEN, M. Agency Costs of Free Cash Flow, Corporate Finance and Takeovers. The American Economic Review. Vol 76. 323-329. 1986.

JP MORGAN. Global M\&A outlook. 2017.

KAPLAN, S.; STROMBERG, P. Financial Contracting Theory Meets the Real World. An Empirical Analysis of Venture Capital Contracts. Review of Economic Studies. 1-35. 2002.

KAPLAN, S.; STROMBERG, P. Characteristics, Contracts, and Actions: Evidence from Venture Capitalist Analyses. Journal of Finance 59, 2177-2210. 2004.

KAPLAN, G. E. Do governance structures matter? New Directions for Higher Education, 23-34. 2004.

KELLOGG, D.; CHARNES, J. Real options valuation for a biotechnology company. Financial Analysis Journal. Vol. 56. 76-84. 2000.

KESTER, C. Today's options for tomorrow's growth. Harvard Business Review. 1983.

KINNUNEN, JANI. Valuing M\&A Synergies as (Fuzzy) Real Options. Institute for Advanced Management Systems Research. 2010. 
KIRILENKO, A. Valuation and Control in Venture Finance. Journal of Finance, Vol. 56. 2001.

KOHERS, N.; ANG, J. Earnouts in Mergers and Acquisitions: Agreeing to disagree and agreeing to stay. The Journal of Business. Vol 73. 445-476. 2000.

KULATILAKA, N.; MARKS, S. The strategic value of flexibility: reducing the ability of compromise. American Economic Review. Vol. 78, 574-580. 1988.

LAMBRECHT, B. The timing and terms of mergers motivated by economies of scale. Journal of Financial Economics. Vol. 72. 41-62. 2004.

LANGETIEG, T. An application of a three-factor performance index to measure stockholder gains from merger. Jo urnal of Financial Economics. Vol.6. 365-383. 1978.

LAZEAR, Edward P. Salaries and Piece Rates. The Journal of Business, vol. 59, no. 3, 1986, pp. 405-431.

LONGSTAFF, F.; SCHWARTZ, E. Valuing American Options by Simulation: A simple least-square approach. The Review of Financial Studies. Vol. 14. 113147. 2001.

LUEHRMAN, T. Investment opportunities as Real Options. Getting started on the numbers. Harvard Business Review. Vol. 76. 1998.

LUKAS, E; REUER, J.; WELLING A. Earnouts in mergers and acquisitions: A game-theoretic option pricing approach. European Journal of Operational Research, 2012.

LUKAS, E.; WELLING, A. On the investment-uncertainty relationship: a game theoretic real option approach. Finance Research Letters. Vol.11. 25-35. 2014.

MANDELKER, G.; RHEE, S. The impact of the degree of operating and financial leverage on systematic risk of common stock. The Journal of Financial and Quantitative Analysis. Vol. 19. 45-57. 1984.

MANNE, H.G. Mergers and the Market for Corporate Control. Journal of Political Economy. 110-120.1965.

MARGRABE, W. The value of an option to exchange one asset for another. The Journal of Finance. Vol.33. 177-186. 1978.

MERTON, R. Theory of Rational Option Pricing. The Bell Journal of Economics. Vol. 4. 141-183. 1973.

MILLER, S.; PARKHE, A. Patterns in the expansion of U.S Banks' foreign operations. Journal of International Business Studies. Vol 29. 359-388. 1998.

MITCHELL, M.; MULHERIN, J. The impact of industry shocks on takeover and restructuring activity. Journal of Financial Economics. Vol.41. 193-229. 1996. 
MODIGLIANI, F.; MILLER, M. The Cost of Capital, Corporate Finance and the Theory of investment. The American Economic Review. Vol 48. 261-297. 1958.

MORELLEC, E.; ZHDANOV, A. The dynamics of mergers and acquisitions. Journal of Financial Economics. Vol. 77. 649-672. 2005.

MUKHERJEE, T.; KIYMAZ, H.; BAKER, $H$. Mergers motives and target valuation: a survey of evidence from CFOs. Journal of Applied Finance. Vol. 14. 2004.

MYERS, S.; N. MAJLUF. Corporate Financing and Investment Decisions When Firms Have Information That Investors Do Not Have. Journal of Financial Economics 13:187-221. 1984.

OLSEN, T. STENSLAND, G. Optimal shutdown decisions in resource extraction. Economics Letters. 215-218. 1988.

PAWLINA, G. Real Options valuation of managerial flexibility in optimally structured M\&A deals. M\&A Review, 11, p. 568-575. 2002.

RAGOZZINO, R.; REUER, J., Contingent Earnouts in Acquisitions of Privately Held Targets. Journal of Management, Vol. 35: 857-879. 2009.

RAJAN, R.; ZINGALES, L. Power in a Theory of the Firm. Quarterly Journal of Economics 103, 387-432. 1998.

RHODES-KROPF, M.; VISWANATHAN, S. Market Valuation and Merger Waves, downloaded from http://papers.ssrn.com/sol3/papers.cfm?abstract id=334944. 2003.

ROLL, R. The Hubris Hypothesis of Corporate Takeovers. The Journal of Business. Vol 59. 197-216. 1986.

ROSS, S. The Determination of Financial Structure: The Incentive-Signaling Approach. The Bell Journal of Economics. Vol 8. 23-40. 1977.

SAHLMAN, W. The Structure and Governance of Venture-Capital Organizations. Journal of Financial Economics, v.27, n.2, p.473-521, Oct. 1990.

SCHERER, F.M.; ROSS, D. Industrial Market Structure and Economic Performance. University of Illinois at Urbana-Champaign's Academy for Entrepreneurial Leadership Historical Research Reference in Entrepreneurship. 1990.

SCHWARTZ, E.; MOON, M. Rational pricing of internet companies. Financial Analysis Journal. Vol. 56. 62-75. 2000.

SERVAES, $H$. Tobin's $\mathbf{Q}$ and the gains from takeovers. The Journal of Finance. 46: 409-419. 1991.

SHARPE, W. Capital Asset Prices: A theory of market equilibrium under conditions of Risk. The Journal of Finance. 1964. 
SHERMAN, A. COOK, C. International Mergers: How to detect corruption. The Journal of Corporate Accounting and Finance. Vol. 22. 11-15. 2011.

SHIBATA, T. The impacts of uncertainties in a real options model under incomplete information. European Journal of Operations Research. Vol.187. 1379-1386. 2008.

SHLEIFER, A.; VISHNY, R. Stock market driven acquisitions. Journal of Financial Economics. Vol. 70. 295-311. 2003.

SMIT, H.; VAN DEN BERG, W.; DE MAESENEIRE, W. Acquisitions as a real options bidding game, FMA Annual meeting. Chicago, Illinois. 2005.

STIGLER, GEORGE. The Development of Utility Theory. The Journal of Political Economy, Vol 58. No 4. Pp 307-327. 1950.

SUDARSANAM, S. Creating Value from Mergers and Acquisitions: The Chalanges. (2nd ed.) Harlow, England: Pearson Education Limited. 2010.

TIROLE, J. Incomplete Contracts: Where do We Stand? Econometrica 67, 741 781. 1999.

TIROLE, J. Cognition and Incomplete Contracts. American Economic Review 99, 265-294. 2009.

TOLL, C.; ROLINCK, J.P. Earnouts to bridge the gap between negotiation parties - curse or blessing? Managerial Economics. Vol. 18. 103-116. 2017.

TRAVLOS, N. Corporate Takeovers Bids, methods of payment and bidding firms' stock returns. Journal of Finance. Vol. 42. 943-963. 1987.

TRIGEORGIS, L. Real options: managerial flexibility and strategy in resource allocation. Massachusetts: MIT Press, 1996.

WANSLEY, J. LANE, W.; YANG, H. Abnormal returns to acquired firms by type of acquisition method of payment. Financial Management. Vol. 12. 16-22. 1983.

WIDDICKS, M.; PAXSON, D.; NEWTON, D. Real R\&D options. International Journal of Management Review. Vol. 5-6. 113-130. 2004.

$\mathrm{YU}, \mathrm{J} . ; \mathrm{XU}, \mathrm{B}$. The game analysis to price the target enterprise of merger and acquisition based on the perspective of real options under stochastic surroundings. Economic Modelling, 28, 1587-1594. 2011

ZHU, J.; LI, G.; LI, J., "Merge to be too big to fail: A real option approach, International Review of Economics \& Finance, Elsevier, vol. 51 (C), pages 342-353. 2017. 